\title{
1 Reconstitution of Alveolar Regeneration via novel DATPs by Inflammatory Niches
} 2

3 Jinwook Choi ${ }^{1}$, Jong-Eun Park $^{2}$, Georgia Tsagkogeorga ${ }^{3,4}$, Motoko Yanagita ${ }^{5}$, Bon-Kyoung $4 \mathrm{Koo}^{6}$, Namshik Han ${ }^{3}$, and Joo-Hyeon Lee ${ }^{1,7}$

$6{ }^{1}$ Wellcome-MRC Cambridge Stem Cell Institute, University of Cambridge, Cambridge, UK

$7 \quad{ }^{2}$ Wellcome Sanger institute, Cambridge, UK

$8 \quad{ }^{3}$ Milner Therapeutics Institute, University of Cambridge, Cambridge, UK

$9 \quad{ }^{4}$ STORM Therapeutics Ltd., Cambridge, UK

10 Department of Nephrology, Kyoto University Graduate School of Medicine, Kyoto, Japan

$11{ }^{6}$ Institute of Molecular Biotechnology of the Austrian Academy of Science (IMBA), Vienna,

12 Austria

$13{ }^{7}$ Department of Physiology, Development and Neurobiology, University of Cambridge, 14 Cambridge, UK

18 Correspondence contact:

19 Joo-Hyeon Lee, jhl62@cam.ac.uk 


\section{Summary}

2 Tissue regeneration involves a multi-step process composed of diverse cellular hierarchies and 3 states that are also implicated in tissue dysfunction and pathogenesis. Here, we leveraged

4 single-cell RNA sequencing analysis in combination with in vivo lineage tracing and organoid

5 models to fine-map trajectories of alveolar lineage cells during injury repair and regeneration.

6 We identified Damage-Associated Transient Progenitors (DATPs) as a distinct AT2-lineaged

7 population arising during alveolar regeneration. Specifically, we found that IL-1 $\beta$, secreted by

8 interstitial macrophages, primes a subset of $I l l r 1^{+}$AT2 cells for conversion into DATPs, via a

9 Hifla-mediated glycolysis pathway, that are functional mediators for mature AT1 cell

10 differentiation. Importantly, we show that chronic inflammation mediated by IL- $1 \beta$ prevents

11 differentiation into AT1 cells, leading to aberrant accumulation of DATPs and impaired

12 alveolar differentiation. Our step-wise fine-mapping of cell fate transitions demonstrates how

13 the inflammatory niche impedes alveolar regeneration by directing stem cell fate behavior.

\section{Key words}

16 Lung stem cells

17 Regeneration

18 Lineage differentiation

19 Inflammation

20 Stem cell niche

21 IL1R1 and IL-1 $\beta$

22 Damage-associated transient progenitors

23 Stem cell fate

\section{Running Title}

26 The Inflammatory Niche Directs Alveolar Regeneration during injury repair 


\section{Introduction}

2 Maintenance of tissue homeostasis and repair following injury relies on the function of adult 3 stem cells (Hogan et al., 2014; Li and Clevers, 2010; Wagers and Weissman, 2004). In the lung, 4 barrier integrity of the epithelium is essential for protection against infection and efficient gas exchange. Lung tissue shows a slow cell turnover at steady state, but harbors regional-specific stem cells that quickly mobilize after tissue injury to replenish the epithelium (Hogan et al., 2014). In the alveoli, alveolar type 2 (AT2) cells maintain lung homeostasis and enable regeneration after injury by proliferating and differentiating into new alveolar type 1 (AT1) cells specialized for gas exchange (Adamson and Bowden, 1974; Barkauskas et al., 2013; Rock et al., 2011). Given the importance of AT2 cells, their self-renewal and differentiation must be tightly coordinated to maintain tissue integrity and efficient repair. Disruption of this balance can lead to life-threatening lung diseases (Hogan et al., 2014; Kotton and Morrisey, 2014). Recent studies have begun to suggest signaling pathways involved in the regulation of proliferation and differentiation of AT2 cells (Finn et al., 2019; Riemondy et al., 2019). However, it remains unclear which factors driven by injury trigger the activation of quiescent AT2 cells to differentiate towards AT1 cell fate and which differentiation trajectory they follow during lung regeneration.

Tissue repair is a complex process that involves dynamic crosstalk between stem cells and their respective niches. Physiological insults, such as a viral infection, are well known to instigate inflammation by triggering the activation or recruitment of immune cells to the affected tissue site (Medzhitov, 2008). In solid tissues, diverse immune cells of innate or adaptive immunity are even integral components of the niche, where they contribute to immune defence against infection and can sense environmental stimuli (Naik et al., 2018). Beyond the ability to clear pathogens, recent studies highlight how restoration of barrier integrity in epithelial organs such as the skin, gut, and lung after destruction is critically dependent on the immune system (Hsu et al., 2014; Klose and Artis, 2016; Lindemans et al., 2015; Naik et al., 2017). Lung epithelium is especially vulnerable to injury, as its surface is exposed to the external environment. In line with this, immune cells have been reported to be involved in lung homeostasis and restoration (Chen et al., 2012; Lechner et al., 2017; Westphalen et al., 2014). Recent advances have increased our insight into the critical role of paracrine niche-generated signals as key modulators of stem cell behaviors. In the distal lung, Pdgfra ${ }^{+}$mesenchymal cells and vascular endothelial cells were identified as supportive niche cells (Barkauskas et al., 2013; Lee et al., 2014). More recently, mesenchymal cell subtypes including Wnt-responding and Wnt- 
1 producing fibroblasts were suggested to regulate stem cell properties and the cellular identity of AT2 cells (Lee et al., 2017; Nabhan et al., 2018; Zepp et al., 2017). However, our knowledge about the specific crosstalk between inflammatory cells and AT2 cells in regeneration remains limited. In particular, a fundamental question yet to be investigated is how the chronic inflammation impacts on tissue destruction, as it is likely caused by impaired stem cell function or regeneration process after injury, both processes that are poorly understood.

Here we set out to identify the lineage trajectory from AT2 toward AT1 cells during alveolar regeneration after injury. Single cell RNA-sequencing (scRNA-seq) analysis of in vivo AT2 lineage-labeled cells and ex vivo AT2 cell-derived organoids allowed us to delineate a precise differentiation trajectory in which AT2 cells adopt a 'priming' state followed by transition into 'Damage-Associated Transition Progenitors (DATPs)' prior to conversion into terminally differentiated AT1 cells. Importantly, we demonstrate that inflammatory niches driven by IL$1 \beta$ and Hifla signaling pathways orchestrate the regeneration process by triggering statespecific differentiation programs of AT2-lineage cells. Overall, our study reveals essential functions of inflammation in alveolar regeneration, providing new insights into how chronic inflammation impairs tissue restoration and leads to lung diseases.

\section{Results}

\section{Reprograming of AT2 cells during alveolar regeneration after tissue injury}

To define molecular identities and states of AT2 lineage cells responding to injury and undergoing regeneration, we treated AT2 reporter mice $\left(S P C-C r e^{E R T 2} ; R 26 R^{\text {tdTomato }}\right)$ with tamoxifen, exposed them to PBS (control, homeostasis) or bleomycin (injury), and isolated lineage-labeled cells for scRNA-seq analysis at day 14 (acute injury) or 28 (resolution of injury) (Fig. 1A and Fig. S1A). Based on the expression of canonical AT1 and AT2 cell markers, we uncovered five distinct cell populations (Fig. 1B and Fig. S1B). Distribution of each cluster across time points allowed us to assess how AT2 cells changed during injury response and repair (Fig. 1C).

As expected, lineage-labeled cells in uninjured mice, comprised mainly of AT2 cells (cluster 1) expressing canonical AT2 markers such as surfactant proteins (Sftpc, Sftpal) (Fig.1, $\mathrm{C}$ and $\mathrm{D})$. At day 14 post injury, three additional distinct populations had emerged while this AT2 cluster had become dramatically reduced (Fig. 1, C and D). Approximately $6 \%$ of lineagelabeled cells expressed proliferation/cell-cycle markers such as Cdk1, Mki67, and Cenpa, 
1 corresponding to Cycling AT2 cells (cAT2, cluster 3) (Fig. 1D and Fig. S1C). A second AT22 like state was highly prominent at this stage (cluster 2). This cluster showed similar expression 3 levels of canonical AT2 markers including Sftpc but lower expression of genes that are involved in the lipid metabolism shown in homeostatic AT2 cells (hAT2, cluster 1) such as Acly, Hmgcr, and Hmgcsl (Fig. 1D and Fig. S1C). We also found enriched expression of genes induced by an inflammatory response such as Ptges, Lcn1, Orm1, Tmem173, and Ifitm2/3 in this cluster (Fig. 1D and Fig. S1C) (Fortier et al., 2008; Kuriakose and Kanneganti, 2018; Ligresti et al., 2012). Remarkably, essential regulators for AT2 lineage specification such as Etv5, Abca3, and Cebpa were also downregulated, suggesting that this population had lost AT2 identity (Fig. 1D and Fig. S1C) (Martis et al., 2006; Rindler et al., 2017; Zhang et al., 2017), suggesting 'primed AT2 state (pAT2)'. In addition, cluster 2 cells had a transcriptional signature similar to that of cAT2 cells with the exception of cell cycle-related genes. We also identified an uncharacterized cellular subset of cluster 4 which we named 'Damage-Associated Transient Progenitors (DATPs)'. DATPs expressed specific markers such as Cldn4, Krt8, Ndrg1, Sprrla, and $A W 112010$ (Fig. 1D and Fig. S1C). Overall, DATPs shared features of the AT1 lineage transcription signature, but showed much lower expression of canonical AT1 markers including Pdpn, Hopx, and Cav-1 (Fig. 1D and Fig. S1C). Analysis of Gene Ontology (GO) terms further revealed that DATPs were characterized by increased expression of genes associated with p53 signaling (e.g. Trp53, Mdm2, Ccnd1, Gdf15), inhibition of proliferation (e.g. Cdknla, Cdkn2a), hypoxia (Hifla, Ndrgl), and the interferon-gamma signaling pathway (e.g. Ifngr1, Ly6a/Sca-1, Irf7, Cxcl16) (Fig. S1D).

As expected, at day 28 post-injury, we observed substantial increases in the mature AT1 and hAT2 populations while cAT2, pAT2, and DATPs were diminished, reflecting return to alveolar homeostasis after injury (Fig. 1C). To better understand the differentiation paths of AT2 cells to AT1 cells during regeneration, we applied partition-based graph abstraction (PAGA, Fig. 1E) and characterized transcriptional programs ordered along pseudotemporal trajectories (Fig. 1F) (Wolf et al., 2019). PAGA shows that AT2 and AT1 cells are connected via a trajectory that includes pAT2 cells and DATPs (Fig. 1E). cAT2 cells were assigned as the population most close to pAT2 cells, suggesting that priming of naïve AT2 cells prior to initiation of differentiation is closely related with a cell cycle event. After excluding cAT2 cells, pseudotime analysis showed that AT2 transitions into AT1 cells via pAT2 cells and DATPs, similar to that what we observed in PAGA (Fig. 1F) (Haghverdi et al., 2016). Taken together, these findings revealed a differentiation trajectory towards AT1 cell fate acquisition that passes through distinct pAT2 and DATP cell states during regeneration. 


\section{$1 \quad$ IL-1 $\beta$ secreted from interstitial macrophages triggers reprograming of AT2 cells}

2 Given our data showing increased expression of genes associated with the immune response

3 signatures in pAT2 cells, we next asked whether bleomycin injury resulted in inflammation

4 (Fig. S2A). By flow cytometry analysis, we found dynamic changes in macrophage behaviors across injury response and regeneration. At day 7 post injury, the number and frequency of interstitial macrophages (IMs) were significantly increased, whereas the number and frequency of alveolar macrophages (AMs) were decreased (Fig. S2, B-D). These changes were restored to homeostatic levels by day 28 , indicating resolution of acute inflammation. Because macrophages localized near AT2 lineage-labeled cells during acute injury (Fig. S2E), we hypothesized that macrophages may affect the behavior of lineage-labeled cells in response to injury. Importantly, we observed that 3D organoid co-cultures in which AT2 cells were cultured together with IMs in the presence of stromal cells revealed more and larger organoid formation than when they were co-cultured with AMs (Fig. 2A-C) (Lee et al., 2014). To further address the contribution of macrophages in alveolar regeneration after injury, we analyzed scRNA-seq of non-lineage-labeled cells from $S P C-C r e^{E R T 2} ; R 26 R^{\text {tdTomato }}$ mice, including immune cells, isolated in parallel with samples (PBS, D14 and D28) in Fig. 1 (Fig. S2, F-H). The expression level of $I L-1 \beta$, which is specifically detected in macrophages, was increased at day 14 post injury and decreased to homeostatic levels at day 28 (Fig. S2, H and I). Quantitative PCR (qPCR) analysis on isolated AMs and IMs from uninjured lungs revealed that $I L-1 \beta$ is highly and specifically expressed in IMs while $I L-18$ is enriched in AMs, consistent with previous reports (Fig. S2J) (Misharin et al., 2017). Furthermore, GM-CSF activation specifically augmented $I L-1 \beta$ expression in IMs but did not affect $I L-18$ expression in AMs (Fig. S2J). Notably, bleomycin injury stimulated $I L-1 \beta$ expression in IMs in vivo (Fig. S2K). IL-1 $\beta$ treatment was also sufficient to increase the number and size of organoids formed by AT2 cells (Fig. 2, D and E).

To further ask how IL-1 $\beta$ affects the cellular and molecular behaviors of AT2 cells, we performed scRNA-seq of control and IL-1 $\beta$-treated organoids. Based on the marker gene expression, we identified five distinctive clusters (AT2, pAT2, cAT2, DATPs, and AT1 cells) similar to those we had seen in AT2 lineage-labeled cells (Fig. 2F and Fig. S3, A-C). In control organoids, most cell types corresponded to AT2 and AT1 cells alongside smaller pAT2 and DATPs clusters (Fig. 2G). In contrast, IL-1 $\beta$-treatment increased the pAT2 fraction to $\sim 77 \%$ of pAT2 cells, classified by low expression of genes, such as Etv5, Abca3, and Cebpa, suggesting that IL-1 $\beta$ triggers AT2 cells to enter a primed state (Fig. 2G). The DATP 
1 population was also increased by IL-1 $\beta$ treatment (Fig. 2G). Pseudotime and PAGA analysis of the scRNA-seq data showed that IL-1 $\beta$-treated organoids skew differentiation of AT2 cells towards AT1 fate (Fig. 2H and Fig. S3D), by enhancing differentiation into pAT2 and DATP states similar to those of regenerating AT2 cells in vivo (Fig. S3, E and F). To investigate if IL$1 \beta$ directly influences AT2 cell fate transitions, we examined cellular states at day 6 and 14, two key differentiation time points across organoid formation. At day 6, qPCR analysis of IL$1 \beta$-treated organoids showed an enriched transcriptional signature of pAT2-state relative to control organoids (Fig. 2I). In addition, day 14 immunostaining and flow cytometry analysis for DATP markers, such as Krt8 and Cldn4, confirmed that DATPs were significantly increased in IL-1 $\beta$-treated organoids (Fig. 2, J and K). These data show that IL-1 $\beta$ treatment in AT2 organoids recapitulate key aspects of in vivo lung regeneration. Taken together, our data demonstrate that an IL-1 $\beta$-mediated inflammatory niche triggers AT2 mediated injury response during alveolar regeneration via proceeding differentiation programs to generate DATPs.

\section{DATPs differentiate into AT1 and AT2 cells during alveolar regeneration after injury}

Our scRNA-seq analysis revealed the previously unknown AT2-lineage derived DATP population emerging during alveolar regeneration and in organoids stimulated with IL-1 $\beta$. Using AT2 reporter mice $\left(S P C-C r e^{E R T 2} ; R 26 R^{t d T o m a t o}\right)$, we found that approximately $10 \%$ of AT2 lineage-labeled cells express Krt8 at 14 days after bleomycin injury, confirming that DATPs originate directly from AT2 cells (Fig. 3, A-C). Importantly, neither the AT2 marker SPC, nor the AT1 marker Pdpn were detected in this population (Fig. 3, B and D). To further assess functional contributions of DATPs to alveolar regeneration, we established lineage reporter mice for N-Myc Downstream Regulated 1 ( $\mathrm{Ndrgl}$ ) which is uniquely expressed in DATPs during alveolar regeneration ( $\mathrm{Ndrg} 1-\mathrm{Cr}^{E R T 2} ; \mathrm{R}^{26 R^{\text {tdTomato }}}$ ) (Figs. 1D and 3E). We did not detect any expression of $N d r g 1$ in airway epithelial cells with or without injury (Fig. S4, A and B). Consistent with our scRNA-seq data, neither AT2 and AT1 cells were labeled by Ndrg1 expression in PBS control mice (Fig. 3, I and K, and Fig. S4, C-E). However, at 9 days after bleomycin injury, $\mathrm{Ndrgl} \mathrm{lineage-labeled} \mathrm{cells} \mathrm{emerged} \mathrm{with} \mathrm{a} \mathrm{majority} \mathrm{of} \mathrm{cells} \mathrm{positive} \mathrm{for}$ Krt8 in the alveolar region (Fig. 3, F and G). At day 28, we found that approximately $30 \%$ of AT1 cells were lineage-labeled by Ndrgl with AT1 cell morphology (Fig. 3, J and K). We also confirmed the contribution of DATPs in AT1 cell generation with lineage-tracing analysis using Krt8 reporter mice $\left(K r t 8-C r e^{E R T 2} ; R 26 R^{t d T o m a t o}\right)$ (Fig. S5A). Consistent with Ndrgl 
1 lineage-labeled cells, neither AT2 nor AT1 cells were labeled in uninjured lungs (Fig. S5B). $K r t 8$ expression was only detected in $\mathrm{Cldn} 4^{+}$DATPs at day 9 in the alveolar region post injury, but was then prominent in Pdpn ${ }^{+}$AT1 cells at day 28 post injury (Fig. S5, C-F).

We observed that a significant number of $\mathrm{SPC}^{+} \mathrm{AT} 2$ cells were lineage-labeled by Ndrgl and Krt8 at day 28 post bleomycin injury (Fig. 3, I and J and Fig. S5, G and H). To confirm that DATPs possessed capacity of dedifferentiating into AT2 cells, we isolated AT2 cells $\left(\mathrm{CD} 31^{-} \mathrm{CD}^{-} 5^{-} \mathrm{EpCAM}^{+} \mathrm{MHCII}^{+}\right.$) (Hasegawa et al., 2017) from $\mathrm{Krt} 8$ reporter mice and performed organoid cultures in the presence of IL-1 $\beta$ (Fig. S5I). At day 14 in culture, we added 4-OH tamoxifen to label Krt8-expressing DATPs. Consistent with immunostaining for Krt8 in organoids (Fig. 2J), we detected Tomato ${ }^{+}$cells (Krt8 ${ }^{+}$DATPs) in the inner part of organoids, which segregated distinctly from Tomato ${ }^{-} \mathrm{MHCII}^{+} \mathrm{AT} 2$ cells by flow cytometric analysis (Fig. $\mathrm{S} 5$, J and K). Furthermore, $\mathrm{Krt}^{+}$DATPs $\left(\mathrm{Tomato}^{+} \mathrm{MHCII}^{-}\right.$) isolated from organoids were capable of forming organoids composed of DATPs and SPC ${ }^{+}$AT2 cells (Fig. S5, K-M).

IL-1及 signaling is required for cell fate conversion into DATPs during alveolar regeneration

Given that IL-1 $\beta$ treatment increased generation of DATPs in organoids, we next asked whether IL-1 $\beta$ signaling is required for differentiation into DATPs in vivo. To answer this question, we generated $I l 1 r 1^{\text {flox/flox }} ; S P C-C r e^{E R T 2} ; R 26 R^{\text {tdTomato }}$ mice to deplete Illrl, a functional receptor for IL-1 $\beta$, specifically in AT2 cells (Fig. 4A). The proliferative activity of Illr1-deficient AT2 cells was comparable to that of Illr1-haplodeficient AT2 cells post injury (Fig. S6A). As IL-1 $\beta$ treatment increased organoid size and forming efficiency (Fig. 2, D and E), we carefully examined AT2 cell proliferation by EdU incorporation assays at early time point (day 4) in organoid cultures. Although IL-1 $\beta$-treated organoids revealed increases in EdU incorporation rates relative to control, notably, Illr1-deficient AT2 cells also showed a similar rate of EdU incorporation, indicating that IL-1 $\beta$ does not directly influence on AT2 cell proliferation (Fig. S6B). Given that differential expressions of growth factors regulating AT2 cell proliferation in IL-1 $\beta$-treated stromal cells co-cultured with AT2 cells in organoids (Fig. S6, C-E), it is highly likely that IL-1 $\beta$ enhances AT2 cell proliferation via modulating surrounding cells rather than direct effects on AT2 cells.

We then further analyzed cAT2 subsets (derived from AT2 lineage-labeled cells post injury, Fig. 1B), which showed step-wise cell cycle transitions based on expression of cell cycle phase-specific genes (Fig. S6F). We discovered that AT2 cells acquired transcriptional 
1 signatures of pAT2 cells during the transition from $\mathrm{S}$ to $\mathrm{G} 2 / \mathrm{M}$ phase in the cell cycle (Fig. S6G). During this transition, the expression of naïve AT2 cell markers including Abca3 was downregulated while the expression of genes associated with inflammatory response including Ptges was induced. Remarkably, Illrl expression was upregulated specifically in G2/M phase (Fig. S6G). Importantly, we found that Illrl-deficient AT2 cells failed to differentiate into DATPs at day 10 post injury (Fig. 4, B and C). Subsequently, lineage-labeled AT1 cells were significantly decreased at day 21 post injury, indicating impaired differentiation of AT2 cells into AT1 cells in the absence of IL-1 $\beta$ signaling (Fig. 4, D and E). Overall, these findings suggest that IL-1 $\beta$ does not directly influence proliferative properties of AT2 cells, but instead primes AT2 cells to initiate cell fate transition into DATPs during alveolar regeneration.

\section{Hif1a signaling is integral for DATP cell conversion and AT1 differentiation}

In our next set of experiments, we asked which downstream targets/factors driven by IL-1 $\beta$ are required for DATP differentiation. Upon further analysis of our in vivo and in vitro scRNAseq data, we discovered a unique metabolic signature with higher expression of genes involved in glycolysis pathway such as Pgkl, Pkm, and Slc16a3 (Fig. 4F). By measuring the extracellular acidification rate (ECAR) in organoids, we found that IL-1 $\beta$ enhanced the glycolysis metabolism (Fig. S7, A-C). IL-1 $\beta$-treated organoids also showed higher rates of glucose uptake compared to control (Fig. S7, D and E). Notably, expression of Hifla, a critical regulator for aerobic glycolysis metabolism, was enriched in DATPs (Fig. 4F) (Dang et al., 2008; Semenza, 2012). To determine whether Hifla signaling is required for the transition into DATPs, we treated AT2 organoids with digoxin, a potent inhibitor of Hifla activity, in the presence of IL-1 $\beta$ (Fig. 4G). At day 6 in culture, when higher gene signatures of pAT2 cells were detected, digoxin-treated organoids showed impaired generation of DATPs and AT1 cells (Fig. 4, H and I). We next deleted Hifla specifically on AT2 cells using Hifla $a^{\text {flox/flox }}$;SPC$C r e^{E R T 2} ; R 26 R^{t d T o m a t o}$ mice (Fig. S8A). Consistent with our observations in organoid results, Hifla-deficient AT2 cells failed to generate DATPs at day 10 post injury (Fig. S8, B and C). Similarly to Illr1-deficient AT2 cells, AT2 cells lacking Hifla failed to differentiate into AT1 cells (Fig. S8, D and E). Taken together, these results demonstrate that IL-1 $\beta$ enhances Hiflamediated glycolysis metabolic changes which are integral for the transition into DATPs and subsequent differentiation into AT1 cells during injury repair. 
$1 \quad I I 1 r 1^{+} \mathrm{AT} 2$ cells are functionally and epigenetically distinct subsets that generate DATPs by IL-1 $\beta$ signals in alveolar regeneration

3 Given the importance of IL-1 $\beta$ signaling in alveolar regeneration, we asked whether all AT2 cells are equally capable of responding to IL-1 $\beta$ inflammatory signals. To answer this question, we generated Illrl reporter mice (Illrl-Cre $\left.e^{E R T 2} ; R 26 R^{\text {tdTomato }}\right)$ and treated them with tamoxifen to lineage trace $I l 1 r 1$-expressing cells (Fig. 5, A and B). We found that $I l l r l$ was expressed in airway ciliated cells and small subsets of mesenchyme cells in uninjured lungs (Fig. 5C and Fig. S9). Although 15\% of AT2 cells were lineage-labeled in the uninjured lung, bleomycin injury significantly increased the population of lineage-labeled AT2 cells up to $\sim 60 \%$ at day 14 post injury (Fig. 5, C and D). Illrl lineage-labeled AT2 cells were also more proliferative than unlabeled AT2 cells (Fig. 5, E and F). Approximately $80 \%$ of DATPs were lineage-labeled by $I l 1 r 1$, suggesting that DATPs are mainly originating from $I l l r 1^{+}$AT2 cells (Fig. 5, G and H). At day 28 post injury, lineage-labeled AT1 cells were nicely observed (Fig. 5I).

We posited that epigenetic mechanisms might shape the active response of $1 l 1 r 1^{+}$AT2 cells and next performed ATAC-seq (Assay for Transposase-Accessible Chromatin with highthroughput sequencing). Although most gene including AT2 markers and general housekeeping genes showed similar chromatin accessibility patterns, notable differences were present in the open chromatin states in $I l 1 r 1^{+}$AT2 cells relative to bulk AT2 cells (Fig. 6, A and B and Fig. S10). Analysis for Gene Ontology (GO) terms distribution of highlighted genes revealed that epigenetic regulation and inflammation-associated pathways including Interleukin-1 signaling were enriched in $I l 1 r 1^{+}$AT2 cells (Fig. 6, C and D). Motif analysis of DNA binding-site showed that $I l l r 1^{+}$AT2-enriched chromatin contains motifs for key transcriptional factors associated with inflammation such as AP-1, CREB, NF-kB and Rorc, while shared genes were enriched in motifs for key lung development factors as Nkx2.1 and Cebp (Fig. 6E) (Martis et al., 2006; Minoo et al., 1999; Miossec and Kolls, 2012; Schonthaler et al., 2011). Taken together, these results demonstrate that $I l 1 r 1$ marks epigenetically distinct AT2 cell subtypes with capacity for rapid expansion and subsequent differentiation into AT1 cells during injury response.

Chronic inflammation mediated by sustained IL-1 $\beta$ levels stalls transition of DATPs into mature AT1 cells

Although expression levels of early AT1 markers such as Lmo7, Pdpn, and Hopx were comparable in control and IL-1 $\beta$-treated organoids (Fig. S11A), we found that AT1-like cells 
1 present in IL-1 $\beta$-treated organoids failed to upregulate mature AT1 markers highly expressed 2 in control AT1 cells such as Aqp5, Vegfa, Cav-1, and Spock2 (Fig. S11B). Instead, AT1-like 3 populations in IL-1 $\beta$-treated organoids highly expressed DATP-associated genes including 4 Cldn4, AW112010, and Lhfp (Fig. S11C), indicating that sustained IL-1 $\beta$ treatment in AT2 organoids causes accumulation of DATPs and prevents terminally differentiation into mature AT1 cells. We then asked whether the stalled transition to mature AT1 cells could be rescued by relieving IL-1 $\beta$-mediated inflammation. We cultured AT2 organoids with IL-1 $\beta$ for 14 days and maintained them for an additional 7 days without IL-1 $\beta$ treatment (Fig. 7A). Indeed, we found that expression of late AT1 markers became significantly upregulated upon IL-1 $\beta$ withdrawal (Fig. 7B), concomitant with downregulation of DATP markers and expression of Hifla and other glycolysis pathway genes (Fig. S11D). These findings prompted us ask whether inhibition of glycolysis in stalled DATPs might facilitate AT1 cell maturation. To this end, we treated AT2 organoids with IL-1 $\beta$ for 14 days and then with the glycolysis inhibitor 2deoxyglucose (2-DG, a glucose analogue that causes hexokinase inhibition and disruption of glycolysis) in the continued presence of IL-1 $\beta$ for additional 4 days (Fig. 7C). Notably, inhibition of high glucose metabolism significantly upregulated expression of mature AT1 makers (Fig. 7D). With immunostaining, we confirmed that AT2 cells with persistent IL-1 $\beta$ treatment failed to generate mature AT1 cells expressing Cav-1, a late AT1 cell marker, whereas the expression level of Hopx, an early AT1 cell marker, was comparable to that seen in control (Fig. 7E). Importantly, 2-DG-treated organoids rescued the impaired maturation of AT1 cells even in the presence of IL-1 $\beta$ (Fig. 7E).

We hypothesized that a chronic inflammatory environment will lead to a gradual accumulation of DATPs and eventually defective differentiation and declined lung regeneration. Consistent with our data, recent studies using a high-resolution scRNA-seq analysis reported that a transcriptionally distinct population aberrantly accumulates in a nonpermissive pathologic environment such as idiopathic pulmonary fibrosis (IPF) (Adams et al., 2019; Habermann et al., 2019; Kobayashi et al., 2019; Wu et al., 2020). Notably, we also observed abundant $\mathrm{KRT}^{+} \mathrm{CLDN}^{+}$DATPs-like cells next to HTII-280 ${ }^{+}$AT2 cells in alveolar regions of IPF patient tissue samples, but not within the alveoli of normal donor lung (Fig. 7, F-H). In addition, given the close relationship between chronic inflammation and lung cancer, and recent reports suggesting transcriptional features of injury responses in lung tumor cells, we also found that $\mathrm{KRT}^{+} \mathrm{CLDN}^{+}{ }^{\mathrm{DATP}}$-like cells are observed within the tumor in patient tissue samples of lung adenocarcinoma (Fig. S12) (Conway et al., 2016; Mantovani et al., 2008; 
1 Maynard et al., 2019; Moll et al., 2018). Taken together, these findings demonstrate that chronic inflammatory signals cause dysregulation of DATPs, which leads to development and/or progression of human lung diseases.

\section{Discussion}

7 Effectively coordinated tissue repair is critical for maintenance of tissue integrity and function.

8 In responding to environmental assault, the ability to sense physiological changes is essential 9 for stem cells to initiate repair and resolve damage. Here, we focused on how inflammatory stimuli direct the cell fate behavior of AT2 stem cells during lung injury repair. Our data reveals, for the first time, the detailed step-wise differentiation trajectories of AT2 cells, which are regulated by IL-1 $\beta$-mediated inflammatory signals during the regeneration process. Significantly, we identified $I l l r 1^{+}$AT2 cells and Damage-Associated Transient Progenitors (DATPs) as two classes of regenerative cell populations dedicated to lung injury repair. Our findings bring new insight into how unresolved inflammation mediated by persistent IL-1 $\beta$ signals prevents cell fate transitions, resulting in impaired regeneration and eventually leading to lung diseases (Fig. 8).

Although mechanisms underlying alveolar regeneration are complex, our scRNA-seq analysis of in vivo AT2 lineage-labeled cells and AT2 cell-derived organoids defines the precise reprograming of AT2 cells into AT1 cells during injury repair. We discovered two distinct populations, pAT2 cells and DATPs, as intermediaries between quiescent AT2 and terminally differentiated AT1 lineages. pAT2 cells highly express genes that respond to inflammation (e.g. Pteges, Orm 1, Zbpl), are involved in promoting angiogenesis (e.g. Lrg1, Cxcl17, and Egfl6/7) and reduce reactive oxidative species (ROS) (e.g. Glrx, Prdx4, and Gstk1/2). These properties suggest that pAT2 cells actively respond to inflammatory stimuli, reshaping reciprocal interactions between epithelial cells and their niches during tissue repair. pAT2 cells display much lower expression of genes that are essential for AT2 identity and maintenance such as Etv5 and Abca3, while still expressing comparable levels of canonical AT2 markers such as $S f t p c$ and $L y z 2$. These transcriptional signatures were also seen in IL-1 $\beta$ -treated AT2 cells, leading us to classify pAT2 cells as a population that is skewed towards the AT1 cell fate.

Our data reveal that pAT2 cells share a transcriptional program resembling that of cAT2 cells but with lower expression levels of cell cycle genes (e.g. MKi67, Cdkl). Interestingly, we found that transcriptional signatures of pAT2 cells were upregulated during the transition from 
$1 \mathrm{~S}$ to $\mathrm{G} 2 / \mathrm{M}$ phase in the cell cycle, suggesting the possibility of entering primed states after exiting proliferation states although further validation studies such as genetic tracing of cAT2 or pAT2 cells are needed to provide the delineated sequence of trajectory between these two states. In addition, at variance with a previous study in $I l l r 1^{-1-}$ mice (Katsura et al., 2019), we found that proliferative activity of AT2 cells is not directly altered by Illrl depletion in AT2 cells. Instead, our findings in organoid co-culture experiments revealed that stromal cells responding to IL-1 $\beta$ likely support AT2 cell proliferation. scRNA-seq analysis of stromal cells co-cultured with AT2 cells showed that expression of growth factors facilitating AT2 cell proliferation, such as EGFR ligands (e.g. Ereg), Sppl, and Hgf (Ganguly et al., 2014; Zeng et al., 2016) was dramatically increased in IL-1 $\beta$-treated stromal cells, whereas Bmp4 (Weaver et al., 2000), which is known to inhibit AT2 cell proliferation was significantly reduced (Fig. S6, C-E). The negative regulators for Bmp4 signaling such as Grem1/2 were increased in IL-1 $\beta$-treated stromal cells. Notably, cAT2 cells acquire transcriptional characteristics of pAT2 cells coupled with upregulation of $I l 1 r 1$ expression at the transition from $\mathrm{S}$ to $\mathrm{G} 2 / \mathrm{M}$ phase. These data suggest that IL-1 $\beta$ directly reprograms daughter AT2 cells to enter primed states during the G2/M phase to initiate cell fate transitions without direct influences on cell proliferation. How IL-1 $\beta$ signaling triggers priming of AT2 cells to initiate the differentiation progress remains unknown. Recently, Wnt signaling was reported to prevent reprograming of AT2 cells into AT1 cells (Nabhan et al., 2018), suggesting that crosstalk between IL-1 $\beta$ and Wnt signaling underlies control of cell fate transitions from naïve AT2 to primed cell states.

We discovered a previously unidentified DATP population as an intermediate plastic subpopulation between pAT2 and AT1 cell differentiation states. DATPs expressing Ndrg1, $C l d n 4$ and $K r t 8$ are extremely rare at steady-state, yet are significantly induced after injury by IL-1 $\beta$-mediated inflammatory signaling. Lineage-tracing analysis demonstrated their capacity to give rise to new AT1 cells during alveolar regeneration after injury. Specifically, we determined that IL-1 $\beta$-driven inflammation and regulation of the Hifla signaling pathway is essential for DATPs generation. Specific deletion of Hifla in AT2 cells impaired this progression, resulting in deficient production of new AT1 cells. In addition, we also defined that reduction of IL-1 $\beta$-driven glycolysis is required for transition of DATPs towards initiating AT1 lineage differentiation. This finding suggests that IL-1 $\beta$-mediated inflammation and transient glycolytic metabolism by generating DATPs may establish a checkpoint determining entry into mature AT1 cell differentiation programs. Of note, DATPs reveal quiescent characteristics represented by expression of cell cycle inhibition, p53 signaling, and senescence 
1 marker genes. In addition, emerging evidence supported by a high-resolution scRNA-seq technology suggests an essential role of 'intermediates' during developmental process in governing cell fate choices (Olsson et al., 2016). Interestingly, we also found that DATPs may have the plasticity required to revert to the AT2 lineage, in addition to proceeding towards AT1 differentiation.

By combining lineage-trancing and ATAC-seq analysis we uncovered that $I l 1 r 1^{+}$AT2 cells take on distinct epigenetic state as they efficiently replenish damaged alveolar lineages in response to IL-1 $\beta$ inflammatory signals. Specific open-chromatin states in regions recognized by epigenetic regulators, including chromatin remodellers (e.g. Ino80) and epigenetic modifiers (e.g. Hat1), allow for their rapid and organized responsiveness to injury during the regeneration process. Significantly, we found that DATPs are mainly arising from $1 l 1 \mathrm{rl}^{+}$AT2 cells in response to IL-1 $\beta$ signaling after injury. Recently, Axin $2^{+}$AT2 cells have been identified as a distinct subset of AT2 cells (Nabhan et al., 2018; Zacharias et al., 2018). Related with the potential role of interconnectivity between IL-1 $\beta$ and Wnt signaling in fate decision of AT2 cells, comparison between $I l 1 r 1^{+}$AT2 and $A x i n 2^{+}$AT2 cells will be helpful to understand their relationships during alveolar regeneration.

Resolution of inflammation is a coordinated and active process aimed at restoration of tissue integrity and function. Our data highlight the importance of macrophage activation in the transient inflammatory niche after tissue injury. The increased number of IMs and level of IL-1 $\beta$ peaked at day 14 and resolved to the homeostatic level at day 28 after injury. Analysis of lineage-tracing and scRNA-seq data also revealed that pAT2 cells and DATPs appearing after injury become dramatically reduced as tissue returns to homeostasis. However, significantly, we found that sustained IL-1 $\beta$ signaling causes the defects in the transition from DATPs to terminal differentiation to AT1 lineage, which results in the impaired regeneration. Our finding, for the first time, reveals the cellular and molecular mechanisms how chronic inflammation is implicated in the tissue dysfunction and pathogenesis. Two recent studies showed fibrosis-specific KRT $17^{+}$cell populations in patient tissues of idiopathic pulmonary fibrosis (IPF) (Adams et al., 2019; Habermann et al., 2019). Here, we find that these populations and DATPs have similar transcriptional signatures, also supported by a recent preprint showing the enriched signatures of $\mathrm{Cldn} 4^{+}$pre-AT1 transitional state in these $\mathrm{KRT} 17^{+}$ populations in IPF tissues (Kobayashi et al., 2019). Furthermore, we detected KRT8 ${ }^{+} \mathrm{CLDN} 4^{+}$ DATPs-like cells in the alveolar regions of IPF tissue samples. In addition, several studies have revealed that mechanisms underlying cancer development co-opt regeneration programs to drive tumoral cellular heterogeneity (Maynard et al., 2019; Moll et al., 2018). Congruent with 
1 this work, we also observed DATP-like cells in tissue samples of human lung adenocarcinoma.

2 Our results strongly suggest that fine modulation of DATPs by IL-1 $\beta$-mediated transient

3 inflammatory niche during injury repair is critical for effective lung restoration and is a

4 potential therapeutic adjunct for treating lung diseases.

\section{$5 \quad$ Limitations of the Study}

6 Our study identified subsets of $I l l r 1^{+}$AT2 cells having distinctive epigenetic signatures and 7 quickly responding to injury-induced inflammation for efficient AT1 cell generation. Despite 8 it is clear that only a subset of AT2 cells expressed Illrl and expanded up to $60 \%$ of total AT2

9 cells during injury repair, we cannot completely rule out the possibility of stochastic expression 10 of cre recombination for Illrl expression during repair process due to the remained tamoxifen 11 activity. Longer wash out periods than 16 days may provide clearer evidences to further define 12 the functionally distinctive subsets of $I l 1 r 1^{+}$AT2 cells during injury repair. 


\section{Acknowledgement}

2 We would like to thank Emma Rawlins (University of Cambridge, UK) for valuable scientific

3 discussions and sharing the mouse lines; We would like to thank Randall Johnson (University

4 of Cambridge, UK) for sharing Hifla $\mathrm{a}^{\text {flox/flox }}$ mouse line; Nisha Narayan and Brian Huntly for

5 sharing materials and discussion on glycolysis experiments; Irina Pshenichnaya (Histology),

6 Maike Paramor (NGS library), Peter Humphreys (Imaging), Andy Riddell (Flow cytometry),

7 Simon McCallum (Flow cytometry, Cambridge NIHR BRC Cell Phenotyping Hub), Katarzyna

8 Kania (single cell sequencing at Cancer Research UK), and Cambridge Stem Cell Institute core

9 facilities for technical assistance; Papworth Hospital Research Tissue Bank for providing tissue samples from IPF and lung adenocarcinoma (T02233); Kelly Evans for sharing histology samples of human lung tissue samples; Seungmin Han and Woochang Hwang for discussion on the scRNA-seq analysis; Life Science Editors for editorial assistance; All Lee Lab members

13 for helpful discussion. This work was supported by Wellcome and the Royal Society 14 (107633/Z/15/Z) and European Research Council Starting Grant (679411). J.C. was supported 15 by the National Research Foundation of Korea (NRF) funded by the Ministry of Education (2017R1A6A3A03005399).

Author contribution: J.C. and J.-H.L. designed the experiments, interpreted the data, and wrote the manuscript; J.C. performed most experiments and data analysis; J.-E.P. performed and analyzed scRNA-seq data; G.T. and N.H. analyzed ATAC-seq data; M.Y. shared Ndrg1$\mathrm{Cre}^{\text {ERT2 }}$ mouse line; B.-K.K. helped the generation of Il1r1-Cre ${ }^{\text {ERT2 }}$ mouse line.

Declaration of interests: The authors declare that they have no competing interests. 


\section{STAR METHODS}

2 KEY RESOURCES TABLE

\begin{tabular}{|c|c|c|}
\hline REAGENT or RESOURCE & SOURCE & IDENTIFIER \\
\hline \multicolumn{3}{|l|}{ Antibodies (Flow cytometry) } \\
\hline CD45 (30-F11)-APC & BD Biosciences & Cat \#: 559864 \\
\hline CD31 (MEC13.3)-APC & BD Biosciences & Cat \#:551262 \\
\hline Biotin- conjugated mouse lineage (Lin) panel & Biolegend & Cat \#:13307 \\
\hline EpCAM (G8.8)-PE-Cy7 & BioLegend & Cat \#:118216 \\
\hline Sca-1 (Ly-6A/E, D7)-APC-Cy7 & BioLegend & Cat \#:560654 \\
\hline MHC-II (I-A/I-E, M5)-FITC & ebioscience & Cat \#:11-5321-81 \\
\hline CD64 (X54-5/7.1)-PeCy7 & BioLegend & Cat \#:139313 \\
\hline CD24(M1/69)-APC & ebioscience & Cat \#:101813 \\
\hline Siglec-F(E50-2440)-PE & BD Bioscience & Cat \#:562068 \\
\hline \multicolumn{3}{|l|}{ Antibodies (Immunofluorescence) } \\
\hline Goat anti-SP-C & Santa Cruz & Cat \#: sc-7706 \\
\hline Rabbit pro-SP-C & Millipore & Cat \#: AB3786 \\
\hline Rabbit anti-Ki67 & A. Menarini & Cat \#: MP-325-CRM1 \\
\hline Rat anti-Ki67 & Biolegend & Cat \#: A16A8 \\
\hline Rabbit anti-RFP & Rockland & Cat \#: 600-401379 \\
\hline Hamster anti-PDPN (T1 $\alpha)$ & DSHB & Cat \#: 8.1.1 \\
\hline Rat anti-Cytokeratin-8 & DSHB & Cat \#: TROMA-I \\
\hline Rabbit anti-Claudin-4 & Thermo Fisher Scientific & Cat \#: 36-4800 \\
\hline Rabbit anti-Hopx & Santa Cruz & Cat \#: sc-30216 \\
\hline Rabbit anti-Aqp5 & Alomone Labs & Cat \#: AQP5-005 \\
\hline Rabbit anti-Caveolin-1 & Cell Signaling & Cat \#: 3267 \\
\hline Mouse anti-Acetyl Tub & Sigma-Aldrich & Cat: \# T7451 \\
\hline Mouse anti-HTII-280 & Terrace Biotechnology & TB-27AHT2-280 \\
\hline Alexa Fluor 647 donkey anti-mouse $\lg G(\mathrm{H}+\mathrm{L})$ & Thermo Fisher Scientific & Cat \#: A-31571 \\
\hline Alexa Fluor 647 donkey anti-rabbit IgG $(\mathrm{H}+\mathrm{L})$ & Thermo Fisher Scientific & Cat \#: A-31571 \\
\hline Alexa Fluor 647 donkey anti-goat lgG $(\mathrm{H}+\mathrm{L})$ & Thermo Fisher Scientific & Cat \#: A-31573 \\
\hline Alexa Fluor 488 donkey anti-rat $\lg G(\mathrm{H}+\mathrm{L})$ & Thermo Fisher Scientific & Cat \#: A-21208 \\
\hline Alexa Fluor 488 donkey anti-mouse $\lg G(\mathrm{H}+\mathrm{L})$ & Thermo Fisher Scientific & Cat \#: A-21202 \\
\hline Alexa Fluor 488 donkey anti-rabbit $\lg G(\mathrm{H}+\mathrm{L})$ & Thermo Fisher Scientific & Cat \#: A-21206 \\
\hline Alexa Fluor 555 donkey anti-rabbit lgG $(\mathrm{H}+\mathrm{L})$ & Thermo Fisher Scientific & Cat \#: A-31572 \\
\hline Alexa Fluor 555 donkey anti-rat $\lg \mathrm{G}(\mathrm{H}+\mathrm{L})$ & Thermo Fisher Scientific & Cat \#: A-21434 \\
\hline Alexa Fluor 647 goat anti-hamster IgG $(\mathrm{H}+\mathrm{L})$ & Thermo Fisher Scientific & Cat \#: A-21451 \\
\hline Alexa Fluor 488 Donkey anti-hamster lgG $(\mathrm{H}+\mathrm{L})$ & Thermo Fisher Scientific & Cat \#: A-21110 \\
\hline \multicolumn{3}{|l|}{ Chemicals, Peptides, and Recombinant Proteins } \\
\hline Tamoxifen & Sigma-Aldrich & Cat \#: T5648-1G \\
\hline Corn Oil & Sigma-Aldrich & Cat \#: C8267-500ML \\
\hline Bleomycin & Sigma-Aldrich & Cat \#: B5507-15UN \\
\hline Growth factor-reduced (GFR) Matrigel (10ml) & Corning & Cat \#: 356231 \\
\hline Dispase $(50 \mathrm{U} / \mathrm{ml})$ & Corning & Cat \#: 354235 \\
\hline Collagenase/dispase & Roche & Cat \#: 10269638001 \\
\hline DNase I & Sigma-Aldrich & Cat \#: D4527-10KU \\
\hline TrypLE Express & Gibco & Cat \#: 12604021 \\
\hline 2-NDBG & Thermo Fisher Scientific & Cat \#: N13195 \\
\hline ITS & Corning & Cat \#: 25-800-CR \\
\hline D-Glucose & Sigma-Aldrich & Cat \#: G8270 \\
\hline 2-Deoxy Glucose & Sigma-Aldrich & Cat \#: D8375 \\
\hline Digoxin & Sigma-Aldrich & Cat \#: D6003 \\
\hline
\end{tabular}




\begin{tabular}{|c|c|c|}
\hline DAPI & Sigma-Aldrich & Cat \#: D9542 \\
\hline ROCK inhibitor Y-27632 & Cambridge bioscience & Cat \#: SM02-100 \\
\hline murine IL-1 $\beta$ & Peprotech & Cat \#: 211-11B \\
\hline murine IL-1 $1 \alpha$ & Peprotech & Cat \#: 211-11A \\
\hline murine GM-CSF & Peprotech & Cat \#: 315-03-5 \\
\hline human IL-18 & R\&D system & Cat \#: 9124-IL \\
\hline \multicolumn{3}{|l|}{ Critical Commercial Assays } \\
\hline Click-i ${ }^{\circledR}$ EdU Imaging Kits & Thermo Fisher Scientific & Cat \#: C10640, C10337 \\
\hline Seahorse glycolysis stress test kit & Agilent Technologies & Cat \#: 103020-100 \\
\hline Superscript IV cDNA synthesis kit & Invitrogen & Cat \#: 18090050 \\
\hline \multicolumn{3}{|l|}{ Deposited Data } \\
\hline $\begin{array}{l}\text { scRNA-sequencing for ex vivo organoids treated } \\
\text { with PBS or IL-1 } \beta\end{array}$ & This Paper & GEO: GSE144468 \\
\hline $\begin{array}{l}\text { scRNA-sequencing for in vivo AT2-lineage } \\
\text { tracing }\end{array}$ & This Paper & GEO: GSE145031 \\
\hline $\begin{array}{l}\text { ATAC-sequencing for bulk AT2 cells and } / / 1 r^{+} \\
\text {AT2 cells }\end{array}$ & This Paper & GEO: GSE144598 \\
\hline \multicolumn{3}{|l|}{ Experimental Models: Organisms/Strains } \\
\hline Mouse: SPC-Cre ERT2 & $\begin{array}{l}\text { Barkauskas et al., } \\
2013\end{array}$ & $\begin{array}{l}\text { Jackson Laboratory: } \\
\text { Stock number: } 028054\end{array}$ \\
\hline Mouse: Ndrg1-Cre ${ }^{E R T 2}$ & Endo et al., 2015 & $\begin{array}{l}\text { Contact: Dr. Motoko } \\
\text { Yanagita (Kyoto } \\
\text { University, JP) }\end{array}$ \\
\hline Mouse: Krt8-Cre ERT2 & $\begin{array}{l}\text { Van Keymeulen et al., } \\
2011\end{array}$ & $\begin{array}{l}\text { Jackson Laboratory: } \\
\text { Stock number: } 017947\end{array}$ \\
\hline Mouse: Hi1fa flox/flox & Garayoa et al., 2000 & $\begin{array}{l}\text { Jackson Laboratory: } \\
\text { Stock number: } 007561\end{array}$ \\
\hline Mouse: $/ 11 r^{\text {flox fllox }}$ & Robson et al., 2016 & $\begin{array}{l}\text { Jackson Laboratory: } \\
\text { Stock number: } 028398\end{array}$ \\
\hline Mouse: Rosa26-Iox-stop-Iox-tdTomato & Madisen et al., 2010 & $\begin{array}{l}\text { Jackson Laboratory: } \\
\text { Stock number: } 007914\end{array}$ \\
\hline Mouse: I/1r1-Cre ${ }^{E R T 2}$ & This paper & N/A \\
\hline \multicolumn{3}{|l|}{ Oligonucleotides } \\
\hline Taqman probe for murine Ager & Thermo Fisher Scientific & Mm_00545815_m1 \\
\hline Taqman probe for murine Pdpn & Thermo Fisher Scientific & Mm_00494716_m1 \\
\hline Taqman probe for murine Aqp5r & Thermo Fisher Scientific & Mm_00437578_m1 \\
\hline Taqman probe for murine Gapdh & Thermo Fisher Scientific & Mm_00805216_m1 \\
\hline Primer for qPCR of SYBR Green & $\begin{array}{l}\text { See the method section } \\
\text { of RT-PCR }\end{array}$ & \\
\hline \multicolumn{3}{|l|}{ Software and Algorithms } \\
\hline FlowJo software & Tree Star & https://www.flowjo.com \\
\hline Prism software package version 7.0 & GraphPad & $\begin{array}{l}\text { https://www.graphpad.c } \\
\text { om/scientific- } \\
\text { software/prism/ }\end{array}$ \\
\hline Fiji software & & https://imagej.net/Fiji \\
\hline HOMER software & Heinz et al., 2010 & $\begin{array}{l}\text { http://homer.ucsd.edu/h } \\
\text { omer/ }\end{array}$ \\
\hline ChIPseeker R/Bioconductor package & Yu et al., 2015 & $\begin{array}{l}\text { https://bioconductor.org/ } \\
\text { packages/release/bioc/h } \\
\text { tml/ChIPseeker.html }\end{array}$ \\
\hline deepTools2 & Ramirez et al., 2016 & $\begin{array}{l}\text { https://deeptools.readth } \\
\text { edocs.io/en/develop/ind } \\
\text { ex.html }\end{array}$ \\
\hline MACS2 callpeak & Feng et al., 2012 & $\begin{array}{l}\text { https://github.com/taoliu/ } \\
\text { MACS/ }\end{array}$ \\
\hline
\end{tabular}




\begin{tabular}{|c|c|c|}
\hline Cell Ranger Software Suite (version 2.0.2) & 10x Genomics Inc & $\begin{array}{l}\text { https://support.10xgeno } \\
\text { mics.com/single-cell- } \\
\text { gene- } \\
\text { expression/software/do } \\
\text { wnloads/latest }\end{array}$ \\
\hline Scanpy: python package (version 1.3.6) & Wolf et al., 2018 & $\begin{array}{l}\text { https://icb- } \\
\text { scanpy.readthedocs- } \\
\text { hosted.com/en/stable/ }\end{array}$ \\
\hline Seurat v2.0 & Butler et al., 2018 & $\begin{array}{l}\text { https://satijalab.org/seur } \\
\text { at/ }\end{array}$ \\
\hline \multicolumn{3}{|l|}{ Other } \\
\hline 24-well Transwell insert with a $0.4-\mu \mathrm{m}$ pore & Corning & Cat \#: 3470 \\
\hline$\mu$-Slide 8 wells & ibidi & Cat \#: 80826 \\
\hline
\end{tabular}

\section{Methods}

Animals. SPC-Cre $e^{E R T 2}$ (Barkauskas et al., 2013), Rosa26-lox-stop-lox-tdTomato (Madisen et al., 2010), Ndrg1-Cre $e^{E R T 2}$ (Endo et al., 2015), Krt8-Cre $e^{E R T 2}$ (Van Keymeulen et

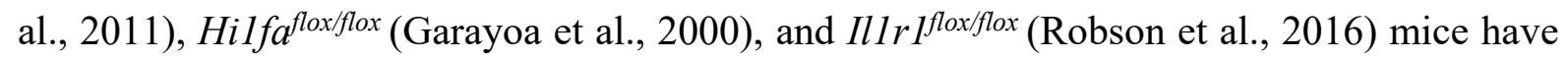
been described and are available from Jackson Laboratory. Il1r1-P2A-eGFP-IRES-Cre ERT2 $^{2}$ (Illr1-Cre $\left.e^{E R T 2}\right)$ mice were generated in our laboratory. Mice for the lineage tracing and injury experiments were on a C57BL/6 background and 6-10 weeks old mice were used for most of the experiments described in this study. Experiments were approved by local ethical review committees and conducted according to UK Home Office project license PC7F8AE82. Mice were bred and maintained under specific-pathogen-free conditions at the Cambridge Stem Cell Institute and Gurdon Institute of University of Cambridge.

Tamoxifen. Tamoxifen (Sigma) was dissolved in Mazola corn oil (Sigma) in a 20mg/ml stock solution. $0.2 \mathrm{mg} / \mathrm{g}$ body weight tamoxifen was given via intraperitoneal (IP) injection. The numbers and date of treatment are indicated in the individual figures of experimental scheme.

Bleomycin Administration. 6-10 week mice were anesthetised via inhalation of isoflurane for approximately 3 mins. The mice were positioned on the intratracheal intubation stand, and $1.25 \mathrm{U} / \mathrm{kg}$ of bleomycin, or PBS control, were delivered intratracheally by a catheter $(22 \mathrm{G})$. During the procedure anaesthesia was maintained by isoflurane and oxygen delivery.

3D Lung organoid co-culture. Lung organoids were established following the previous report (Lee et al., 2014). Briefly, freshly sorted lineage-labeled cells were resuspended in 3D basic media (DMEM/F12 (Gibco) supplemented with 10\% FBS. (Gibco) and ITS (Insulin- 
1 Transferrin-Selenium, Corning)), and mixed with cultured lung stromal cells, followed by resuspension in growth factor-reduced Matrigel (BD Biosciences) at a ratio of 1:5. A 100 $\mu 1$ mixture was placed in a $24-w e l l$ Transwell insert with a $0.4-\mu \mathrm{m}$ pore (Corning). Approximately $5 \times 10^{3} S P C^{+}$cells were seeded in each insert. $500 \mu \mathrm{L}$ of $3 \mathrm{D}$ basic media was placed in the lower chamber, and medium was changed every other day with or without IL-1 $\beta(20 \mathrm{ng} / \mathrm{ml}$,

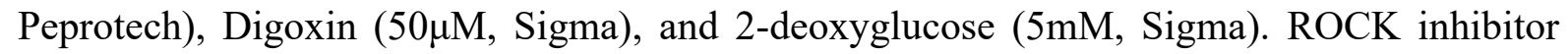
Y27632 (10uM, Sigma) was added in the medium for the first 2 days of culture. For isolation of stroma cells, cells negatively isolated by CD31 via MACS column were further negatively sorted by CD326 (EpCAM) and CD45 microbeads (Miltenyi Biotech). For co-culture with macrophages, sorted interstitial or alveolar macrophages were added to organoids with lineagelabeled $S P C^{+}$cells at a ratio of 1:6 in the presence of lung stromal cells. GM-CSF $(20 \mathrm{ng} / \mathrm{ml}$, Peprotech) was included in some cultures. Analysis of colony forming efficiency (C.F.U) and size of organoids were at 14 days after plating if there is no specific description. For organoid culture of DATPs, AT2 cells $\left(\mathrm{CD} 31^{-} \mathrm{CD} 45^{-} \mathrm{EpCAM}^{+} \mathrm{MHCII}^{+}\right)$isolated from Krt8$C r e^{E R T 2} ; R 26 R^{\text {tdTomato }}$ were cultured with for 14 days with IL-1 $\beta$ (20ng/ml, Peprotech). Then, 4$\mathrm{OH}$ tamoxifen was added at day14 and day16 in culture to label Krt8-expressing cells. Organoids were cultured with $\mathrm{EpCAM}^{+} \mathrm{MHCII}^{-} \mathrm{Tomato}^{+}$DATPs isolated by flow cytometry.

Lung tissue dissociation and flow cytometry. Lung tissues were dissociated with a collagenase/dispase solution as previously described. Briefly, after lungs were cleared by perfusion with cold PBS through the right ventricle, $2 \mathrm{~mL}$ of dispase (BD Biosciences, $50 \mathrm{U} / \mathrm{ml}$ ) was instilled into the lungs through the trachea until the lungs inflated, followed by instillation of $1 \%$ low melting agarose (BioRad) through the trachea to prevent leakage of dispase. Each lobe was dissected and minced into small pieces in a conical tube containing $3 \mathrm{ml}$ of PBS, $60 \mu \mathrm{L}$ of collagenase/dispase (Roche), and $7.5 \mu \mathrm{L}$ of $1 \%$ DNase I (Sigma) followed by rotating incubation for $45 \mathrm{~min}$ at $37^{\circ} \mathrm{C}$. The cells were then filtered sequentially through $100-$ and $40-$ $\mu \mathrm{m}$ strainers and centrifuged at $1000 \mathrm{rpm}$ for $5 \mathrm{~min}$ at $4^{\circ} \mathrm{C}$. The cell pellet was resuspended in $1 \mathrm{ml}$ of ACK lysis buffer (0.15 M NH4Cl, 10mM KHCO3, $0.1 \mathrm{mM}$ EDTA) and lysed for $90 \mathrm{~s}$ at room temperature. $6 \mathrm{ml}$ basic F12 media (GIBCO) was added and $500 \mu \mathrm{l}$ of FBS (Hyclone) was slowly added in the bottom of tube. Cells were centrifuged at $1500 \mathrm{rpm}$ for $5 \mathrm{~min}$ at $4{ }^{\circ} \mathrm{C}$. The cell pellet was resuspended in PF10 buffer (PBS with 10\% FBS) for further staining. The antibodies used were as follows: CD45 (30-F11)-APC or -APC-Cy7 (BD Biosciences), CD31 
1 contains anti-B220 (RA3-6B2), -CD3e(145-2C11), -Gr-1 (RB6-8C5), -CD11b (Mac-1, M1/70),

2 -Ter-119 antibodies (Biolegend), EpCAM (G8.8)-PE-Cy7 or FITC (BioLegend), Sca-1 (Ly-

3 6A/E, D7)-APC-Cy7 (BD Bioscience), MHC-II (I-A/I-E, M5)-FITC (eBiosceince), CD64

4 (X54-5/7.1)-PeCy7 (Biolegend), CD24(M1/69)-APC (eBioscience), and Siglec-F(E50-2440)-

5 PE (BD Bioscience). 4', 6-diamidino-2-phenylindole (DAPI) (Sigma) was used to eliminate

6 dead cells. Data were acquired on LSRII analyzer (BD Biosceince) and then analyzed with

7 FlowJo software (Tree Star). MOFLO system (Beckman Coulter) was used for the sorting at

8 Wellcome-MRC Stem Cell Institute Flow Cytometry Facility.

\section{Human Adult Lung Tissue}

Papworth Hospital NHS Foundation Trust (Research Tissue Bank Generic REC approval, Tissue Bank Project number T02233) provided deidentified lung samples obtained from IPF patients at the time of transplantation, normal background lung tissue from adult donor lungs that were deemed unsuitable for transplant, and lung adenocarcinoma tissues from lobectomies. Fresh tissues were fixed with $4 \%$ paraformaldehyde (PFA) overnight at $4^{\circ} \mathrm{C}$ and paraffin sections (7um) were used for immunofluorescent (IF) analysis.

Macrophage culture in vitro. Interstitial macrophages $\left(\mathrm{CD} 45^{+} \mathrm{CD} 64^{+} \mathrm{Siglec}-\mathrm{F}^{-} \mathrm{CD} 11 \mathrm{~b}^{\text {high }}\right)$ or alveolar macrophages $\left(\mathrm{CD} 45^{+} \mathrm{CD}^{+} 4^{+}\right.$Siglec- $\left.\mathrm{F}^{+} \mathrm{CD} 11 \mathrm{~b}^{\text {low }}\right)$ were isolated from $\mathrm{C} 57 \mathrm{BL} / 6$ by MOFLO system (Beckman Coulter). Isolated macrophages were cultured for 24 hrs in RPMI1640 medium containing $10 \%$ FBS and $50 \mu \mathrm{M}$ 2-mercaptoethanol with or without GM-CSF (10 ng/ml).

EdU incorporation Assays in organoids. Lineage-labeled AT2 cells from $\operatorname{Illr} 1^{\text {flox/+ }}$;R26R $\mathrm{R}^{\text {tdTomato }}$ or Illr1 $1^{\text {flox/flox }} ; R 26 R^{\text {tdTomato }}$ mice given by two doses of tamoxifen were isolated at day 4 post final injection. Organoids established in 8 well chamber slides $(\mu$-Slide 8 wells, ibidi) were treated with EdU $(10 \mu \mathrm{M})$ at day 4 for 4 hrs. EdU staining was performed according to manufacturer's instructions (Click-iT ${ }^{\circledR}$ EdU Imaging Kits, Thermo Fisher Scientific).

Measurement of Extracellular Acidification Rate (ECAR). ECAR of organoids was measured using a XF94 analyzer (Seahorse Bioscience). Seahorse plates were pre-coated with $10 \%$ Matrigel in PBS for $1 \mathrm{hr}$ at $37^{\circ} \mathrm{C}$. Organoids treated with PBS control or IL- $1 \beta$ were added with dispase to remove Matrigel and washed twice with XF Base Medium (DME, pH 7.4) 
1 supplemented with $1 \mathrm{mM}$ glutamine (Seahorse Bioscience). 30,000 cells were seeded on each well and incubated for $1 \mathrm{hr}$ at $37^{\circ} \mathrm{C}$ in non- $\mathrm{CO}_{2}$ incubator before measurement. Three components were injected automatically during the assay to achieve the following final concentrations: Glucose $(10 \mathrm{mM})$, Oligomycin $(1 \mu \mathrm{M})$, and 2-Deoxy Glucose (2-DG, 50mM). ECAR were normalized to the cell numbers of each wells.

Glucose Uptake (2-NDBG incorporation) assays. Organoids at day 14 were washed twice with PBS and incubated with glucose-free medium supplemented with $10 \%$ FBS and GlutaMax (Gibco) for $1 \mathrm{hr}$. $200 \mu \mathrm{M}$ of 2-NBDG (Life Technologies) were subsequently added for $1 \mathrm{hr}$. Organoids were dissociated into single cells with trypLE Express (Gibco) and cells were harvested for flow cytometry. A control sample lacking 2-NBDG was used to set the flow cytometer compensation and gate parameters for 2-NBDG positive events.

Quantitative RT-PCR. Total RNA was isolated using TRI- reagent (Molecular Research Center) or using a Qiagen RNeasy Micro Kit according the manufacturer's instructions. Equivalent quantities of total RNA were reverse-transcribed with SuperScript cDNA synthesis kit (Life Technology) or QuantiTect (Qiagen). Diluted cDNA was analyzed by real-time PCR (StepOnePlus; Applied Biosystem). Pre-designed probe sets and TaqMan universal PCR Master Mix (2x, Thermo Fisher Scientific) were used as follows: Ager (Mm_00545815_m1), Pdpn (Mm_00494716_m1)

Aqp5

(Mm_00437578_m1).

Gapdh expression (Mm_00805216_m1) was used to normalise samples using the $\Delta \mathrm{Ct}$ method. Sybr green assays were also used with SYBR Green Master Mix (2x, Thermo Fisher Scientific). Primer sequences are as follows: Vegfa: F-CCGGTTTAAATCCTGGAGCG, R-TTTAACTCAAGCTGCCTCGC Clic5: F-ATGACGGACTCAGCGACAAC, R-GTAGATCGGCTGGCTTTCTTTT Cav-1: F-TGAGAAGCAAGTGTATGACGC, R-CTTCCAGATGCCGTCGAAAC Aqp5: F-TCTTGTGGGGATCTACTTCACC, R-TGAGAGGGGCTGAACCGAT Sdpr: F-GCTGCACAGGCAGAAAAGTTC, R-GTGACAGCATTCACCTGCG Spock2: F-ACCCCCGGCAATTTCATGG, R-TGTCTTCCCAGCTCTTGATGTAA 
1 Lpcat1: F-GGCTCCTGTTCGCTGCTTT, R-TTCACAGCTACACGGTGGAAG

2 Itga7: F-CTGCTGTGGAAGCTGGGATTC, R-CTCCTCCTTGAACTGCTGTCG

3 Lrg1: F-TTGGCAGCATCAAGGAAGC, R-CAGATGGACAGTGTCGGCA

Orm1: F-CGAGTACAGGCAGGCAATTCA, R-ACCTATTGTTTGAGACTCCCGA

Slc2a1: F-CAGTTCGGCTATAACACTGGTG, R-GCCCCCGACAGAGAAGATG

Slc16a3: F-TCACGGGTTTCTCCTACGC, R-GCCAAAGCGGTTCACACAC

Cldn4: F-GTCCTGGGAATCTCCTTGGC, R-TCTGTGCCGTGACGATGTTG

Hifla: F-ACCTTCATCGGAAACTCCAAAG, R-ACTGTTAGGCTCAGGTGAACT

IL-1 $\beta$ : F-GCAACTGTTCCTGAACTCAACT, R-ATCTTTTGGGGTCCGTCAACT

IL-13: F-CCTGGGCTCTTGTCTGCCTT, R-GGTCTTGTTGATGTTGCTCA

IL-18: F-GACTCTTGCGTCAACTTCAAGG, R-CAGGCTGTCTTTTGTCAACGA

Histology and Immunohistochemistry. Mouse lung tissues were routinely perfused, inflated, and fixed with 4\% PFA for 4-6 hrs at 4 degrees and cryosections (8um) and paraffin sections (7um) were used for histology and IF analysis. Cultured colonies from organoids were fixed with 4\% PFA for 2-4 hrs at room temperature followed by immobilization with Histogel (Thermo Scientific) for paraffin embedding. Sectioned lung tissues or colonies were stained with hematoxylin and eosin (H\&E) or immunostained: after antigen retrieval with citric acid (0.01M, pH 6.0), blocking was performed with 5\% normal donkey serum in $0.2 \%$ Triton$\mathrm{X} / \mathrm{PBS}$ at room temperature for $1 \mathrm{hr}$. Primary antibodies were incubated overnight at $4^{\circ} \mathrm{C}$ at the indicated dilutions: goat anti-SP-C (1:200, Santa Cruz Biotechnology Inc., sc-7706), pro-SPC (1:300, Millipore, AB3786), rabbit anti-Ki67 (1:250, A. Menarini, MP-325-CRM1), rat antiKi67 (1:200, Biolegend, A16A8), rabbit anti-RFP (1:250, Rockland, 600-401379), hamster anti-PDPN (1:1000, DSHB, 8.1.1), rat anti-Cytokeratin-8 (1:300, DSHB, TROMA-I), rabbit anti-Claudin-4 (1:200, Thermo Fisher Scientific, 36-4800), rabbit anti-Hopx (1:100, Santa Cruz Biotechnology Inc., sc-30216), rabbit anti-Aqp5 (1:200, Alomone Labs, AQP5-005), rabbit anti-Caveolin-1 (1:500, Cell Signaling, \#3267), and mouse anti-HTII-280 (1:200, Terrace Biotechnology, TB-27AHT2-280). Alexa Fluor-coupled secondary antibodies (1:500, Invitrogen) were incubated at room temperature for $60 \mathrm{~min}$. After antibody staining, nuclei 
1 were stained with DAPI (1:1000, Sigma) and sections were embedded in Vectashield (Vector 2 Labs). Fluorescence images were acquired using a confocal microscope (Leica TCS SP5). All 3 the images were further processed with Fiji software.

Statistical Analysis. Statistical methods relevant to each figure are outlined in the figure legend. Statistical analyzes were performed with Prism software package version 7.0 (GraphPad). $P$ values were calculated using two-tailed unpaired or paired Student's $t$ test. Sample size for animal experiments was determined based upon pilot experiments. Mice cohort size was designed to be sufficient to enable accurate determination of statistical significance. No animals were excluded from the statistical analysis. Mice were randomly assigned to treatment or control groups, while ensuring inclusion criteria based on gender and age. Animal studies were not performed in a blinded fashion. The number of animals shown in each figure is indicated in the legends as $n=x$ mice per group. Data shown are either representative of three or more independent experiments, or combined from three or more independent experiments as noted and analyzed as mean \pm SEM.

Cell Counting and Image Analysis. Sections included in cell scoring analysis for lung tissue were acquired using Leica TCS SP5 confocal microscope. At least five different sections including at least 10 alveolar regions from three individual mice per group were used. Cell counts were performed on ImageJ using the 'Cell Counter' plug-in and the performer was blinded to the specimen genotype and condition. At least two step sections (30um apart) per individual well were used for quantification of AT1 or AT2 cells.

ATAC-seq analysis. The ATAC-seq assay was performed on 50,000 FACS-purified cells as previously described (Buenrostro et al., 2015). In brief, two biological independent samples were used for ATAC-seq experiment. 5 mice were pooled for $I l l r I^{+}$AT2 cells and 1 mouse was used for bulk AT2 cells per group. Purified cells were lysed in ATAC lysis buffer for 5 min to get nuclei and then transposed with Tn5 transposase (Illumina) for $30 \mathrm{~min}$. Fractionated DNA was used for amplification and library preparation according to manufacturer's guidelines (Illumina) and 150 bp-paired end sequencing was performed by pooling two samples of $I l l r I^{+}$AT2 and bulk AT2 cells, respectively, in one lane of the Illumina HiSeq 4000 platform. The quality of the generated sequencing data was checked using the FastQC program, followed by filtering of adaptor and/or overrepresented sequences using Trimmomatic (Bolger et al., 2014). Filtered reads were next mapped to the mouse primary genome assembly 
1 (mm9/GRCm38) using STAR (Dobin et al., 2013), with parameters 2 outFilterMatchNminOverLread 0.4 -outFilterScoreMinOverLread 0.4, and a GTF annotation 3 file of the latest mouse assembly (GCA_000001635.8) downloaded from ENSEMBL ftp.

4 Duplicate reads were flagged and removed using MarkDuplicates from Picard tools. MACS2(Feng et al., 2012) callpeak was used for ATAC-seq peak calling of the $I l 1 r 1^{+}$AT2 and bulk AT2 samples, using the options -nomodel-shift -100-extsize 200. Differentially enriched peaks in $I l l r I^{+}$AT2 and bulk AT2 populations were next inferred using the MACS2 bdgdiff with a $\log 10$ likelihood ratio score cutoff of 10. ATAC-seq heatmaps were plotted using deepTools2 (Ramirez et al., 2016). Annotation of ATAC-seq enriched peaks overlapping with promoter and other gene regions was performed using the ChIPseeker R/Bioconductor package, together with GO enrichment and pathway analyzes (Yu et al., 2015). Finally, motif identification was performed using the findMotifsGenome.pl program of the HOMER software (Heinz et al., 2010).

scRNA-seq Library Preparation and Sequencing. Established organoids of control or IL$1 \beta$-treatment were incubated with dispase (BD Bioscience) for 30-60min. Then, cells were dissociated with TripLE (Gibco) for $5 \mathrm{~min}$, followed by washing with buffer (PBS/0.01\% BSA). For SPC lineage-labeled cells, $\mathrm{CD} 45^{-} \mathrm{CD} 31^{-} \mathrm{EpCAM}^{+}$Tomato $^{+}$cells were sorted at specific time points (at day 14 and day 28 post damage) from PBS or Bleomycin-treated mice (2 mice were pooled for each experiment). For non-lineage-labeled cells isolated from $S P C$ $C r e^{E R T 2} ; R 26 R^{t d T o m a t o}$ mice in parallel with experiment of SPC lineage-labeled cells, we combined the cells of $\mathrm{EpCAM}^{+}$Tomato $^{-}$and $\mathrm{EpCAM}^{-}$population with a ratio of 2:1, respectively. The resulting cell suspension $(\sim 110,000$ cells each) were submitted as separate samples to be barcoded for the droplet-encapsulation single- cell RNA-seq experiments using the Chromium Controller (10X Genomics). Single cell cDNA synthesis, amplification and sequencing libraries were generated using the Single Cell $3^{\prime}$ Reagent Kit as per the 10x Genomics protocol. Libraries were multiplexed so that 2 libraries were sequenced per single lane of HiSeq 4000 using the following parameters: Read1: 26 cycles, i7: 8 cycles, i5: 0 cycles; Read2: 98 cycles to generate $75 \mathrm{bp}$ paired end reads.

Alignment, quantification and quality control of single cell RNA sequencing data. Software Suite (version 2.0.2, 10x Genomics Inc) using the Mus musculus genome (GRCm38) (official Cell Ranger reference, version 1.2.0). Cells were filtered by custom cutoff (more than 
1500 and less than 7000 detected genes, more than 2000 UMI count) to remove potential empty droplets and doublets. Downstream analysis included data normalisation, highly variable gene detection, log transformation, principal component analysis, neighbourhood graph generation and Louvain graph-based clustering, which was done by python package scanpy (version 1.3.6) (Wolf et al., 2018) using default parameters.

Excluding stromal cells and contaminated cells in scRNA-seq analysis of organoids and SPC lineage-tracing after bleomycin injury. For scRNA-seq analysis of organoids, we excluded the cluster of EpCAM- cells of stromal cells we put together with AT2 cells in culture. For in vivo scRNA-seq analysis of AT2 cells after bleomycin injury, we excluded nonepithelial cells and ciliated cells based on marker gene expression. Although cells were sorted based on the expression of EpCAM, CD31, CD45, and Tomato before scRNA-seq, 255 contaminating cells among 12514 cells captured were observed in the initial droplet dataset. These comprised: 214 ciliated cells expressing Foxj $1, W n t 7 b$, and $C d 24 a ; 16$ mesenchyme cells expressing Vcam1, Acta2, Des, and Pdgfra; 25 immune cells expressing Ptprc (CD45), Tyrobp, $I l 2 \mathrm{rg}$, and $\mathrm{Lck}$. Each of these cell populations was identified by an initial round of unsupervised Louvain graph-based clustering analysis as they formed extremely distinct clusters and then removed. For scRNA-seq analysis of in vivo non-lineage-labeled cells, we excluded the doublet cluster of cells expressing both $\mathrm{EpCAM}^{+} \mathrm{CD}^{+} 5^{+}$(1125 cells among 14017 cells).

Doublet Exclusion. To exclude doublets from single-cell RNA sequencing data, we applied scrublet algorithm per sample to calculate scrublet-predicted doublet score per cell with following parameters: $\operatorname{sim} \_$doublet_ratio $=2 ;$ n_neighbors $=30$; expected_doublet_rate $=0.1$. Any cell with scrublet score $>0.7$ was flagged as doublet. To propagate the doublet detection into potential false-negatives from scrublet analysis, we over-clustered the dataset (sc.tl.louvain function from scanpy package version 1.3.4; resolution $=20$ ), and calculated the average doublet score within each cluster. Any cluster with averaged scrublet score $>0.6$ was flagged as a doublet cluster. All remaining cell clusters were further examined to detect potential false-negatives from scrublet analysis according to the following criteria: (1) Expression of marker genes from two distinct cell types which are unlikely according to prior knowledge, (2) higher number of UMI counts.

Pseudotime Analysis. All data contained within our processed Seurat object for the wildtype data set was converted to the AnnaData format for pseudotime analysis in Scanpy (version 
1 1.3.6). We recalculated $k$-nearest neighbors at $\mathrm{k}=15$. Pseudotime was calculated using 2 Scanpy's partitioned-based graph abstraction function, PAGA. Diffusion pseudotime was 3 performed using Scanpy's DPT function with default parameters.

4 


\section{References}

2 Adams, T.S., Schupp, J.C., Poli, S., Ayaub, E.A., Neumark, N., Ahangari, F., Chu, S.G.,

3 Raby, B.A., DeIuliis, G., Januszyk, M., et al. (2019). Single Cell RNA-seq reveals ectopic and aberrant lung resident cell populations in Idiopathic Pulmonary Fibrosis. bioRxiv https://doi.org/10.1101/759902.

6 Adamson, I.Y., and Bowden, D.H. (1974). The type 2 cell as progenitor of alveolar epithelial 7 regeneration. A cytodynamic study in mice after exposure to oxygen. Lab Invest 30, 35-42.

8 Barkauskas, C.E., Cronce, M.J., Rackley, C.R., Bowie, E.J., Keene, D.R., Stripp, B.R., 9 Randell, S.H., Noble, P.W., and Hogan, B.L. (2013). Type 2 alveolar cells are stem cells in adult lung. J Clin Invest 123, 3025-3036.

Bolger, A.M., Lohse, M., and Usadel, B. (2014). Trimmomatic: a flexible trimmer for Illumina sequence data. Bioinformatics 30, 2114-2120. Buenrostro, J.D., Wu, B., Chang, H.Y., and Greenleaf, W.J. (2015). ATAC-seq: A Method for Assaying Chromatin Accessibility Genome-Wide. Curr Protoc Mol Biol 109, 2129 2129.

Chen, F., Liu, Z., Wu, W., Rozo, C., Bowdridge, S., Millman, A., Van Rooijen, N., Urban, J.F., Jr., Wynn, T.A., and Gause, W.C. (2012). An essential role for TH2-type responses in limiting acute tissue damage during experimental helminth infection. Nat Med 18, 260-266. Conway, E.M., Pikor, L.A., Kung, S.H., Hamilton, M.J., Lam, S., Lam, W.L., and Bennewith, K.L. (2016). Macrophages, Inflammation, and Lung Cancer. Am J Respir Crit Care Med 193, 116-130.

Dang, C.V., Kim, J.W., Gao, P., and Yustein, J. (2008). The interplay between MYC and HIF in cancer. Nat Rev Cancer 8, 51-56.

Dobin, A., Davis, C.A., Schlesinger, F., Drenkow, J., Zaleski, C., Jha, S., Batut, P., Chaisson, M., and Gingeras, T.R. (2013). STAR: ultrafast universal RNA-seq aligner. Bioinformatics 29, 15-21.

Endo, T., Nakamura, J., Sato, Y., Asada, M., Yamada, R., Takase, M., Takaori, K., Oguchi, A., Iguchi, T., Higashi, A.Y., et al. (2015). Exploring the origin and limitations of kidney regeneration. J Pathol 236, 251-263.

30 Feng, J., Liu, T., Qin, B., Zhang, Y., and Liu, X.S. (2012). Identifying ChIP-seq enrichment using MACS. Nat Protoc 7, 1728-1740.

Finn, J., Sottoriva, K., Pajcini, K.V., Kitajewski, J.K., Chen, C., Zhang, W., Malik, A.B., and 
1 Differentiation of Alveolar Type II to Type I Cells during Repair. Cell Rep 26, 2942-2954 $2 \mathrm{e} 2945$.

3 Fortier, M.A., Krishnaswamy, K., Danyod, G., Boucher-Kovalik, S., and Chapdalaine, P.

4 (2008). A postgenomic integrated view of prostaglandins in reproduction: implications for 5 other body systems. J Physiol Pharmacol 59 Suppl 1, 65-89.

6 Ganguly, K., Martin, T.M., Concel, V.J., Upadhyay, S., Bein, K., Brant, K.A., George, L.,

7 Mitra, A., Thimraj, T.A., Fabisiak, J.P., et al. (2014). Secreted phosphoprotein 1 is a

8 determinant of lung function development in mice. Am J Respir Cell Mol Biol 51, 637-651.

9 Garayoa, M., Martinez, A., Lee, S., Pio, R., An, W.G., Neckers, L., Trepel, J., Montuenga, L.M., Ryan, H., Johnson, R., et al. (2000). Hypoxia-inducible factor-1 (HIF-1) up-regulates adrenomedullin expression in human tumor cell lines during oxygen deprivation: a possible promotion mechanism of carcinogenesis. Mol Endocrinol 14, 848-862.

Habermann, A.C., Gutierrez, A.J., Bui, L.T., Yahn, S.L., Winters, L.I., Calvi, C.L., Peter, L., Chung, M.I., Taylor, C.J., Jetter, C., et al. (2019). Single-cell RNA-sequencing reveals profibrotic roles of distinct epithelial and mesenchymal lineages in pulmonary fibrosis. bioRxiv https://doi.org/10.1101/753806. Haghverdi, L., Buttner, M., Wolf, F.A., Buettner, F., and Theis, F.J. (2016). Diffusion pseudotime robustly reconstructs lineage branching. Nat Methods 13, 845-848. Hasegawa, K., Sato, A., Tanimura, K., Uemasu, K., Hamakawa, Y., Fuseya, Y., Sato, S., Muro, S., and Hirai, T. (2017). Fraction of MHCII and EpCAM expression characterizes distal lung epithelial cells for alveolar type 2 cell isolation. Respir Res 18,150 . Heinz, S., Benner, C., Spann, N., Bertolino, E., Lin, Y.C., Laslo, P., Cheng, J.X., Murre, C., Singh, H., and Glass, C.K. (2010). Simple combinations of lineage-determining transcription factors prime cis-regulatory elements required for macrophage and B cell identities. Mol Cell 38, 576-589.

Hogan, B.L., Barkauskas, C.E., Chapman, H.A., Epstein, J.A., Jain, R., Hsia, C.C., Niklason, L., Calle, E., Le, A., Randell, S.H., et al. (2014). Repair and regeneration of the respiratory system: complexity, plasticity, and mechanisms of lung stem cell function. Cell Stem Cell 15, 123-138.

Hsu, Y.C., Li, L., and Fuchs, E. (2014). Emerging interactions between skin stem cells and their niches. Nat Med 20, 847-856.

Katsura, H., Kobayashi, Y., Tata, P.R., and Hogan, B.L.M. (2019). IL-1 and TNFalpha 
1 Klose, C.S., and Artis, D. (2016). Innate lymphoid cells as regulators of immunity,

2 inflammation and tissue homeostasis. Nat Immunol 17, 765-774.

3 Kobayashi, Y., Tata, A., Konkimalla, A., Katsura, H., Lee, F.R., Ou, J., Banovich, E.N.,

4 Kropski, A.J., and Tata, R.P. (2019). Persistence of a novel regeneration-associated

5 transitional cell state in pulmonary fibrosis. BioRxiv https://doi.org/10.1101/855155.

6 Kotton, D.N., and Morrisey, E.E. (2014). Lung regeneration: mechanisms, applications and

7 emerging stem cell populations. Nat Med 20, 822-832.

8 Kuriakose, T., and Kanneganti, T.D. (2018). ZBP1: Innate Sensor Regulating Cell Death and

9 Inflammation. Trends Immunol 39, 123-134.

Lechner, A.J., Driver, I.H., Lee, J., Conroy, C.M., Nagle, A., Locksley, R.M., and Rock, J.R. (2017). Recruited Monocytes and Type 2 Immunity Promote Lung Regeneration following Pneumonectomy. Cell Stem Cell 21, 120-134 e127. Lee, J.H., Bhang, D.H., Beede, A., Huang, T.L., Stripp, B.R., Bloch, K.D., Wagers, A.J., Tseng, Y.H., Ryeom, S., and Kim, C.F. (2014). Lung stem cell differentiation in mice directed by endothelial cells via a BMP4-NFATc1-thrombospondin-1 axis. Cell 156, 440455.

Lee, J.H., Tammela, T., Hofree, M., Choi, J., Marjanovic, N.D., Han, S., Canner, D., Wu, K., Paschini, M., Bhang, D.H., et al. (2017). Anatomically and Functionally Distinct Lung Mesenchymal Populations Marked by Lgr5 and Lgr6. Cell 170, 1149-1163 e1112. Li, L., and Clevers, H. (2010). Coexistence of quiescent and active adult stem cells in mammals. Science $327,542-545$.

Ligresti, G., Aplin, A.C., Dunn, B.E., Morishita, A., and Nicosia, R.F. (2012). The acute phase reactant orosomucoid-1 is a bimodal regulator of angiogenesis with time- and contextdependent inhibitory and stimulatory properties. PLoS One 7, e41387. Lindemans, C.A., Calafiore, M., Mertelsmann, A.M., O'Connor, M.H., Dudakov, J.A., Jenq, R.R., Velardi, E., Young, L.F., Smith, O.M., Lawrence, G., et al. (2015). Interleukin-22 promotes intestinal-stem-cell-mediated epithelial regeneration. Nature 528, 560-564. Palmiter, R.D., Hawrylycz, M.J., Jones, A.R., et al. (2010). A robust and high-throughput Cre reporting and characterization system for the whole mouse brain. Nat Neurosci 13, 133-140. Mantovani, A., Allavena, P., Sica, A., and Balkwill, F. (2008). Cancer-related inflammation. Nature 454, 436-444.

33 Martis, P.C., Whitsett, J.A., Xu, Y., Perl, A.K., Wan, H., and Ikegami, M. (2006). 
1 Maynard, A., McCoach, C.E., Julia K. Rotow, L.H., Haderk, F., Kerr, L., Yu, E.A., Schenk,

2 E.L., Tan, W., Zee, A., Tan, M., et al. (2019). Heterogeneity and targeted therapy-induced

3 adaptations in lung cancer revealed by longitudinal single-cell RNA sequencing. bioRxiv doi:

4 https://doi.org/10.1101/2019.12.08.868828.

5 Medzhitov, R. (2008). Origin and physiological roles of inflammation. Nature 454, 428-435.

6 Minoo, P., Su, G., Drum, H., Bringas, P., and Kimura, S. (1999). Defects in

7 tracheoesophageal and lung morphogenesis in Nkx2.1(-/-) mouse embryos. Dev Biol 209, 60871.

9 Miossec, P., and Kolls, J.K. (2012). Targeting IL-17 and TH17 cells in chronic inflammation. Nat Rev Drug Discov 11, 763-776.

Misharin, A.V., Morales-Nebreda, L., Reyfman, P.A., Cuda, C.M., Walter, J.M., McQuattie-

Pimentel, A.C., Chen, C.I., Anekalla, K.R., Joshi, N., Williams, K.J.N., et al. (2017).

Monocyte-derived alveolar macrophages drive lung fibrosis and persist in the lung over the life span. J Exp Med 214, 2387-2404.

Moll, H.P., Pranz, K., Musteanu, M., Grabner, B., Hruschka, N., Mohrherr, J., Aigner, P.,

Stiedl, P., Brcic, L., Laszlo, V., et al. (2018). Afatinib restrains K-RAS-driven lung tumorigenesis. Sci Transl Med 10.

Nabhan, A.N., Brownfield, D.G., Harbury, P.B., Krasnow, M.A., and Desai, T.J. (2018).

Single-cell Wnt signaling niches maintain stemness of alveolar type 2 cells. Science 359, $1118-1123$.

21 Naik, S., Larsen, S.B., Cowley, C.J., and Fuchs, E. (2018). Two to Tango: Dialog between Immunity and Stem Cells in Health and Disease. Cell 175, 908-920.

Naik, S., Larsen, S.B., Gomez, N.C., Alaverdyan, K., Sendoel, A., Yuan, S., Polak, L.,

Kulukian, A., Chai, S., and Fuchs, E. (2017). Inflammatory memory sensitizes skin epithelial stem cells to tissue damage. Nature 550, 475-480.

Olsson, A., Venkatasubramanian, M., Chaudhri, V.K., Aronow, B.J., Salomonis, N., Singh, H., and Grimes, H.L. (2016). Single-cell analysis of mixed-lineage states leading to a binary cell fate choice. Nature 537, 698-702.

Ramirez, F., Ryan, D.P., Gruning, B., Bhardwaj, V., Kilpert, F., Richter, A.S., Heyne, S., Dundar, F., and Manke, T. (2016). deepTools2: a next generation web server for deepsequencing data analysis. Nucleic Acids Res 44, W160-165.

Riemondy, K.A., Jansing, N.L., Jiang, P., Redente, E.F., Gillen, A.E., Fu, R., Miller, A.J., 
1 identifies TGFbeta as a key regenerative cue following LPS-induced lung injury. JCI Insight

25

3 Rindler, T.N., Stockman, C.A., Filuta, A.L., Brown, K.M., Snowball, J.M., Zhou, W.,

4 Veldhuizen, R., Zink, E.M., Dautel, S.E., Clair, G., et al. (2017). Alveolar injury and

5 regeneration following deletion of ABCA3. JCI Insight 2.

6 Robson, M.J., Zhu, C.B., Quinlan, M.A., Botschner, D.A., Baganz, N.L., Lindler, K.M.,

7 Thome, J.G., Hewlett, W.A., and Blakely, R.D. (2016). Generation and Characterization of

8 Mice Expressing a Conditional Allele of the Interleukin-1 Receptor Type 1. PLoS One 11,

$9 \mathrm{e} 0150068$.

10 Rock, J.R., Barkauskas, C.E., Cronce, M.J., Xue, Y., Harris, J.R., Liang, J., Noble, P.W., and

11 Hogan, B.L. (2011). Multiple stromal populations contribute to pulmonary fibrosis without

12 evidence for epithelial to mesenchymal transition. Proc Natl Acad Sci U S A 108, E1475-

131483.

14 Schonthaler, H.B., Guinea-Viniegra, J., and Wagner, E.F. (2011). Targeting inflammation by 15 modulating the Jun/AP-1 pathway. Ann Rheum Dis 70 Suppl 1, i109-112.

16 Semenza, G.L. (2012). Hypoxia-inducible factors in physiology and medicine. Cell 148, 39917408.

18 Van Keymeulen, A., Rocha, A.S., Ousset, M., Beck, B., Bouvencourt, G., Rock, J., Sharma,

19 N., Dekoninck, S., and Blanpain, C. (2011). Distinct stem cells contribute to mammary gland 20 development and maintenance. Nature 479, 189-193.

21 Wagers, A.J., and Weissman, I.L. (2004). Plasticity of adult stem cells. Cell 116, 639-648.

22 Weaver, M., Dunn, N.R., and Hogan, B.L. (2000). Bmp4 and Fgf10 play opposing roles during lung bud morphogenesis. Development 127, 2695-2704.

Westphalen, K., Gusarova, G.A., Islam, M.N., Subramanian, M., Cohen, T.S., Prince, A.S., and Bhattacharya, J. (2014). Sessile alveolar macrophages communicate with alveolar epithelium to modulate immunity. Nature 506, 503-506.

Wolf, F.A., Angerer, P., and Theis, F.J. (2018). SCANPY: large-scale single-cell gene expression data analysis. Genome Biol 19, 15.

Wolf, F.A., Hamey, F.K., Plass, M., Solana, J., Dahlin, J.S., Gottgens, B., Rajewsky, N., Simon, L., and Theis, F.J. (2019). PAGA: graph abstraction reconciles clustering with trajectory inference through a topology preserving map of single cells. Genome Biol 20, 59. Wu, H., Yu, Y., Huang, H., Hu, Y., Fu, S., Wang, Z., Shi, M., Zhao, X., Yuan, J., Li, J., et al. 33 (2020). Progressive Pulmonary Fibrosis Is Caused by Elevated Mechanical Tension on 34 Alveolar Stem Cells. Cell 180, 107-121 e117. 
1 Yu, G., Wang, L.G., and He, Q.Y. (2015). ChIPseeker: an R/Bioconductor package for ChIP 2 peak annotation, comparison and visualization. Bioinformatics 31, 2382-2383.

3 Zacharias, W.J., Frank, D.B., Zepp, J.A., Morley, M.P., Alkhaleel, F.A., Kong, J., Zhou, S.,

4 Cantu, E., and Morrisey, E.E. (2018). Regeneration of the lung alveolus by an evolutionarily

5 conserved epithelial progenitor. Nature 555, 251-255.

6 Zeng, L., Yang, X.T., Li, H.S., Li, Y., Yang, C., Gu, W., Zhou, Y.H., Du, J., Wang, H.Y.,

7 Sun, J.H., et al. (2016). The cellular kinetics of lung alveolar epithelial cells and its

8 relationship with lung tissue repair after acute lung injury. Respir Res 17, 164.

9 Zepp, J.A., Zacharias, W.J., Frank, D.B., Cavanaugh, C.A., Zhou, S., Morley, M.P., and

10 Morrisey, E.E. (2017). Distinct Mesenchymal Lineages and Niches Promote Epithelial Self-

11 Renewal and Myofibrogenesis in the Lung. Cell 170, 1134-1148 e1110.

12 Zhang, Z., Newton, K., Kummerfeld, S.K., Webster, J., Kirkpatrick, D.S., Phu, L., Eastham-

13 Anderson, J., Liu, J., Lee, W.P., Wu, J., et al. (2017). Transcription factor Etv5 is essential

14 for the maintenance of alveolar type II cells. Proc Natl Acad Sci U S A 114, 3903-3908. 


\section{$1 \quad$ Figures and Legends}

A

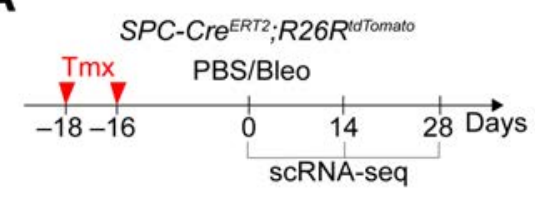

B

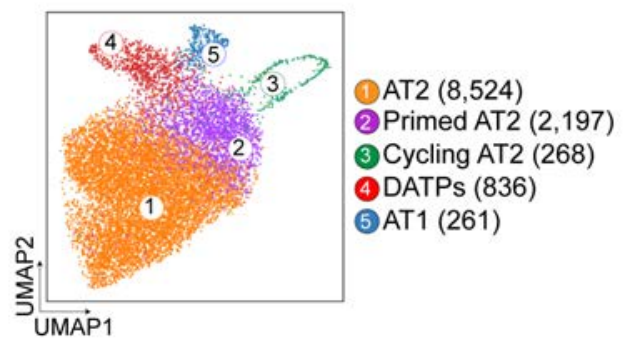

C

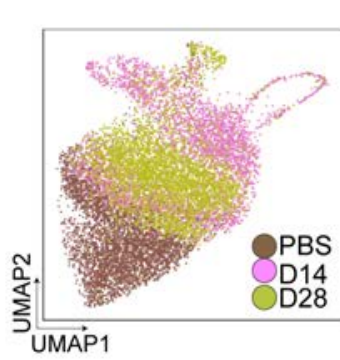

D

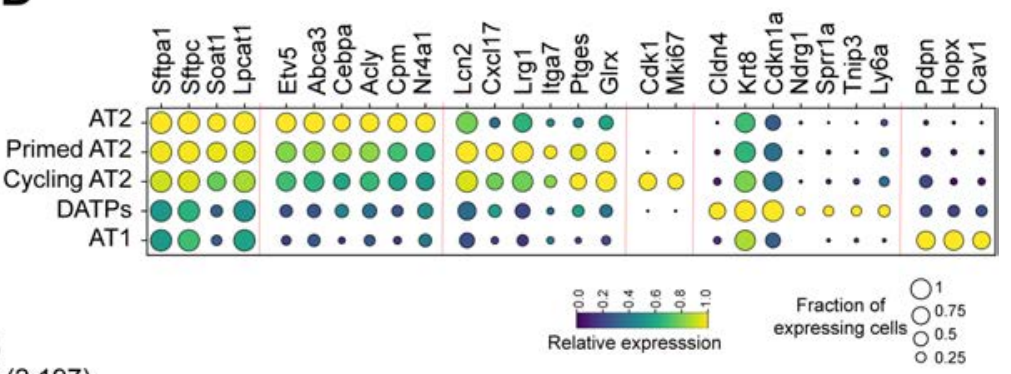

E
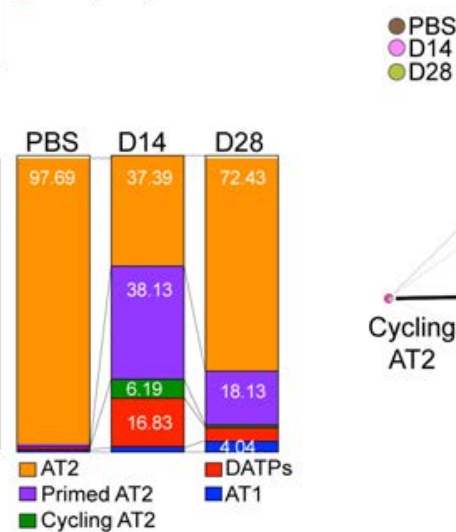

F

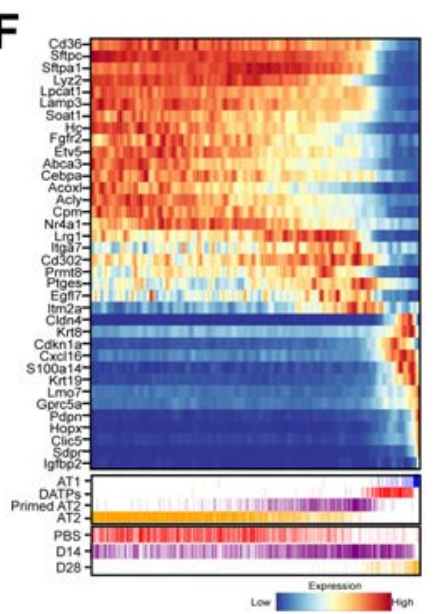

Figure 1. scRNA-seq reveals a dynamic lineage trajectory from AT2 cells to AT1 cells during alveolar regeneration after injury.

(A) Schematics of experimental design for $S P C$ lineage-labeled single cell isolation at indicated time points after bleomycin injury.

(B) Clusters of SPC lineage-labeled alveolar cells $(12,086)$ from 10xGenomics 3' single-cell RNA sequencing (scRNA-seq) analysis visualized by UMAP, assigned by specific colors. Number of cells in the individual cluster is depicted in the figure.

(C) Distribution of each cluster across indicated time points after injury.

(D) Gene expression of key markers in each distinctive cluster.

2 (E) Network topology among clusters from single cell data revealed by Partition-based graph abstraction (PAGA). Colors indicate the proportion of each cluster by time point. Each node in 14 the PAGA graph represents a cluster and the weight of the lines represents the statistical measure of connectivity between clusters.

(F) Heat map of gene expression profiles according to pseudotime trajectory. Lower color bars 7 indicate cell types (upper panel) and actual time (bottom panel). See also Fig. S1. 


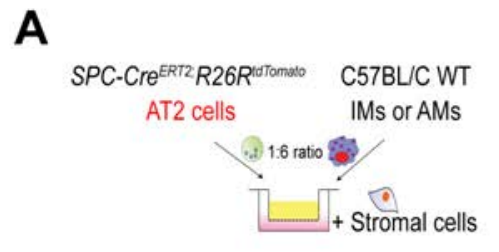

B

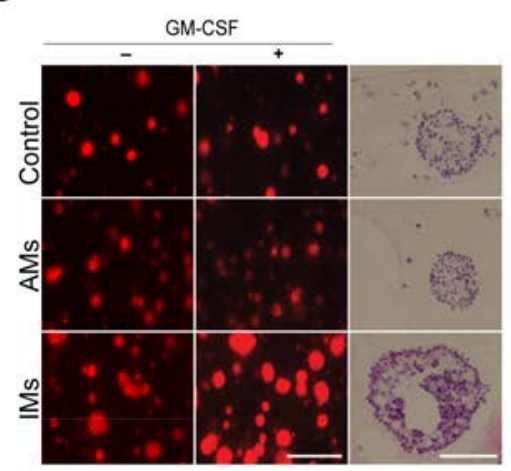

C

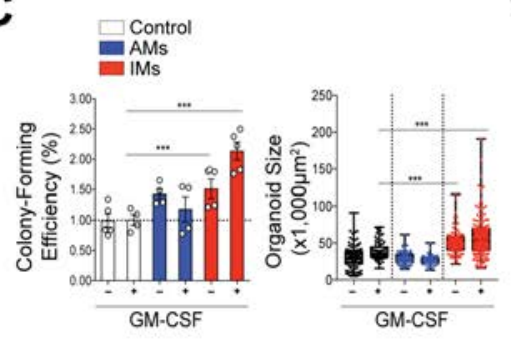

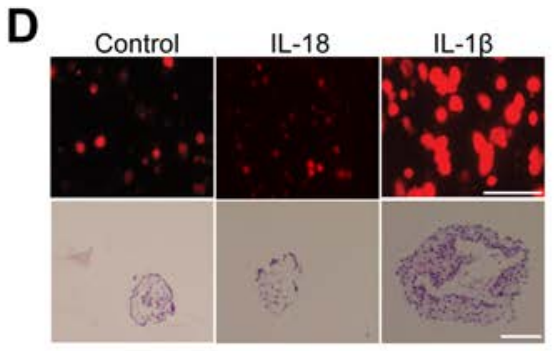

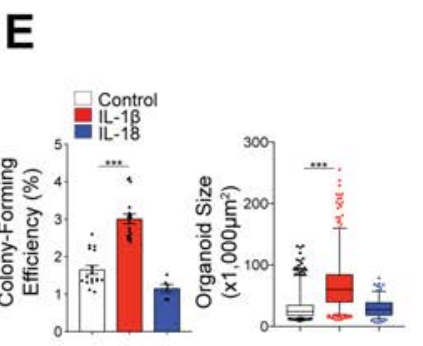

$\mathbf{F}$

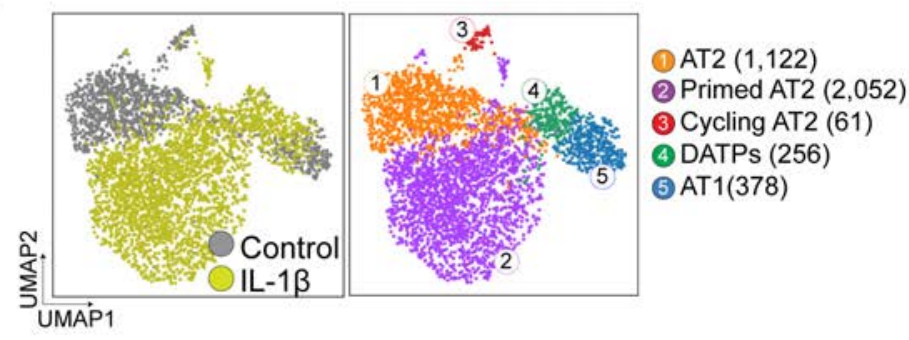

G

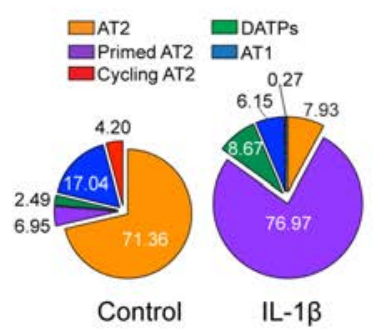

H

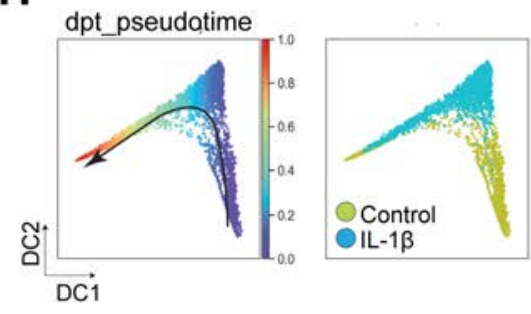

I

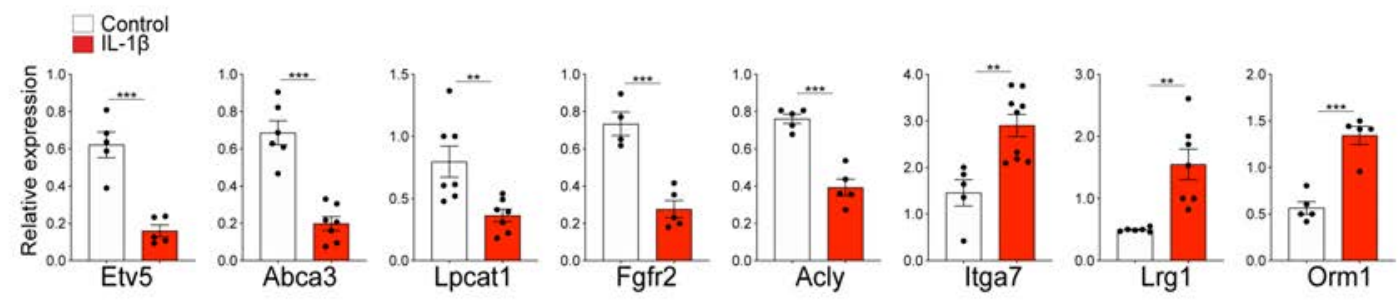

$\mathbf{J}$

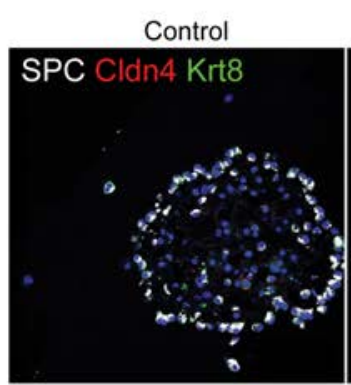

$\mathrm{IL}-1 \beta$

K
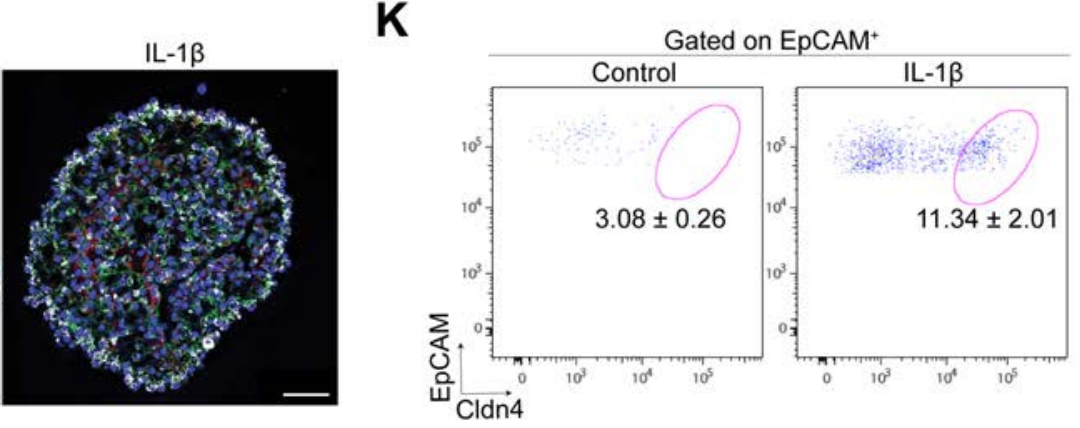

2 Figure 2. IL-1 $\beta$ signaling directly promotes reprograming of AT2 cells.

3 (A) Schematics of organoid co-culture of $S P C$ lineage-labeled AT2 cells $\left(\mathrm{SPC}^{+} \mathrm{Tomato}^{+}\right)$with 4 interstitial (IMs) or alveolar macrophages (AMs) isolated from wildtype lung tissues in the 5 presence of stromal cells. See also Fig. S2. 
1 (B) Representative fluorescent images (left and middle) and H\&E (right) staining of AT2 2 organoids. GM-CSF was added to activate macrophages. Scale bar, 1,000 $\mu \mathrm{m}$ (left) and $50 \mu \mathrm{m}$ 3 (right).

4 (C) Statistical quantification of colony forming efficiency and size of organoids. Each 5 individual dot represents one experiment from one mouse and date are presented as mean and $6 \quad$ SEM. $* * * p<0.001$.

7 (D) Representative fluorescent images (top) and H\&E staining (bottom) of primary organoids 8 derived from SPC lineage-labeled AT2 cells $\left(\mathrm{SPC}^{+} \mathrm{Tomato}^{+}\right)$treated with vehicle (PBS), IL$91 \beta$ or IL-18. Scale bar, $1,000 \mu \mathrm{m}$ (top) and $50 \mu \mathrm{m}$ (bottom).

10 (E) Quantification of colony forming efficiency and size. Date are presented as mean and SEM.

11 (F) UMAP visualization of cell clusters from scRNA-seq analysis of epithelial cells from 12 control (1,286 cells) or IL-1 $\beta$-treated organoids (10 ng/ml, 2,584 cells). Cells were isolated at 13 day 21 in organoid culture. Colors indicate samples and distinct cell types. Number of cells in 14 the individual cluster is depicted in the figure. See also Fig. S3.

15 (G) The percentage of each cluster in total cells of control or IL-1 $\beta$-treated organoids.

16 (H) Diffusion map according to diffusion pseudotime (DPT, left) order colored by samples 17 (right).

18 (I) qPCR analysis of genes that are upregulated (Itga 7, Lrg1, Orm1) or downregulated (Etv5, Abca3, Lpcat1, Fgfr2, and Acly) in Primed AT2 cells. EpCAM ${ }^{+}$epithelial cells were isolated from organoids treated with PBS or IL-1 $\beta$ at day 6 in AT2 organoid culture. Each individual dot represents one experiment and data are presented as mean \pm SEM. ${ }^{* *} p<0.01, * * * p<0.001$.

22 (J) Representative IF images showing the generation of DATPs marked by Cldn4 and Krt8

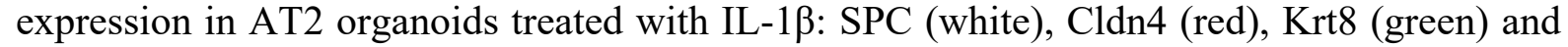
24 DAPI (blue). Scale bars, $50 \mu \mathrm{m}$.

25 (K) Flow cytometry analysis of DATPs by gating with Cldn4 and EpCAM. Data are presented as mean $\pm \operatorname{SEM}(\mathrm{n}=5) . * * * \mathrm{p}<0.001$. 
A

B

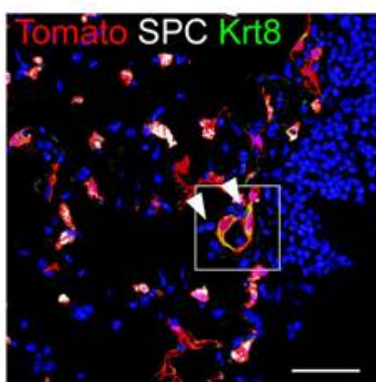

$S P C-C r e^{E R T 2} ; R 26 R^{\text {tdTomato }}$
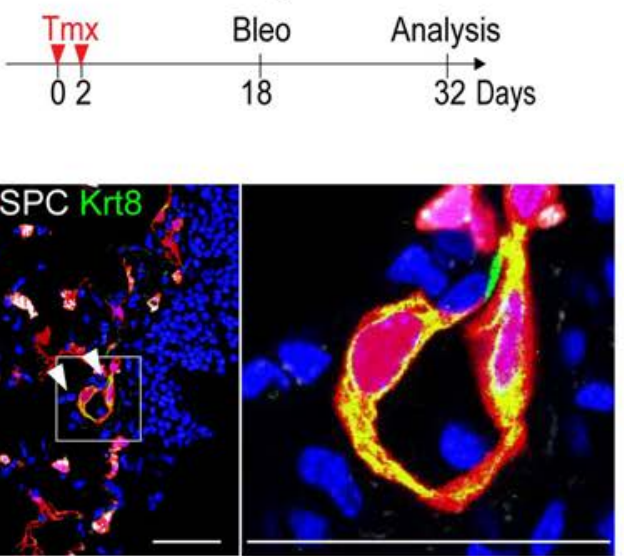

E

$\mathbf{F}$

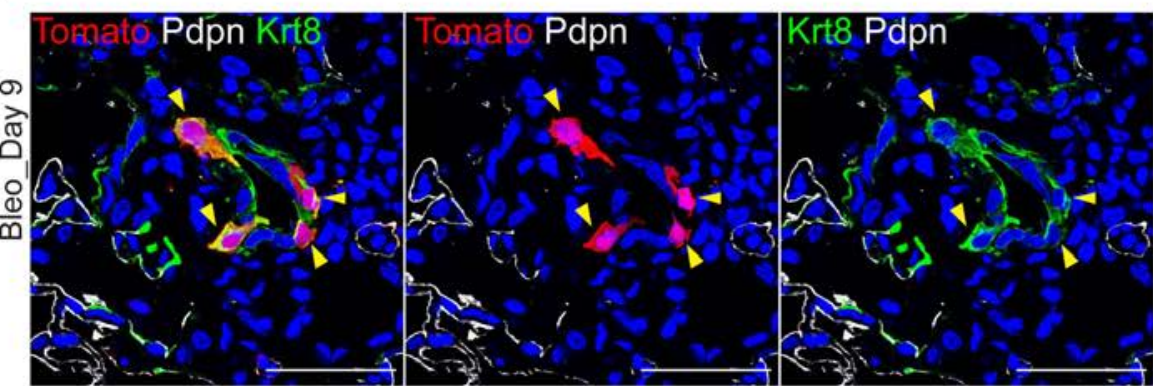

Ndrg1-Cre ${ }^{\text {ERT2; }}$ R26R tdTomato $^{\text {to }}$
C

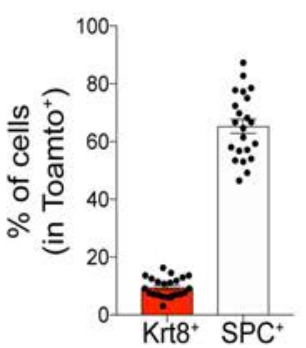

D

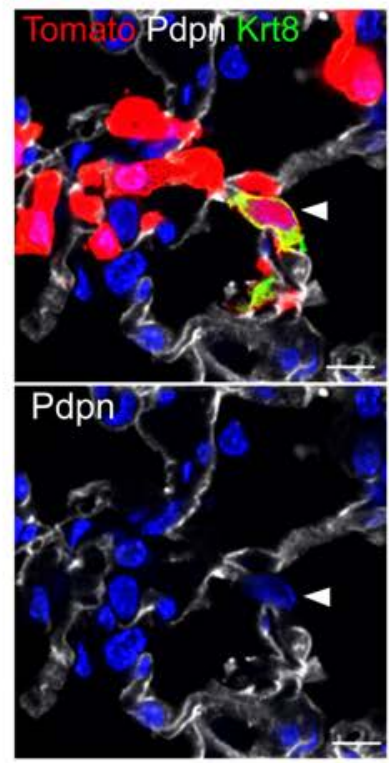

G

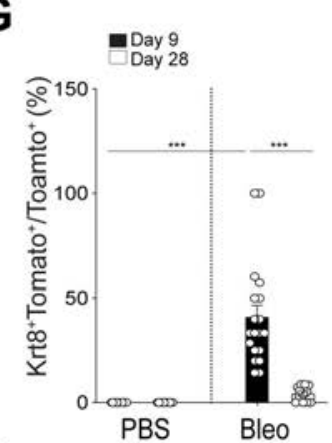

I

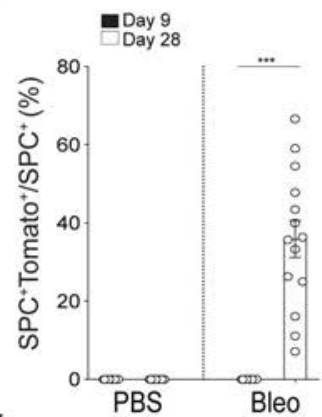

K

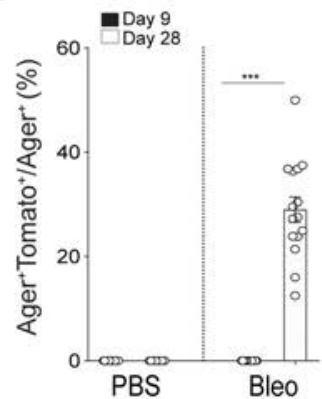

$\mathrm{H}$

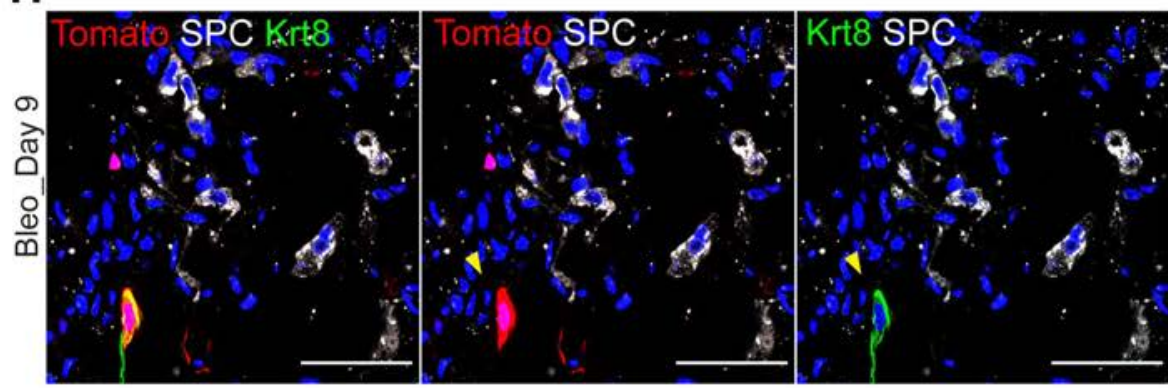

$\mathbf{J}$

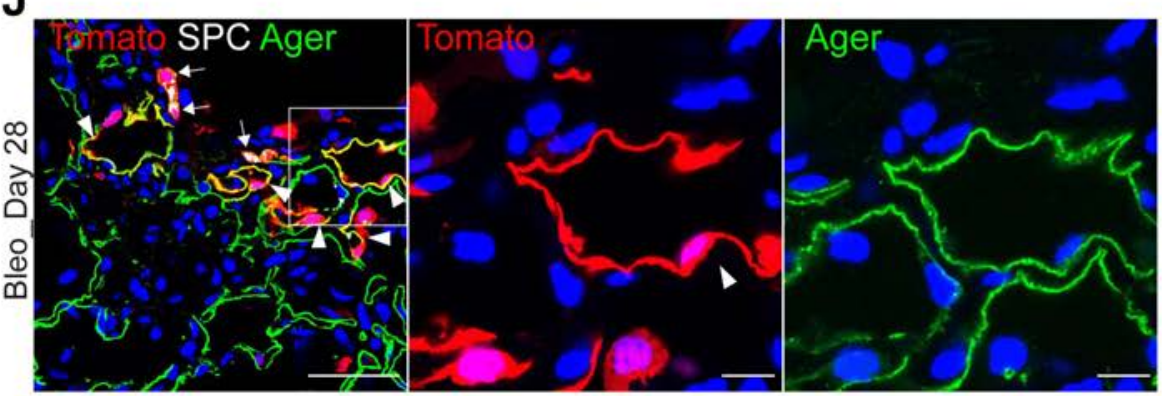

2 Figure 3. Injury response-specific DATPs are derived from AT2 cells and mediate AT1

3 lineage differentiation. 
1 (A) Schematics of experimental design for SPC lineage-tracing analysis using SPC-

$2 C r e^{E R T 2} ; R 26 R^{t d T o m a t o}$ mice at indicated time points after bleomycin injury.

3 (B) Representative IF images showing the derivation of DATPs from AT2 lineage-labeled cells at day 14 post injury: Tomato (red), SPC (white), and Krt8 (green). White boxed insets are shown on the right. Arrowhead points to lineage-labeled $K r t 8^{+}$DATPs that do not express AT2 marker SPC. Scale bar, $50 \mu \mathrm{m}$.

(C) Quantification of lineage-labeled $\mathrm{SPC}^{+} \mathrm{AT} 2$ cells or $K r t 8^{+}$DATPs at day 14 post injury.

8 Each individual dot represents one section and data are presented as mean \pm SEM with three independent experiments $(\mathrm{n}=4)$.

(D) Representative IF images showing the derivation of DATPs from AT2 lineage-labeled cells at day 14 post injury: Tomato (red), Pdpn (white). Arrowhead points to lineage-labeled $K r t 8^{+}$ DATPs that do not express AT1 marker Pdpn. Scale bar, $10 \mu \mathrm{m}$.

(E) Experimental design for $\mathrm{Ndrg} 1$ lineage-tracing analysis using $\mathrm{Ndrg} 1-\mathrm{Cr} e^{E R T 2} ; R_{26} R^{\text {tdTomato }}$ mice after bleomycin injury. Specific time points for tamoxifen injection and analysis are indicated. See also Fig. S4.

(F) Representative IF images showing the derivation of Ndrgl lineage-labeled DATPs that are negative for AT1 marker but positive for Krt8 at day 9 post injury: Tomato (red), Pdpn (white), Krt8 (green), and DAPI (blue). Arrowhead points to lineage-labeled DATPs. Scale bar, $50 \mu \mathrm{m}$. (G) Statistical quantification of $\mathrm{Krt}^{+} \mathrm{Tomato}^{+}$cells at indicated time points post PBS or bleomycin injury. Each individual dot represents one section and data are presented as mean \pm SEM ( $\mathrm{n}=2$ PBS control, $\mathrm{n}=3$ for bleomycin). ${ }^{* * *} \mathrm{p}<0.001$.

(H) Representative IF images showing the derivation of $N d r g l$ lineage-labeled DATPs that are negative for AT2 marker at day 9 post injury: Tomato (red), SPC (white), Krt8 (green), and DAPI (blue). Arrowhead points to lineage-labeled DATPs. Scale bar, $50 \mu \mathrm{m}$.

(I) Statistical quantification of lineage-labeled AT2 $\left(\mathrm{SPC}^{+} \mathrm{Tomato}^{+}\right)$cells at indicated time points post PBS or bleomycin injury. Each individual dot represents one section and data are presented as mean \pm SEM ( $n=2$ PBS control, $n=3$ for bleomycin). ${ }^{*} * * p<0.001$.

(J) Representative IF images showing the differentiation of Ndrgl lineage-labeled AT1 and AT2 cells at day 28 after injury: Tomato (red), SPC (white), Ager (green), and DAPI (blue). Arrowhead points to lineage-labeled Ager ${ }^{+}$cells. White boxed insets (left) are shown on the right. Scale bar, $50 \mu \mathrm{m}$ (left) and $10 \mu \mathrm{m}$ (right).

(K) Statistical quantification of Ager $^{+}$Tomato $^{+}$AT1 cells at indicated time points post PBS or bleomycin injury. Each individual dot represents one section and data are presented as mean \pm SEM ( $\mathrm{n}=2$ PBS control, $\mathrm{n}=3$ for bleomycin). ${ }^{* * *} \mathrm{p}<0.001$. See also Fig. $\mathbf{S 5}$. 
A
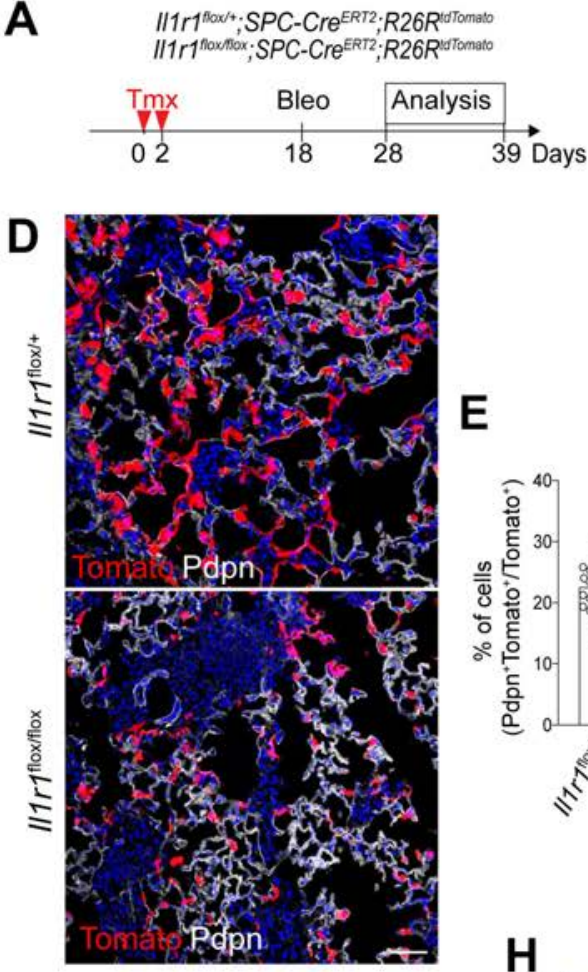

F

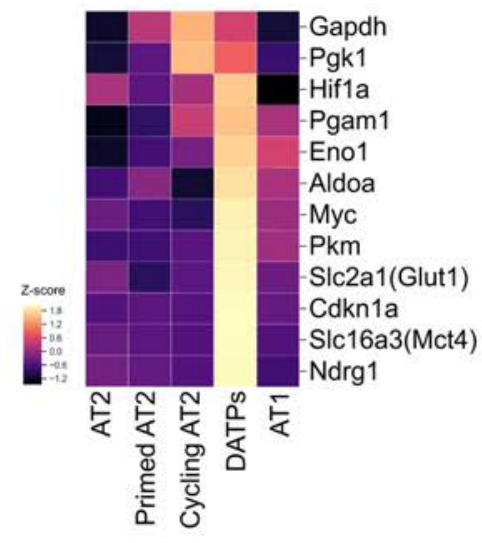

G

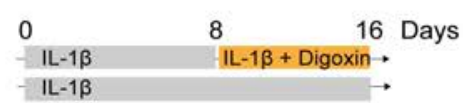

B

\section{E}

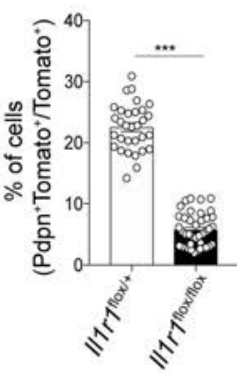

H

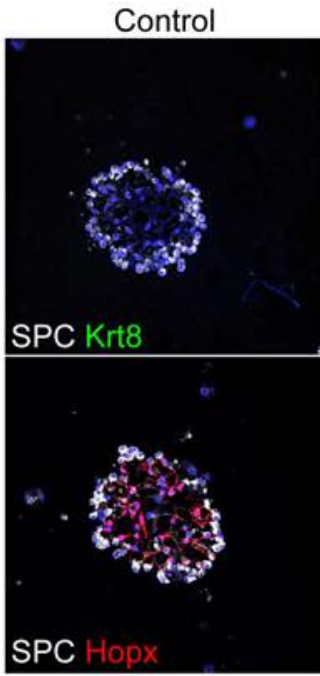

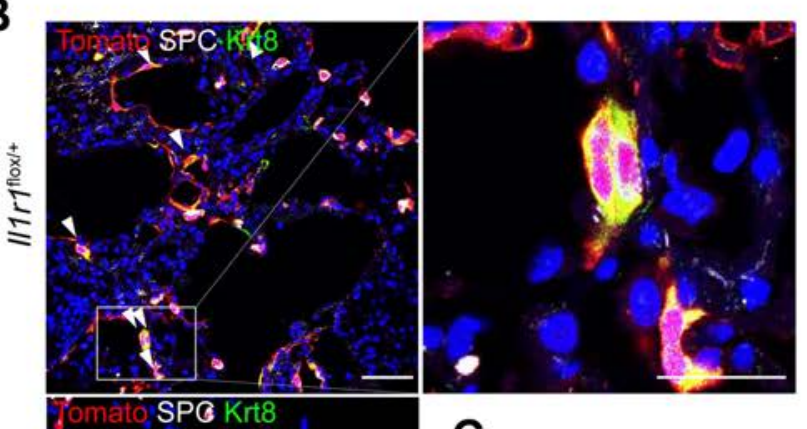

C

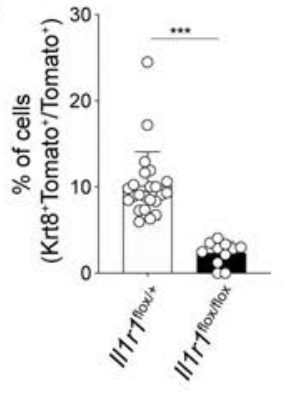

IL-1 $\beta$

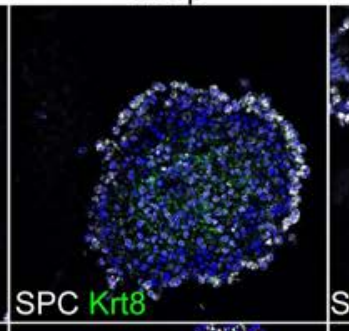

IL-1ß/Digoxin
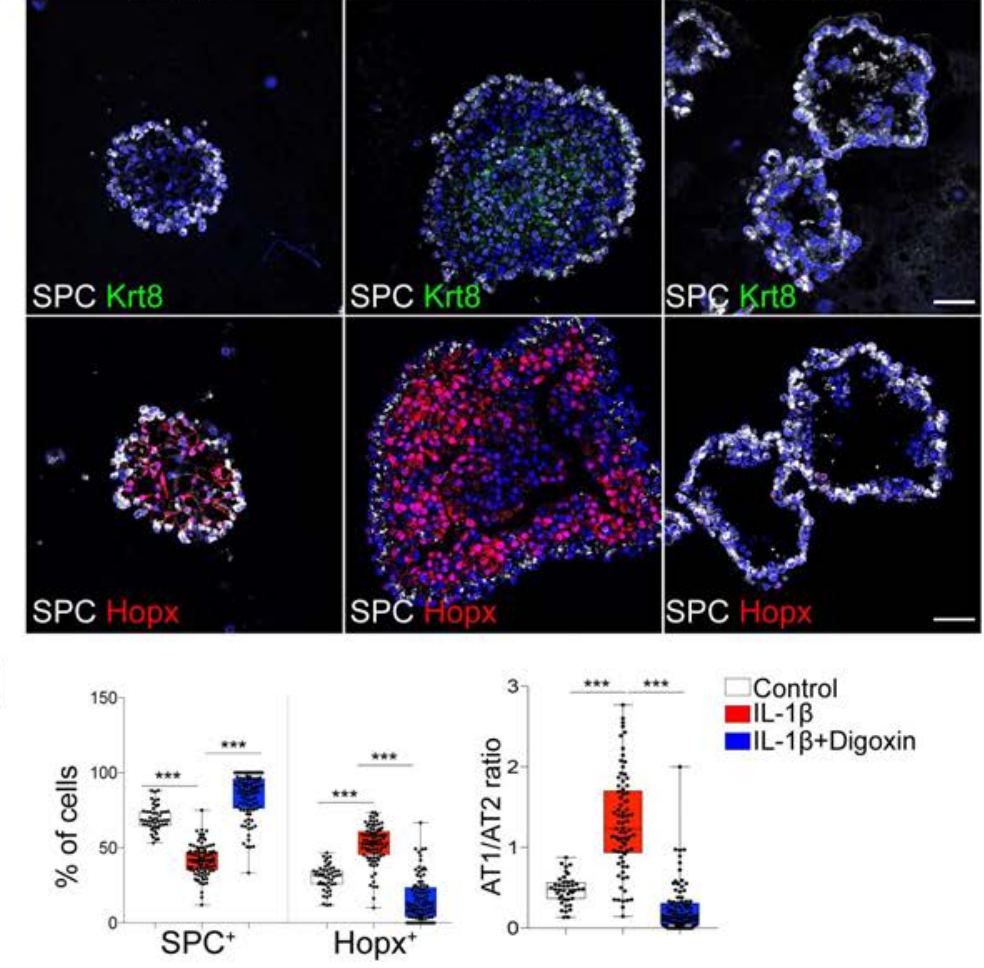

2 Figure 4. DATPs induced by IL-1 $\beta$-driven Hif1a signaling are essential mediators for 3 alveolar regeneration.

4 (A) Experimental design for lineage tracing of Il $1 r 1$ - haplodeficient or deficient AT2 cells post

5 bleomycin administration. 
1 (B) Representative IF images showing DATPs generation from SPC lineage-labeled cells at 2 day 10 post injury in the indicated genotype: Tomato (for SPC lineage, red), SPC (white), Krt8 3 (green), and DAPI (blue). Scale bars, $50 \mu \mathrm{m}$. See also Fig. S6.

4 (C) Quantification of lineage-labeled $K r t 8^{+}$DATPs at day 10 post injury. Each individual dot 5 represents one section and data are presented as mean $\pm \operatorname{SEM}(n=3)$.

6 (D) Representative IF images showing AT1 cell differentiation from SPC lineage-labeled cells 7 at day 21 post injury in the indicated genotype: Tomato (for SPC lineage, red), Pdpn (white), 8 and DAPI (blue). Scale bars, $50 \mu \mathrm{m}$.

9 (E) Quantification of lineage-labeled Pdpn ${ }^{+}$AT1 cells at day 21 post injury. Each individual 10 dot represents one section and data are presented as mean $\pm \operatorname{SEM}(n=6)$.

11 (F) Heat map of the transcriptional profiles of genes that are associated with Hifla-mediated 12 signaling including glycolysis pathway in the subset of clusters. See also Fig. S7.

13 (G) Schematic of AT2 organoid culture treated with digoxin in the presence of IL-1 $\beta$.

14 (H) Representative IF images showing the impaired generation of DATPs and AT1 lineage in 15 digoxin-treated organoids: SPC (white), Krt8 (top, green), Hopx (bottom, red), and DAPI 16 (blue). Scale bar, $50 \mu \mathrm{m}$.

17 (I) Quantification of the frequency of $\mathrm{AT} 2\left(\mathrm{SPC}^{+}\right)$or $\mathrm{AT} 1\left(\mathrm{Hopx}^{+}\right)$cells (left) and the ratio of 18 AT1/AT2 (right). Each individual dot represents one experiment and data are presented as 19 mean \pm SEM. ${ }^{* * *} p<0.001$. See also Fig. S8. 

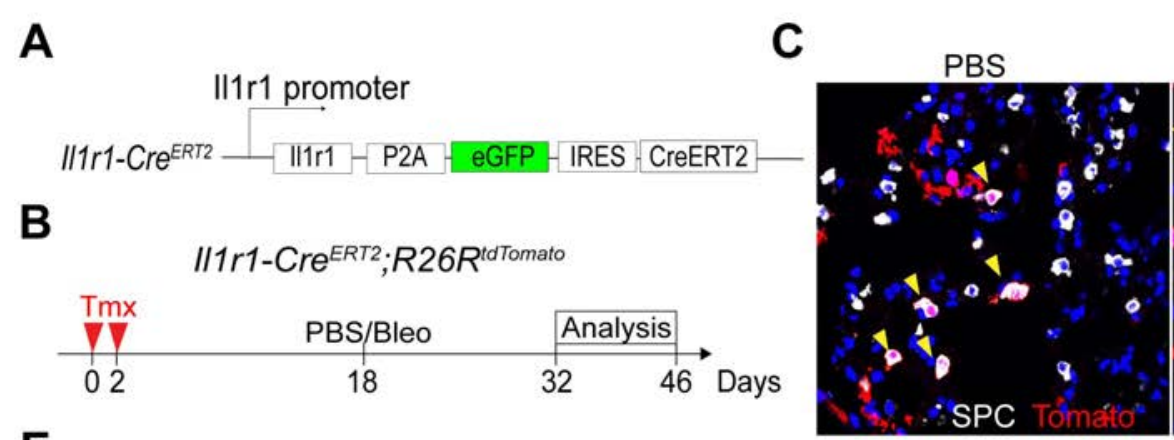

E
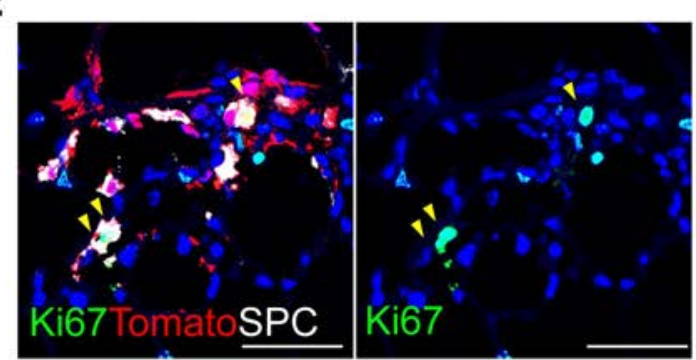

D

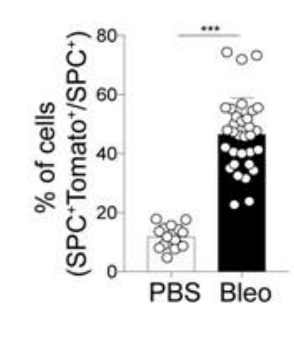

$\mathbf{F}$

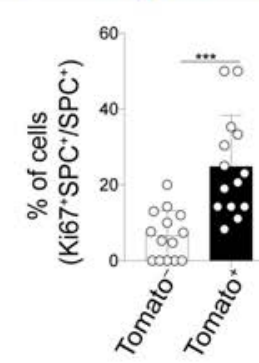

$\mathrm{H}$

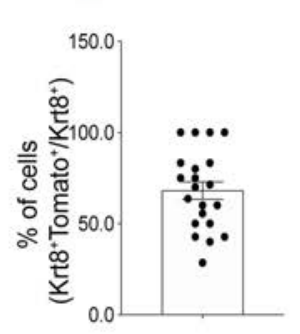

G
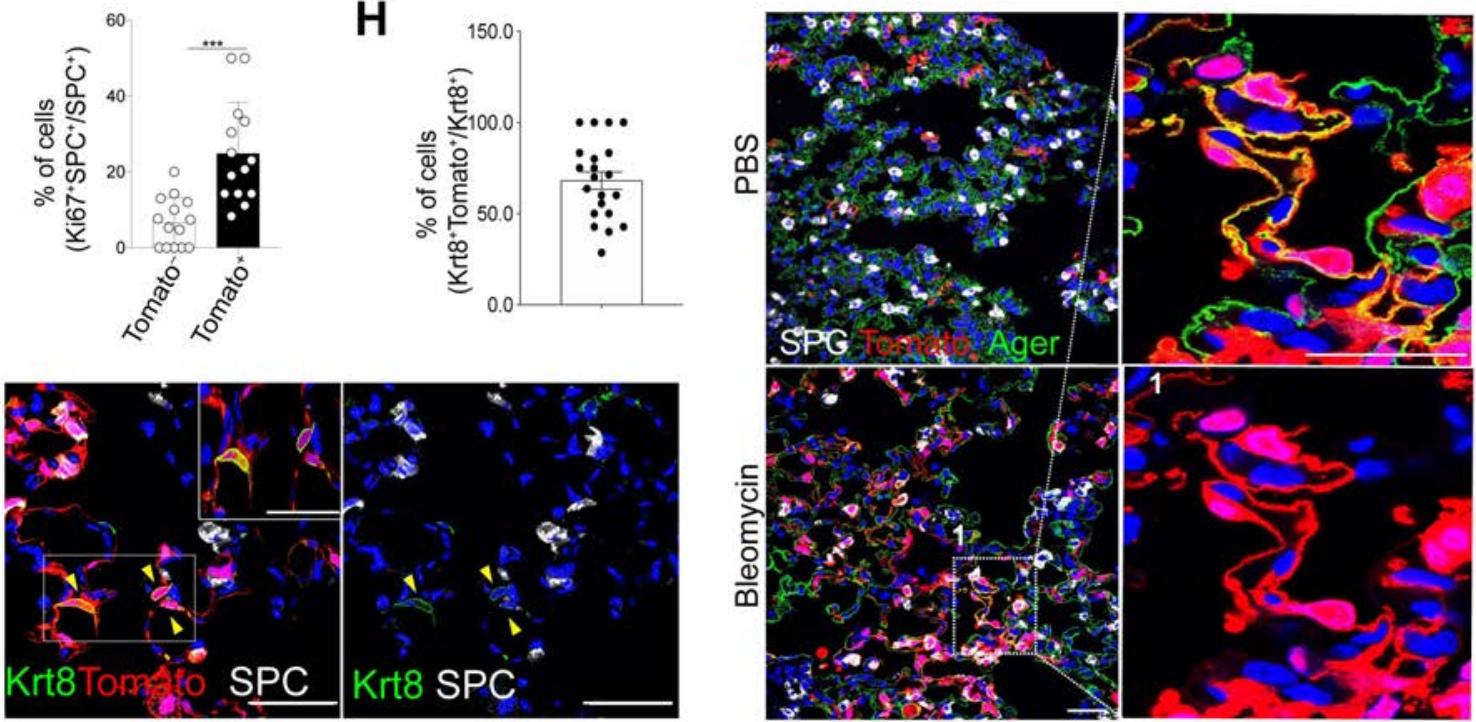

2 Figure 5. $I I 1 r 1^{+} \mathrm{AT} 2$ cells are distinct subsets that generate DATPs during alveolar 3 regeneration after injury.

4 (A) Schematic of Illr1-Cre $e^{E R T 2}$ mice. See also Fig. S9.

5 (B) Experimental design for lineage tracing. Date for analysis is as indicated.

6 (C) Representative IF images showing Illr1 lineage-labeled AT2 cells in the lung of mice 7 treated with control (PBS) or bleomycin at day 14 post injury: Tomato (for Illrl lineage, red), 8 SPC (white), and DAPI (blue). Arrowheads, Illrl lineage-labeled SPC ${ }^{+}$AT2 cells. Scale bars, $950 \mu \mathrm{m}$.

10 (D) Quantification of Illr1 lineage-labeled SPC ${ }^{+}$AT2 cells in (C). Each individual dot 11 represents one section and data are presented as mean \pm SEM with three independent 12 experiments. $* * * \mathrm{p}<0.001$. 
1 (E) Representative IF images showing $\mathrm{Ki} 67^{+}$cells in lineage-labeled or - unlabeled $\mathrm{SPC}^{+} \mathrm{AT}_{2}$ 2 cells at day 14 post injury: Tomato (for Illrl lineage, red), SPC (white), Ki67 (green), and 3 DAPI (blue). Arrowheads, Illrl lineage-labeled proliferating AT2 cells. Scale bars, $50 \mu \mathrm{m}$.

4 (F) Quantification of $\mathrm{Ki}^{+} 7^{\mathrm{AT}} 2$ cells in lineage-labeled or -unlabeled $\mathrm{SPC}^{+}$cells. Each 5 individual dot represents one section and data are presented as mean \pm SEM with three 6 independent experiments. $* * * p<0.001$.

7 (G) Representative IF images showing Illrl lineage-labeled DATPs at day 28 post injury: 8 Tomato (for Illrl lineage, red), Krt8 (green), and DAPI (blue). Arrowheads, Illrl lineage9 labeled DATPs. Insets (left) show high-power view (right top). Scale bars, $50 \mu \mathrm{m}$.

10 (H) Quantification of Illrl lineage-labeled DATPs at day 14 post bleomycin injury. Each 11 individual dot represents one section and data are presented as mean \pm SEM with three 12 independent experiments.

13 (I) Representative IF images showing Il1rl lineage-labeled AT1 cells at day 28 post injury:

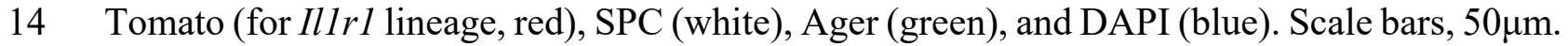


A

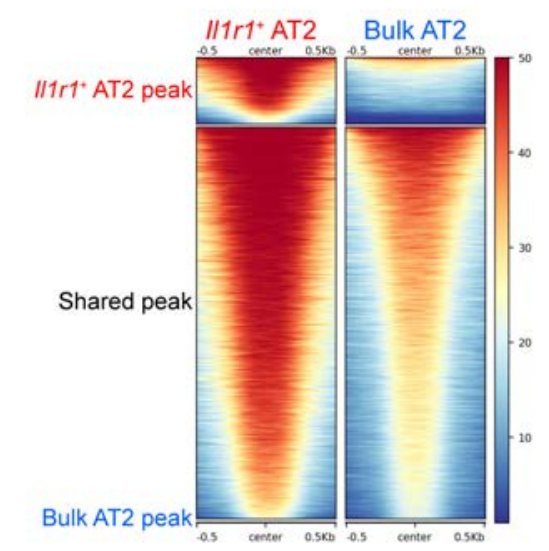

D
B

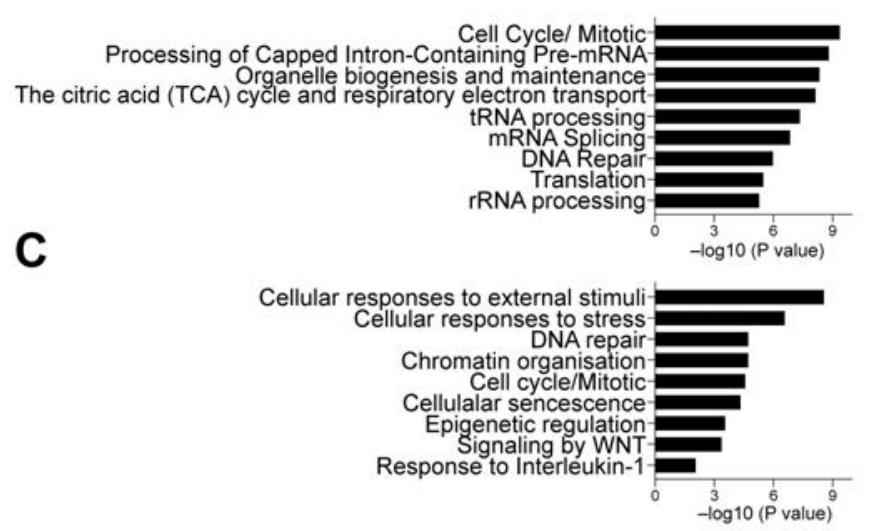

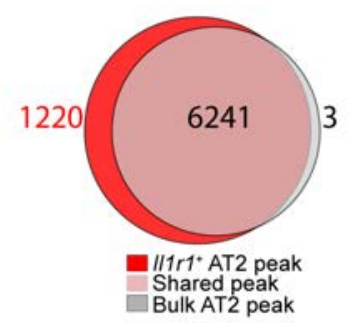

E

\begin{tabular}{|c|c|c|}
\hline \multicolumn{3}{|c|}{$\| 1 r 1^{+}$AT2 peak } \\
\hline TF & Sequence & $P$-value \\
\hline Sp2 & 도솓ㄷC. & $10^{-27}$ \\
\hline Ets & CCGGAAGT & $10^{-20}$ \\
\hline KIf5 & AGGGTGTGC & $10^{-15}$ \\
\hline AP-1 & T्रूTGCGTCAC & $10^{-24}$ \\
\hline CREB & PCAC & $10^{-18}$ \\
\hline NF-kB & TGGAAACCCC & $10^{-18}$ \\
\hline Rorc & 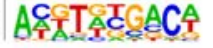 & $10^{-13}$ \\
\hline
\end{tabular}
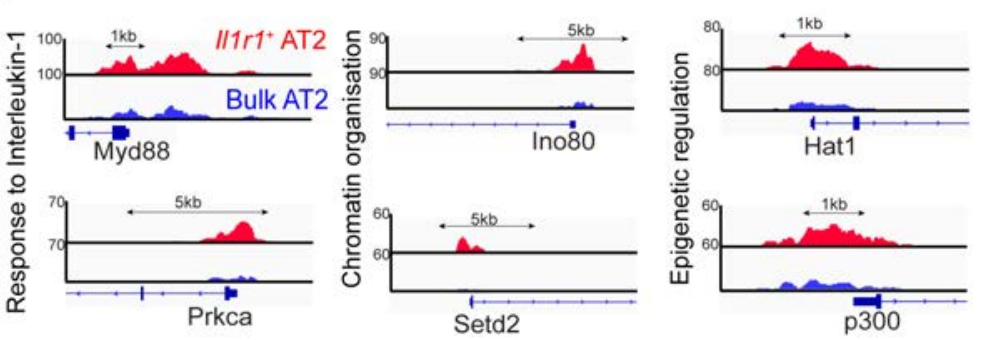

\begin{tabular}{|c|c|c|}
\hline \\
\hline TF & Sequence & P-value \\
\hline NFY & T्रCCEATTGGCE & $10^{-182}$ \\
\hline Cebp & ATT C CAAC & $10^{-62}$ \\
\hline Foxm1 & TATACAAACA & $10^{-73}$ \\
\hline Atf3 & 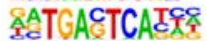 & $10^{-37}$ \\
\hline Nkx2.1 & ССАСТСААС & $10^{-33}$ \\
\hline BATF & TETGACTCAT & $10^{-31}$ \\
\hline
\end{tabular}

2 Figure 6. $111 r \mathrm{I}^{+} \mathrm{AT} 2$ cells possess a chromatin architecture that enables a rapid response 3 to injury.

4 (A) ATAC-seq heat map (Top) and Venn diagrams (bottom) showing genome-wide regions of 5 differential open chromatin peaks in $I l l r I^{+} \mathrm{AT} 2$ versus bulk AT2 cells in duplicates. The values 6 correspond to the peak signal distribution around TSS (Transcription Start Sites). Number of 7 nearest neighbour genes covered by peaks are indicated on diagrams.

8 (B) GO enrichment analysis of the nearest neighbour genes in the vicinity of peaks shared 9 between $I l l r I^{+}$AT2 and bulk AT2 cells.

10 (C) GO enrichment analysis of the nearest neighbour genes in the vicinity of $I l 1 r I^{+} \mathrm{AT} 2$ peaks.

11 (D) Snapshots of genomic loci in which the chromatin-accessible peaks are specifically opened in $I l l r 1^{+}$AT2 cells identified by GO enrichment analysis shown in (C). 
bioRxiv preprint doi: https://doi.org/10.1101/2020.06.14.151324; this version posted June 17, 2020. The copyright holder for this preprint (which was not certified by peer review) is the author/funder. All rights reserved. No reuse allowed without permission.

1 (E) Transcription factor motif enrichment within $I l 1 r 1^{+}$AT2-specific peaks or peaks shared 2 between $I l 1 r 1^{+}$AT2 and bulk AT2 cells. See also Fig. S10. 
A

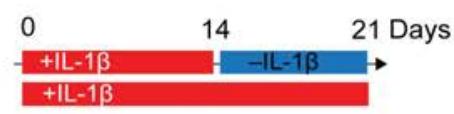

B

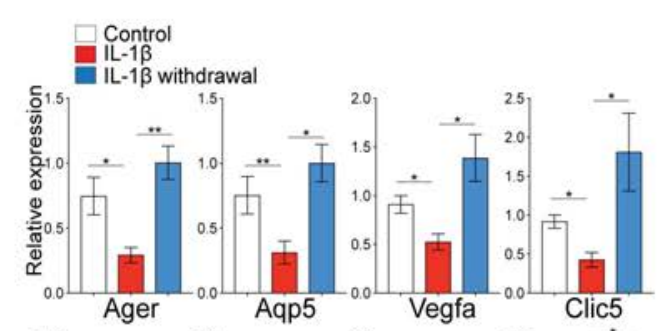

E
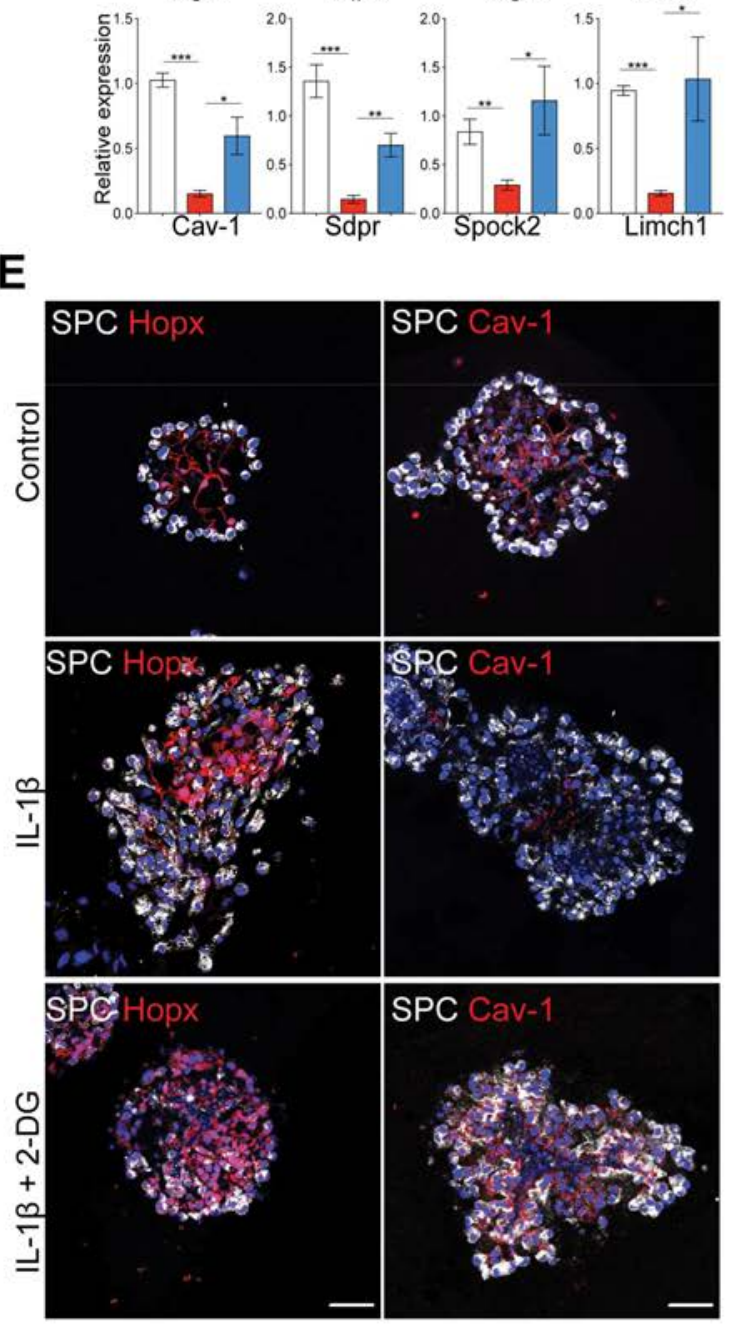

C

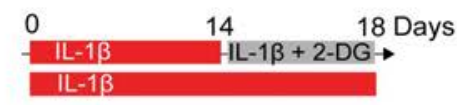

D
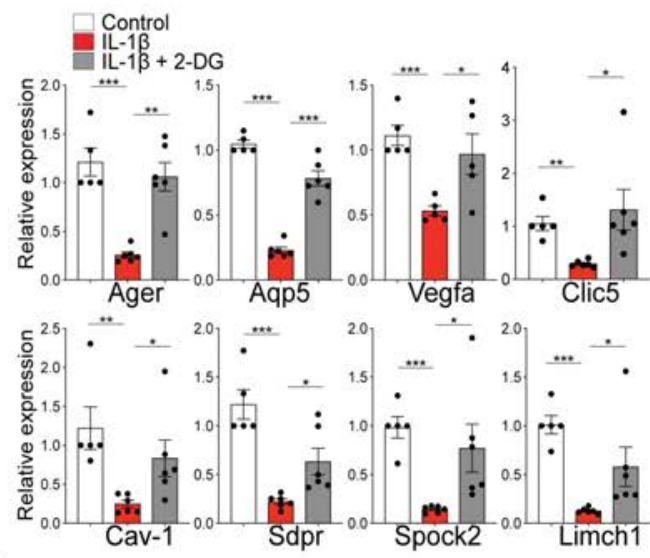

$\mathbf{F}$

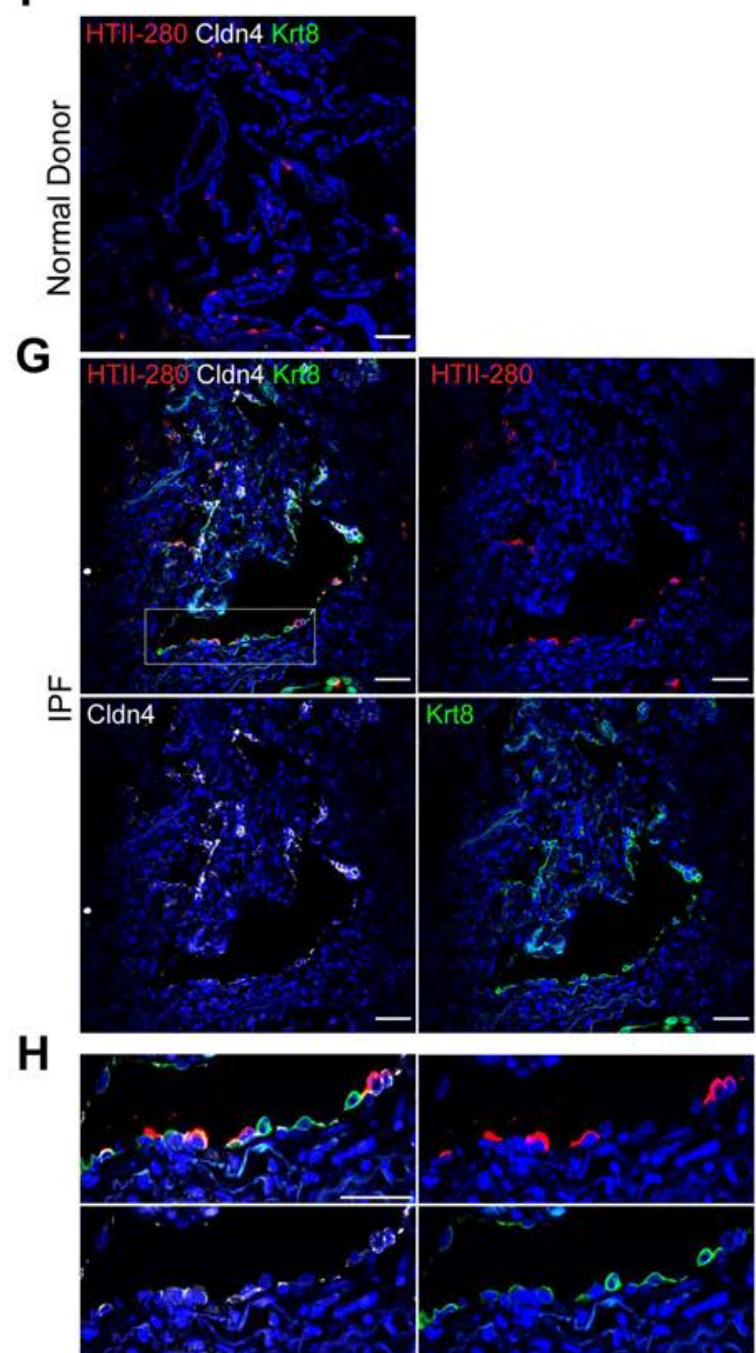

2 Figure 7. Glycolysis pathway driven by IL-1 $\beta$ prevent DATPs from converting into 3 terminally mature AT1 cells.

4 (A) Schematic of AT2 organoid culture treated with or without IL-1 $\beta$. 
1 (B) qPCR analysis for mature AT1 markers on isolated epithelial cells from AT2 organoids.

2 Date are presented as mean \pm SEM of four biological replicates from two-independent 3 experiments. ${ }^{*} \mathrm{p}<0.05,{ }^{*} \mathrm{p}<0.01, * * * \mathrm{p}<0.001$.

4 (C) Schematic of AT2 organoid culture treated with or without 2-deoxy glucose (2-DG) in the 5 presence of IL-1 $\beta$.

6 (D) qPCR analysis for mature AT1 markers on isolated epithelial cells from AT2 organoids.

7 Each individual dot represents one experiment and date are presented as mean \pm SEM. ${ }^{*} \mathrm{p}<0.05$, $8 \quad * * \mathrm{p}<0.01, * * * \mathrm{p}<0.001$.

9 (E) Representative IF images showing the rescued maturation of AT1 cells in 2-DG treated 10 organoids in the presence of IL-1 $\beta$ : SPC (white), Hopx (top, red), Cav-1 (bottom, red) and 11 DAPI (blue). Scale bar, $50 \mu \mathrm{m}$. See also Fig. S11.

12 (F) Representative IF images of $\mathrm{KRT}^{+} \mathrm{CLDN}^{+}$DATPs-like population in the lung from 13 normal donors (n=3). HTII-280 (red), CLDN4 (white), KRT8 (green) and DAPI (blue). Scale 14 bar, $50 \mu \mathrm{m}$. See also Fig. S12.

15 (G) Representative IF images of $\mathrm{KRT}^{+} \mathrm{CLDN} 4^{+}$DATPs-like population in the lung from IPF 16 patients ( $\mathrm{n}=5)$. HTII-280 (red), CLDN4 (white), KRT8 (green) and DAPI (blue). Scale bar, 50 $17 \mu \mathrm{m}$.

18 (H) High-power view of white boxed insets in Fig. 7G. HTII-280 (red), CLDN4 (white), KRT8 19 (green) and DAPI (blue). Scale bar, $50 \mu \mathrm{m}$. 


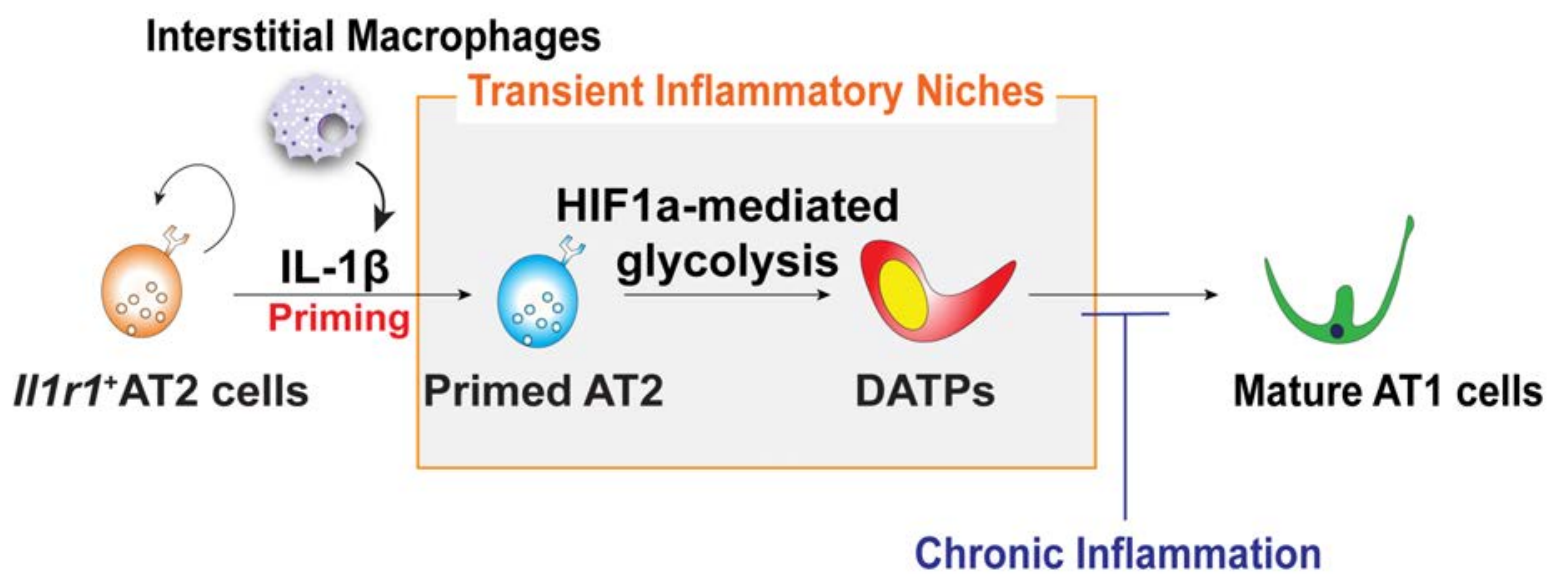

Figure 8. Reconstitution of lineage differentiation programs from AT2 to AT1 cells via

3 DATPs is directed by IL-1 $\beta$ signaling during injury repair.

4 Molecular mechanism governing the AT2 cell reprograming by IL-1 $\beta$-driven transient

5 inflammatory niches during alveolar regeneration. Pro-inflammatory cytokine IL-1 $\beta$ secreted

6 from interstitial macrophages triggers the reprograming of $I l 1 r 1^{+}$AT2 cells to lose AT2 identity

7 and enter a primed state during cell cycle transition. In turn, IL-1 $\beta$-driven HIF1a signaling

8 promotes the transition into DATPs that are essential mediators for mature AT1 cell

9 differentiation. Moreover, unresolved inflammation mediated by persistent IL-1 $\beta$ signals

10 causes the blockade in the transition to terminally differentiated AT1 lineage, which results in

11 the accumulation of DATPs. This finding highlights the important therapeutic implications of

12 DATPs and their modulation by IL-1 $\beta$ signalling in the context of chronic inflammation 13 associated diseases. 


\section{Supplemental Information}

2

3 Reconstitution of Alveolar Regeneration via novel DATPs by Inflammatory Niches

4

5 Jinwook Choi, Jong-Eun Park, Georgia Tsagkogeorga, Motoko Yanagita, Bon-Kyoung Koo,

6 Namshik Han, and Joo-Hyeon Lee

7

8

9 
bioRxiv preprint doi: https://doi.org/10.1101/2020.06.14.151324; this version posted June 17, 2020. The copyright holder for this preprint (which was not certified by peer review) is the author/funder. All rights reserved. No reuse allowed without permission.

A

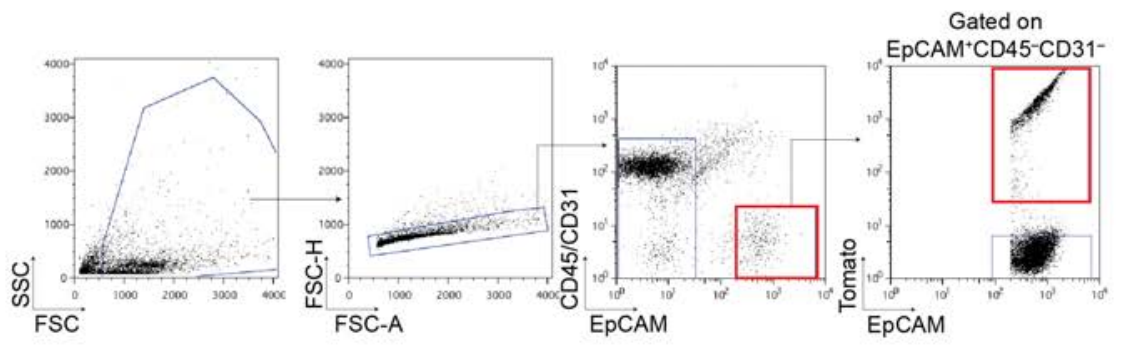

B

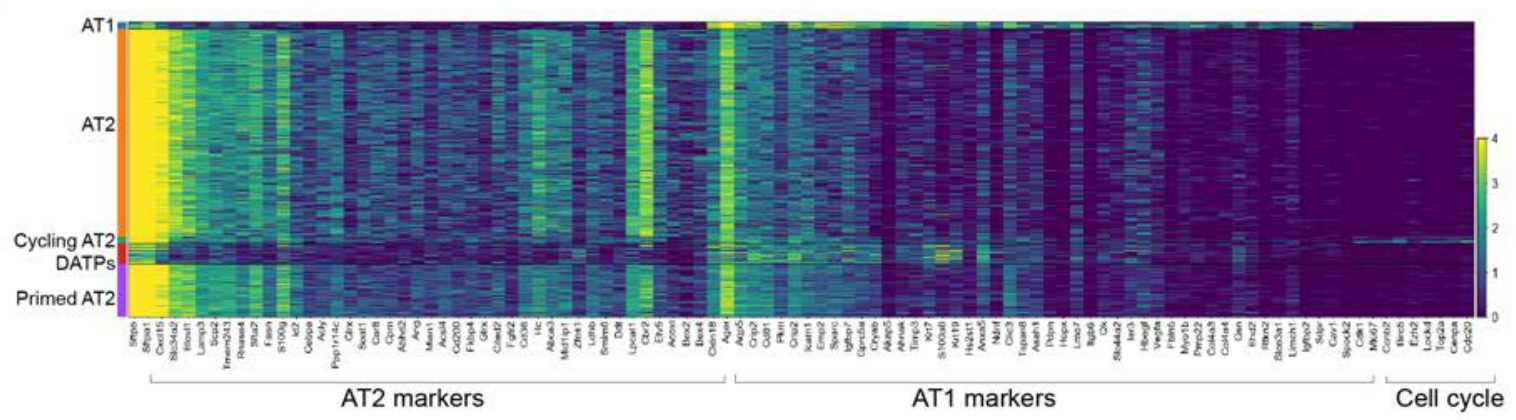

C

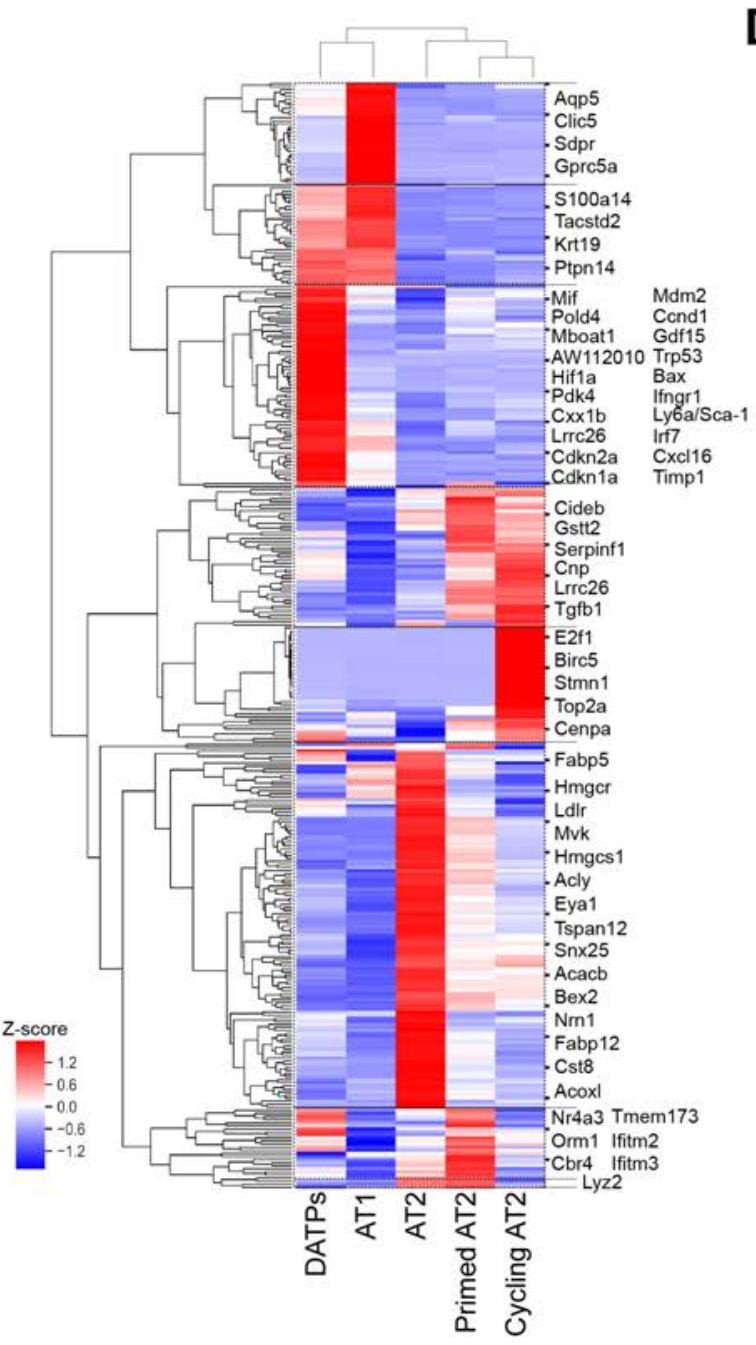

D

P53 signalling pathway Positive regulation of cell migration Negative regulation of cell proliferation Apoptotic signaling pathway

Negative regulation of cell growth Blood vessel remodeling Response to lipopolysaccharide Cell adhesion Inflammatory response Cellular response to hypoxia Cellular response to interleukin-1 Response to wounding

Response to interferon-gamma

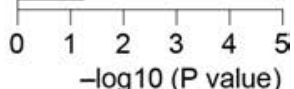

repair. 
1 (A) Sorting strategy for SPC lineage-labeled cells by flow cytometry after bleomycin injury.

2 (B) Gene expression of AT2 markers, AT1 markers, or cell cycle markers across single cells

3 from distinctive subsets revealed by single-cell RNA sequencing (scRNA-seq) analysis during 4 injury repair.

5 (C) Heap map showing relative expression of marker genes in distinctive subsets revealed by 6 scRNA-seq analysis.

7 (D) GO analysis of enriched genes in DATPs. 
bioRxiv preprint doi: https://doi.org/10.1101/2020.06.14.151324; this version posted June 17, 2020. The copyright holder for this preprint (which was not certified by peer review) is the author/funder. All rights reserved. No reuse allowed without permission.

A

C57BL/6 WT mice

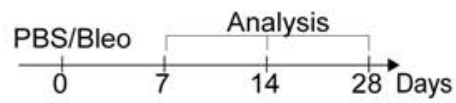

E
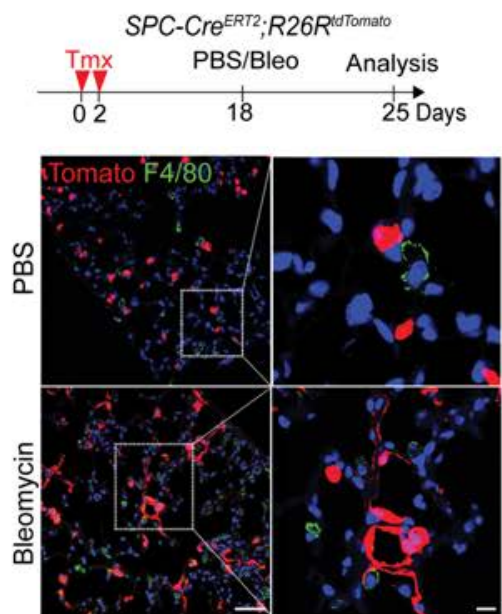

$\mathbf{F}$

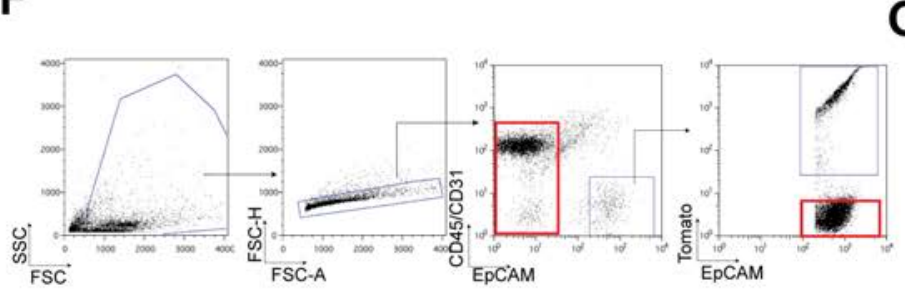

H
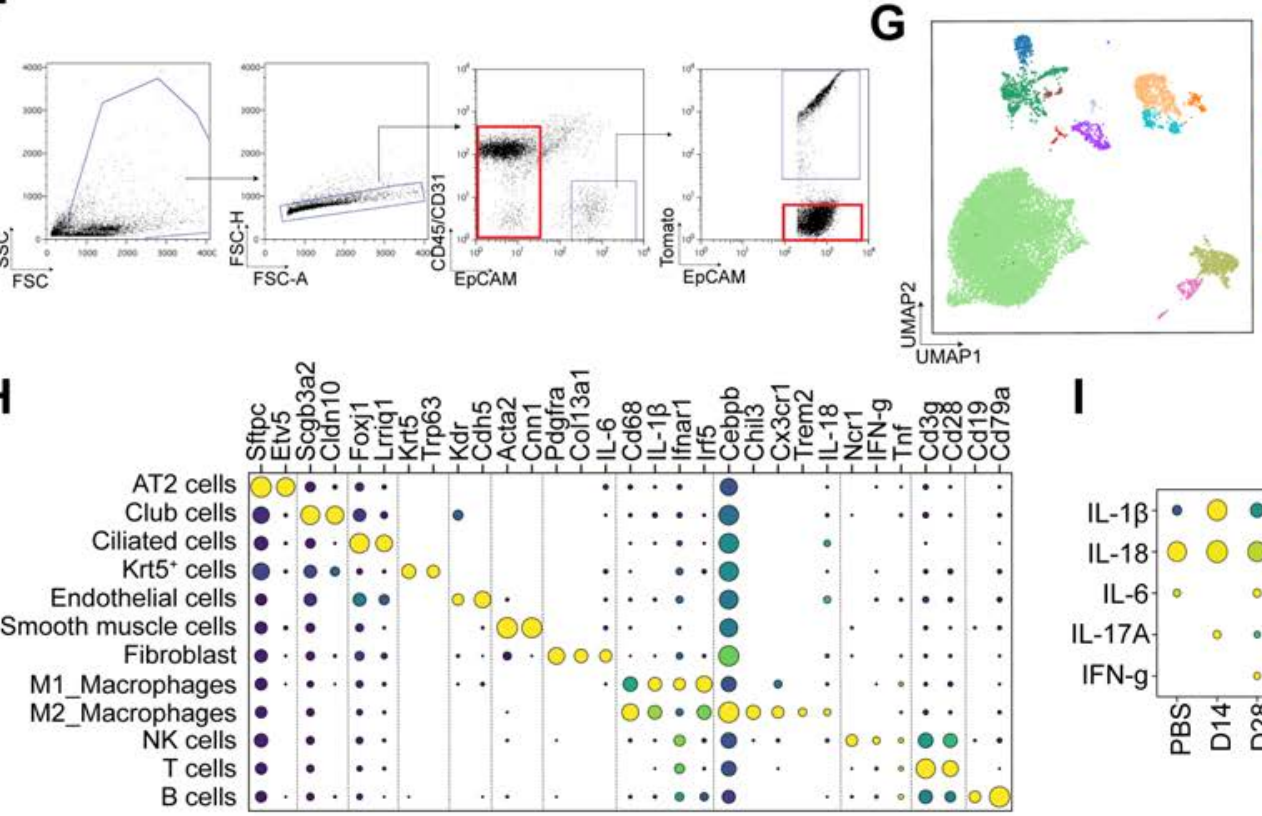

-AT2 cells (241)

- B cells (94)

- Club cells (657)

- Endothelial cells (32

- Fibroblast (270)

- Krt5* cells (59)

- M1_Macrophages (178)

- M2_Macrophages (648)

NK cells (197)

Smooth muscle cells (45)

- T cells (702)

- Ciliated cells $(10,894)$
$\mathbf{J}$

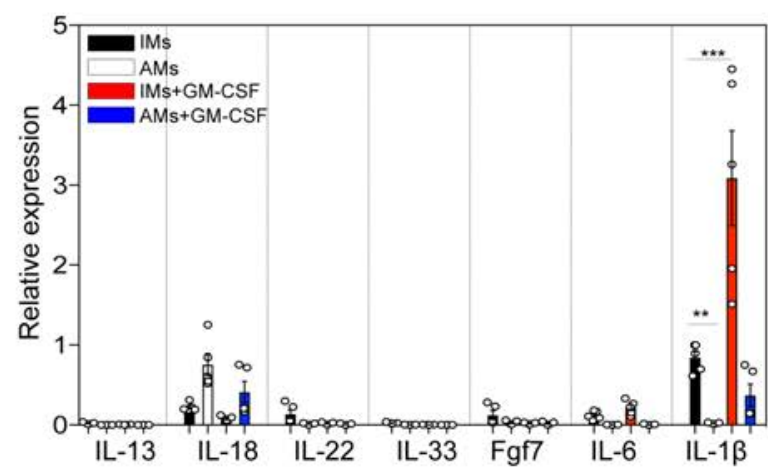

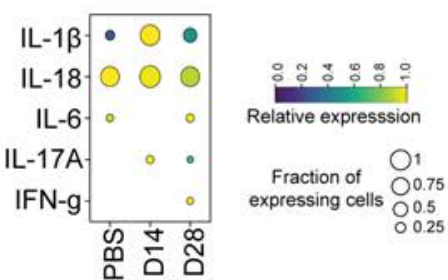

$\mathbf{K}$
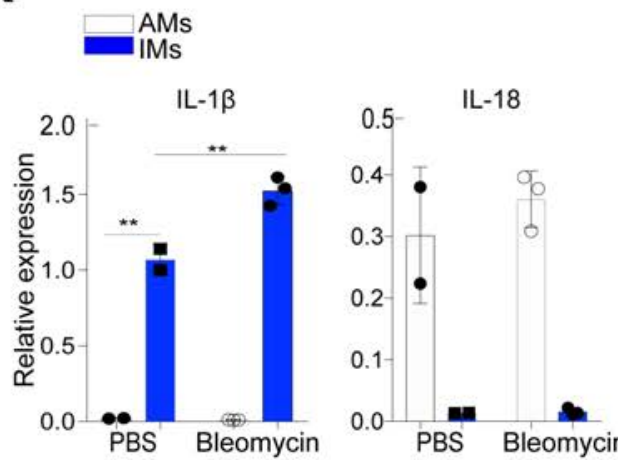

Figure S2, related to Fig. 2. Dynamics of macrophages during alveolar regeneration after 
1 (A) Schematic of experimental design for analysis of immune cells at indicated time points 2 after bleomycin injury.

3 (B) Flow cytometry analysis of alveolar (Siglec- $\mathrm{F}^{+} \mathrm{CD} 11 \mathrm{~b}{ }^{\text {low }}$ ) and interstitial (Siglec-F ${ }^{-}$ $\left.4 \mathrm{CD} 11 \mathrm{~b}^{\text {high }}\right)$ macrophages at indicated time points post injury. Cells gated on $\mathrm{CD} 45^{+} \mathrm{CD} 64^{+} \mathrm{Gr}-$ $5 \quad 1^{-}$were analyzed further for expression of Siglec-F and CD11b. Numbers adjacent to the 6 outlined area indicate the percentage of populations.

7 (C, D) Frequencies (C) and absolute cell numbers (D) of alveolar (AMs) or interstitial (IMs) 8 macrophages at indicated time points. Each individual dot represents one experiment and date are presented as mean \pm SEM. ${ }^{*} \mathrm{p}<0.05, * * \mathrm{p}<0.01$, and $* * * \mathrm{p}<0.001$.

(E) Experimental design (top) of SPC lineage-tracing and immunofluorescent (IF, bottom) images of tissue samples after bleomycin treatment. IF images show the increased numbers of F4 $/ 80^{+}$macrophages at day 7 post injury. A high magnification images (right) show the interaction between macrophages and $S P C$ lineage-labeled cells. Data are the representative of two independent experiments. Scale bar, $50 \mu \mathrm{m}$ (left) and $10 \mu \mathrm{m}$ (right). Tomato (red), F4/80 (green), and DAPI (blue).

(F) Sorting strategy for SPC unlabeled single cells pooling of $\mathrm{EpCAM}^{+} \mathrm{Tomato}^{-}$and $\mathrm{EpCAM}^{-}$ population by flow cytometry after bleomycin injury.

(G) Clusters of unlabeled cells $(14,017)$ after bleomycin injury from 10xGenomics 3' scRNAseq analysis visualized by UMAP, assigned by specific colors. Number of cells in the individual cluster is depicted in the figure.

(H) Gene expression of key markers in each distinctive cluster. $I L-1 \beta$ is specifically expressed in macrophages.

(I) Gene expression of $I L-1 \beta, I L-18, I L-6, I L-17 A$, and $I F N-g$ at indicated time points after bleomycin injury. Of note, the expression of $I L-1 \beta$ is dramatically increased at day 14 post injury and returns back to the homeostatic level at day 28 post injury.

(J) qPCR analysis of specific cytokine expression in alveolar (AMs) or interstitial (IMs) macrophages in response to activation by GM-CSF. Isolated subsets of macrophages were cultured in the presence or absence of GM-CSF for $24 \mathrm{hrs}$ in vitro. Each individual dot represents one experiment and date are presented as mean \pm SEM.

30 (K) qPCR analysis for $I L-18$ and $I L-1 \beta$ in alveolar (AMs, white bar) or interstitial (IMs, blue bar) macrophages isolated at day 7 after PBS or bleomycin treatment. Each individual dot represents one experiment from one mouse and date are presented as mean $\pm \mathrm{SEM}$. ${ }^{*} \mathrm{p}<0.01$, $* * * \mathrm{p}<0.001$. 
A

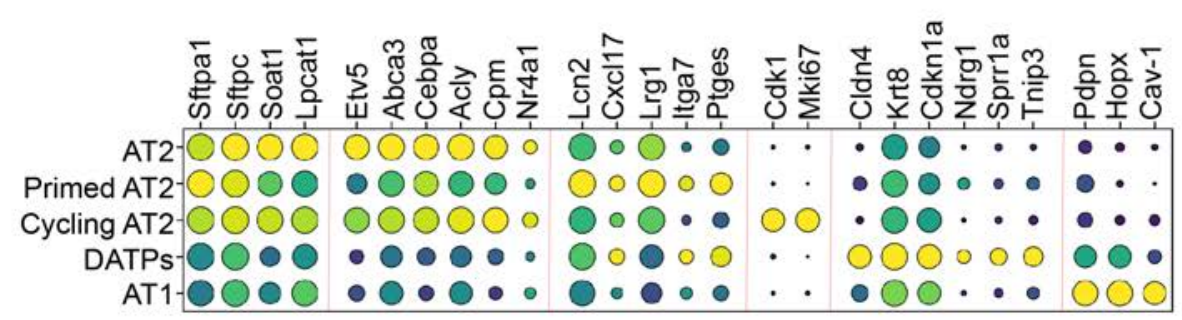

B
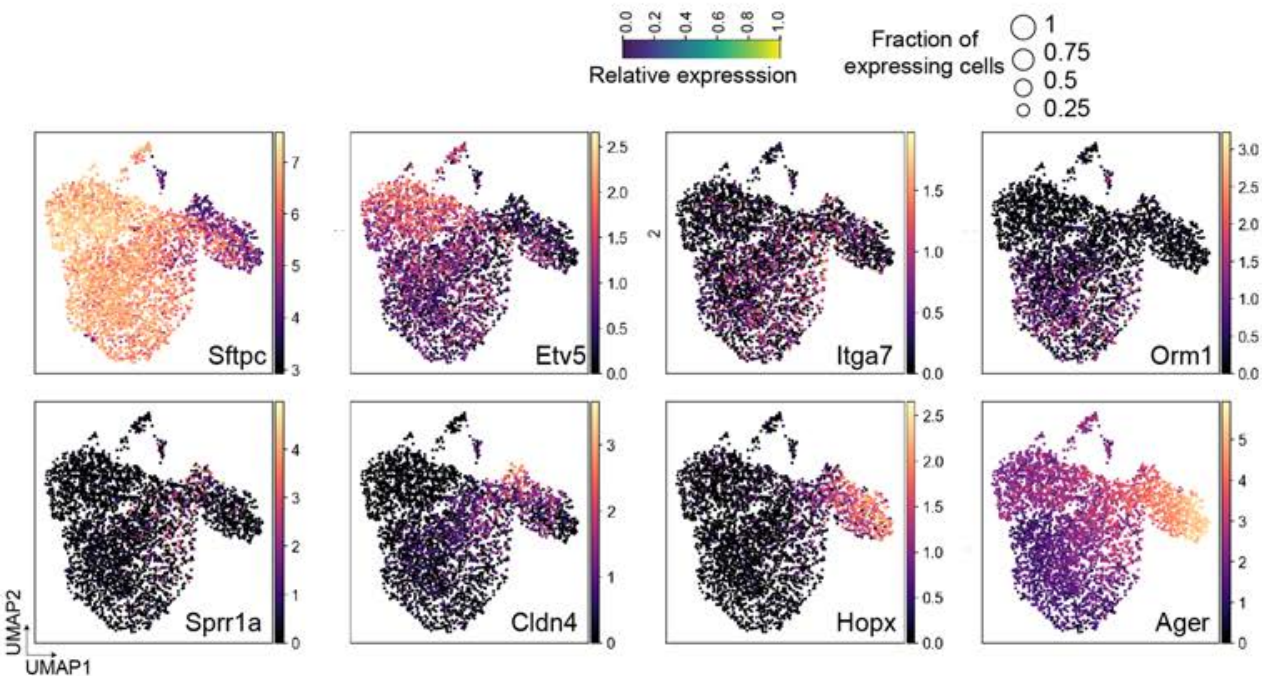

C

D

E
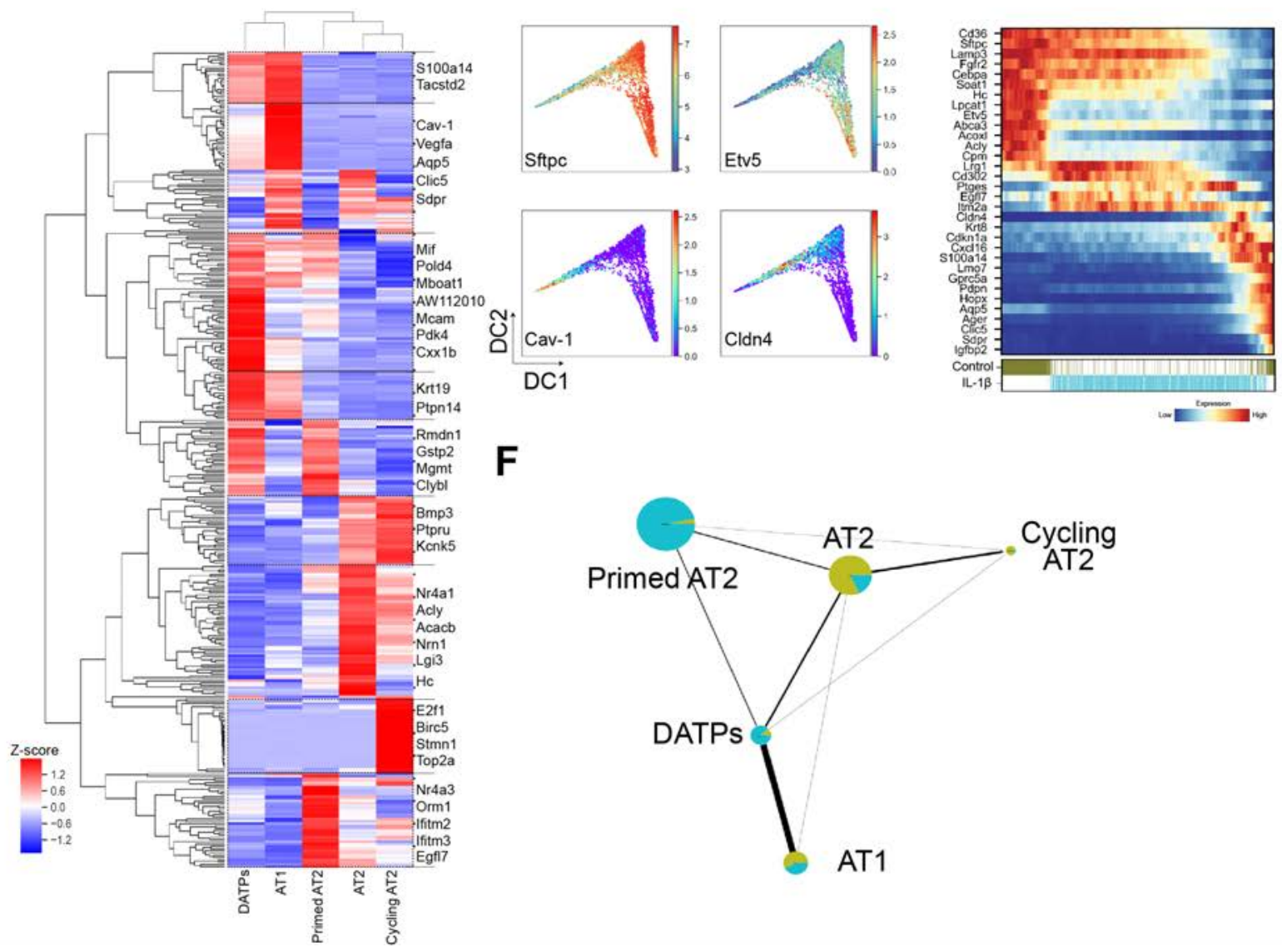

F

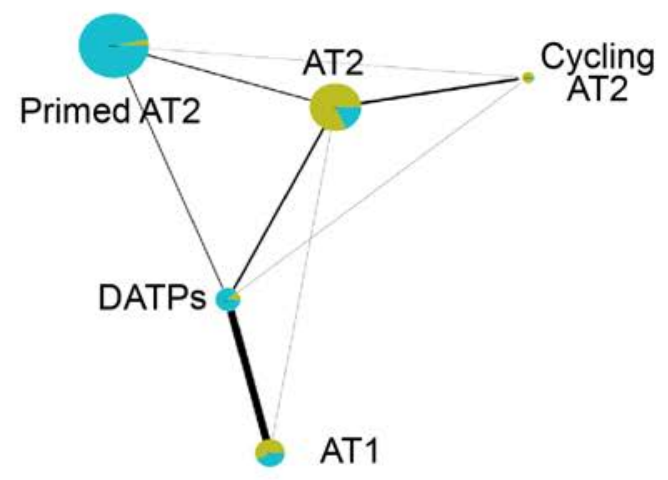

Figure S3, related to Fig. 2, F-H. Alveolar organoids challenged by IL-1ß recapitulate the

\section{3 behavior of regenerating AT2 cells during injury repair.}

4 (A) Gene expression of key markers in each distinctive cluster. 
1 (B) UMAP visualization of the log-transformed $\left(\log _{10}(\mathrm{TPM}+1)\right)$, normalized expression of 2 selected marker genes in distinctive clusters.

3 (C) Heap map showing relative expression of selected genes that are specifically expressed in 4 distinctive clusters revealed by scRNA-seq analysis.

5 (D) Diffusion map according to diffusion pseudotime order colored by expression $6 \quad\left(\log _{10}(\mathrm{TPM}+1)\right)$ of specific genes.

7 (E) Gene expression profiles of control and IL-1 $\beta$-treated organoids ordered according to 8 pseudotime trajectory. Lower color bars indicate annotation by samples.

9 (F) Network topology among clusters from single cell data revealed by Partition-based graph 10 abstraction (PAGA). Colors indicate the proportion of each cluster by time point. Each node in 11 the PAGA graph represents a cluster and the weight of the lines represents the statistical 12 measure of connectivity between clusters. 
A

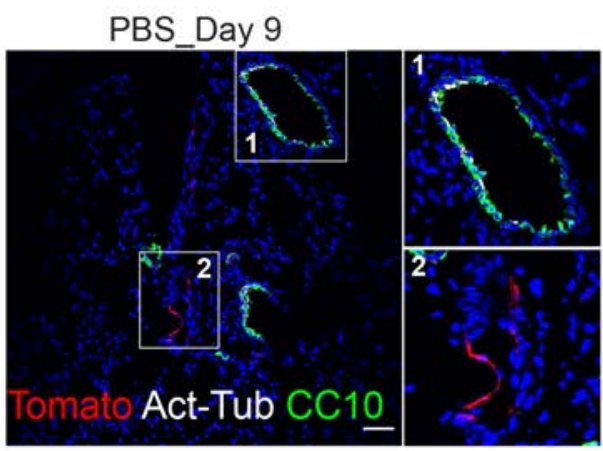

B

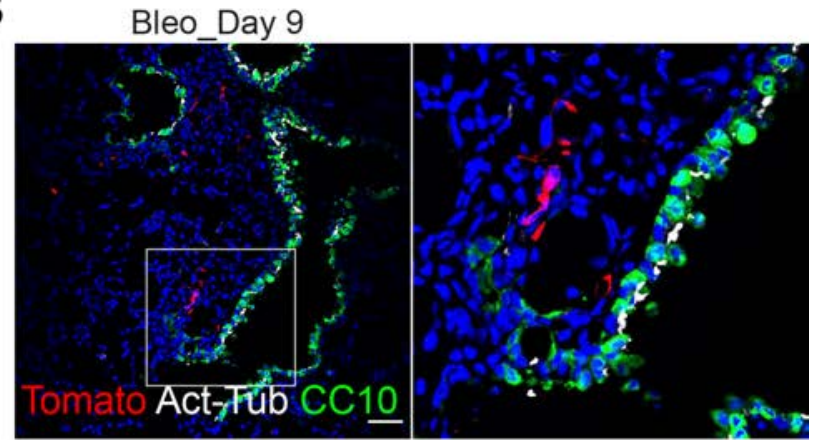

C

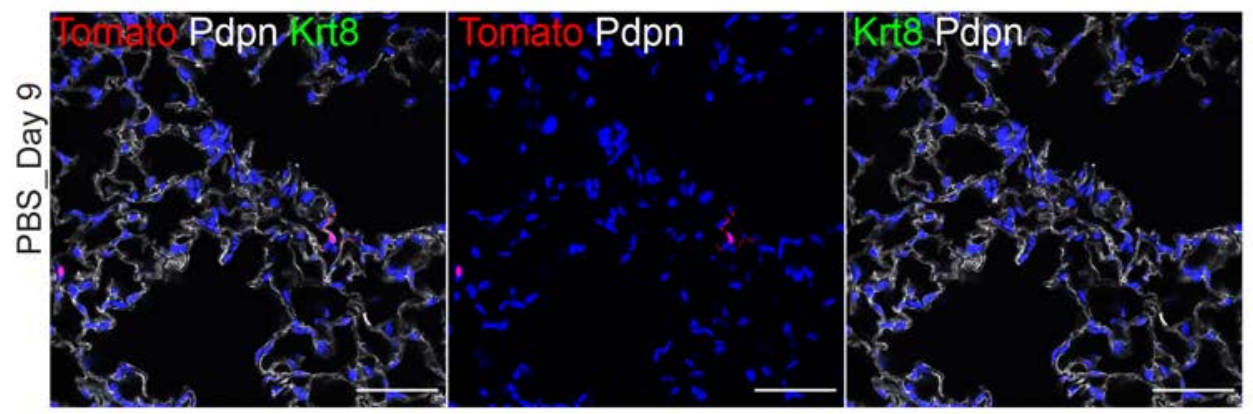

D

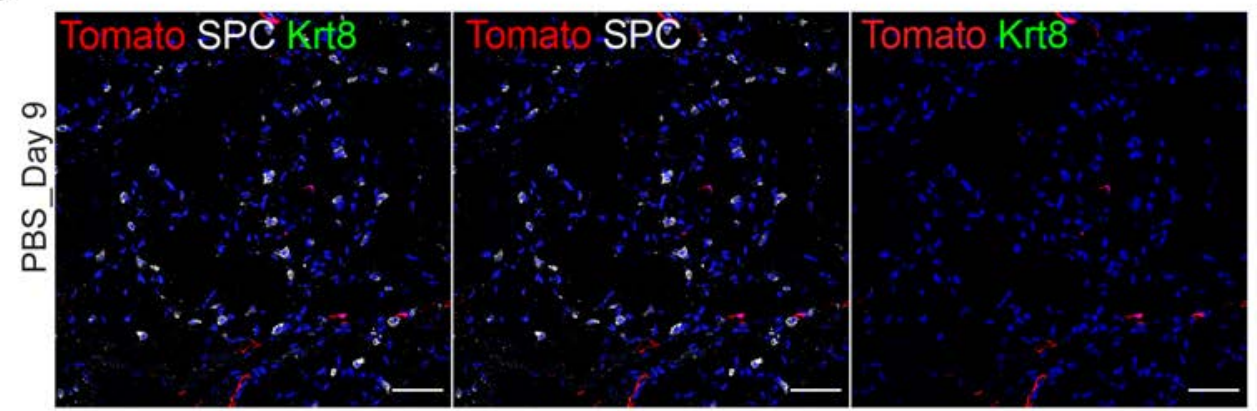

E

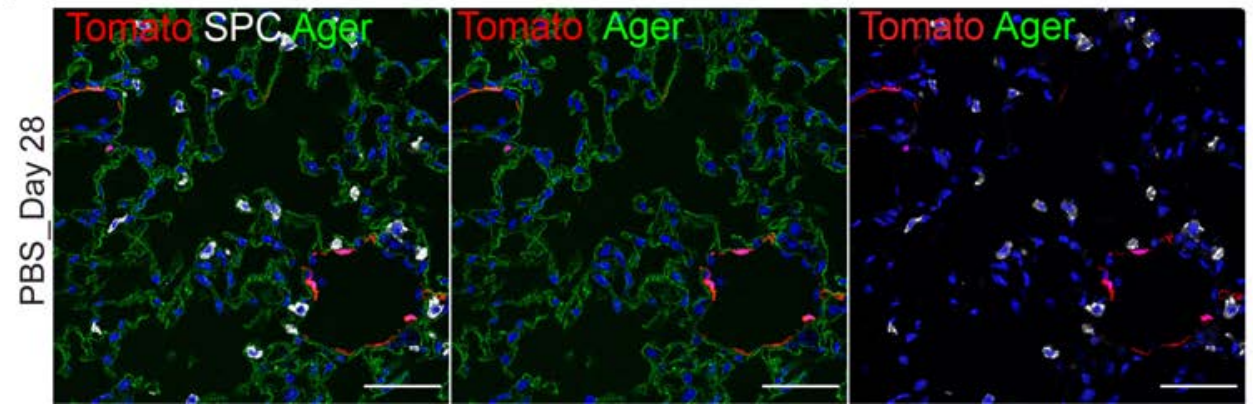

2 Figure S4, related to Fig. 3. Ndrg1 does not mark epithelial cells in steady-state lungs.

3 (A) Representative IF images show that airway cells are not marked by $\mathrm{Ndrg} I$ expression at 4 day 9 post PBS treatment: Tomato (for $N d r g 1$ lineage, red), CC10 (green, club cells), Acetyl5 Tub (white, ciliated cells), and DAPI (blue). Insets (left) show high-power view (right).

6 (B) Representative IF images show that airway cells are not marked by $N d r g l$ expression at 7 day 9 post bleomycin injury: Tomato (for $N d r g l$ lineage, red), CC10 (green, club cells), Acetyl-

8 Tub (white, ciliated cells), and DAPI (blue). Insets (left) show high-power view (right). 
1 (C) Representative IF images show that lineage-labeled DATPs are barely observed at day 9 2 post PBS treatment: Tomato (for Ndrgl lineage, red), Pdpn (white) and Krt8 (green). Scale bar, $350 \mu \mathrm{m}$.

4 (D) Representative IF images show that $\mathrm{SPC}^{+} \mathrm{AT} 2$ cells are not labeled by $N d r g 1$ expression 5 at day 9 post PBS treatment: Tomato (for Ndrgl lineage, red), SPC (white) and Krt8 (green). 6 Scale bar, $50 \mu \mathrm{m}$.

7 (E) Representative IF images show that neither AT2 and AT1 cells are labeled by $N d r g 1$ 8 expression at day 28 post PBS treatment: Tomato (for Ndrgl lineage, red), SPC (white) and 9 Ager (green). Scale bar, $50 \mu \mathrm{m}$. 

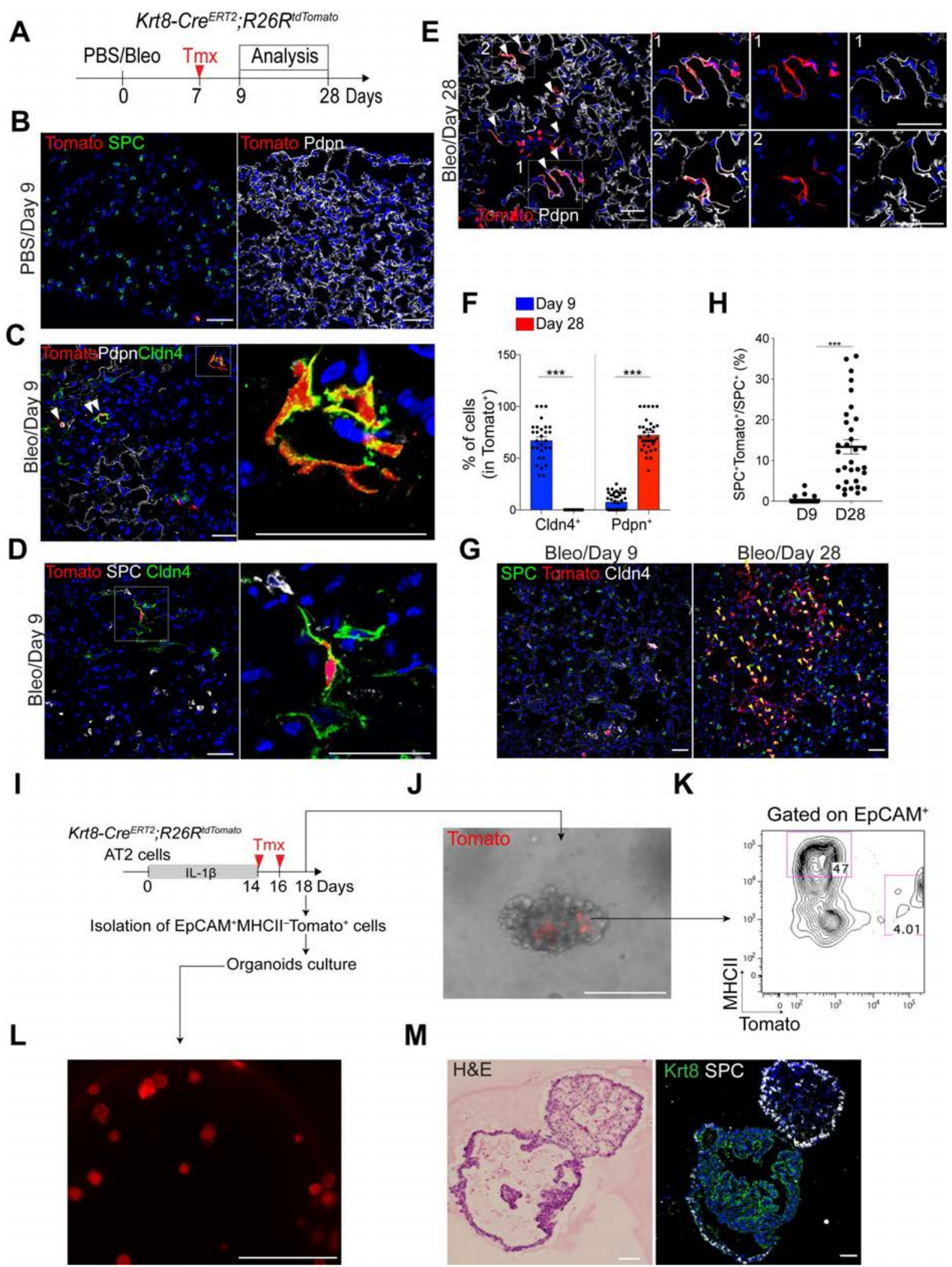

2 Figure S5, related to Fig. 3. Lineage tracing analysis of $\mathrm{KrtB}^{+}$cells reveals that DATPs

3 are capable of producing AT1 cells and reverting to AT2 cells during alveolar

4 regeneration. 
1 (A) Experimental design for $K r t 8$ lineage-tracing analysis using $K r t 8-C r e^{E R T 2} ; R 26 R^{t d T o m a t o}$ reporter mice after bleomycin injury. Specific time points for tamoxifen injection and analysis are indicated.

(B) Representative IF images show that none of AT2 (left) and AT1 (right) cells are lineagelabeled by Krt8 expression in uninjured lung (PBS control): Tomato (red), SPC (green, left), Pdpn (white, right), and DAPI (blue). Scale bar, $50 \mu \mathrm{m}$.

(C, D) Representative IF images show that $\mathrm{Krt} 8$ lineage-labeled cells express Cldn 4 at day 9 post injury. None of AT1 (C) and AT2 (D) cells are lineage-labeled by Krt8 expression at this time point: Tomato (red), Pdpn (white), Cldn4 (green), and DAPI (blue). Arrowhead points to Krt8 lineage-labeled DATPs. White boxed insets are shown on the right. Scale bar, $50 \mu \mathrm{m}$.

(E) Representative IF images show that Krt8 lineage-labeled cells generate new AT1 cells at day 28 after injury: Tomato (red), Pdpn (white), and DAPI (blue). Arrowhead points to lineagelabeled $\mathrm{Pdpn}^{+}$cells. Insets (left) show high-power view (1, right top; 2, right bottom). Scale bar, $50 \mu \mathrm{m}$.

(F) Statistical quantification of $\mathrm{Cldn}^{+} \mathrm{Tomato}^{+}$or $\mathrm{Pdpn}^{+} \mathrm{T}^{-}$mato ${ }^{+}$cells at indicated time points after injury. Each individual dot represents one section and data are presented as mean \pm SEM with two independent experiments $(\mathrm{n}=5) .{ }^{* * *} \mathrm{p}<0.001$.

(G) Representative IF images show that $K r t 8$ lineage-labeled cells generate AT2 cells at day 28 post injury. Notably, there are few AT2 cells that are marked by Krt8 expression at day 9 post injury: Tomato (for Krt8 lineage, red), SPC (green), Cldn4 (white), and DAPI (blue). Arrowhead points to lineage-labeled AT2 cells. Scale bars, $50 \mu \mathrm{m}$.

(H) Quantification of Krt8 lineage-labeled $\mathrm{SPC}^{+} \mathrm{AT} 2$ cells. Each individual dot represents one section and data are presented as mean \pm SEM with three independent experiments $(n=4)$. $* * * \mathrm{p}<0.001$.

(I) Scheme of experimental design for organoid culture assays. AT2 cells were isolated by

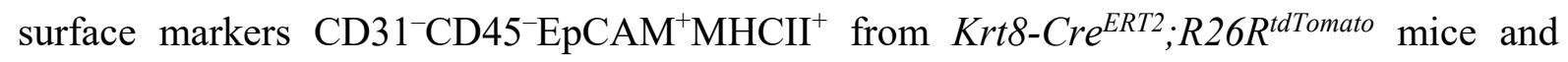
cultured as organoids with IL-1 $\beta$ for 14 days. 4-OH tamoxifen was added at day 14 and day 16 in culture to label Krt8-expressing cells. At day 18, organoids were further analyzed for a microscopy (I), flow cytometry (J), and organoid formation (K and L).

(J) Representative merged fluorescent and brightfield image of organoids in (H). Treatment of 4-OH tamoxifen allows to mark $\mathrm{Krt}^{+}$(Tomato $^{+}$) cells. Scale bar, $200 \mu \mathrm{m}$. Notably, Tomato signals were detected only in inner parts of organoids. 
1 (K) Flow cytometry analysis of AT2 (EpCAM ${ }^{+} \mathrm{MHCII}^{+}$Tomato $\left.^{-}\right)$and DATPs

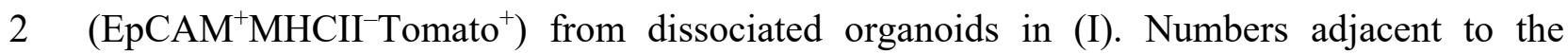
3 outlined area indicate the percentage of populations. Of note, Tomato ${ }^{+}$cells are not AT2 cells. 4 (L, M) Representative fluorescent image (K), and H\&E staining ( $\mathbf{L}$, left) and IF image (L, 5 right) of organoids derived from dissociated $\mathrm{Krt}^{+} \mathrm{Tomato}^{+}$cells in (I and J). Scale bar, 1,000 $6 \mu \mathrm{m}(\mathbf{K})$ and $50 \mu \mathrm{m}(\mathbf{L})$. 
A

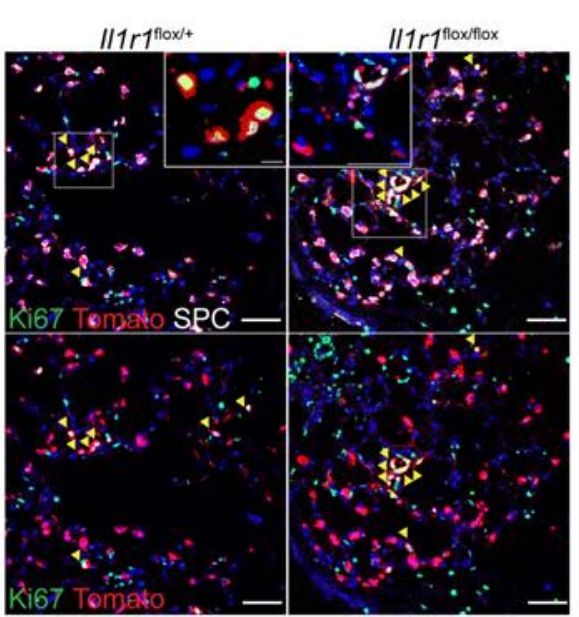

D
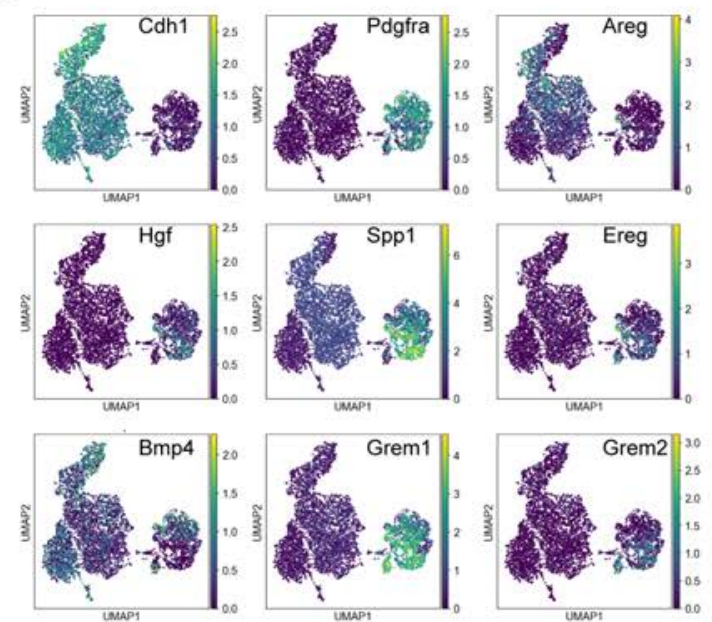

$\mathbf{F}$

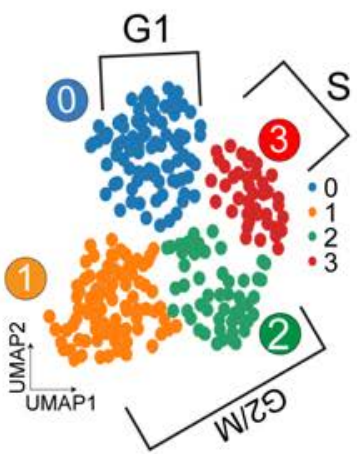

B

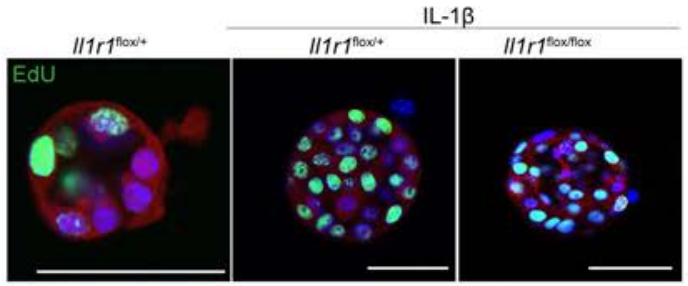

C
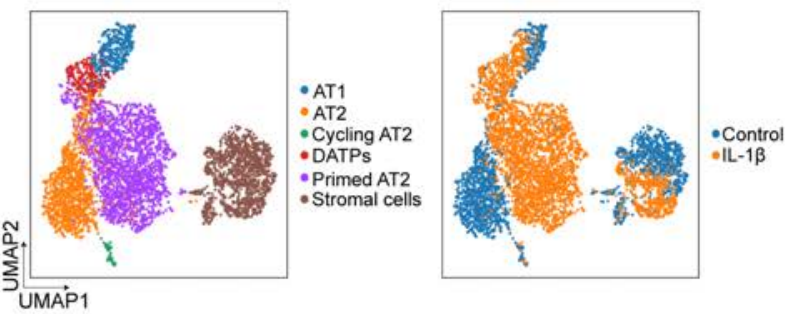

E

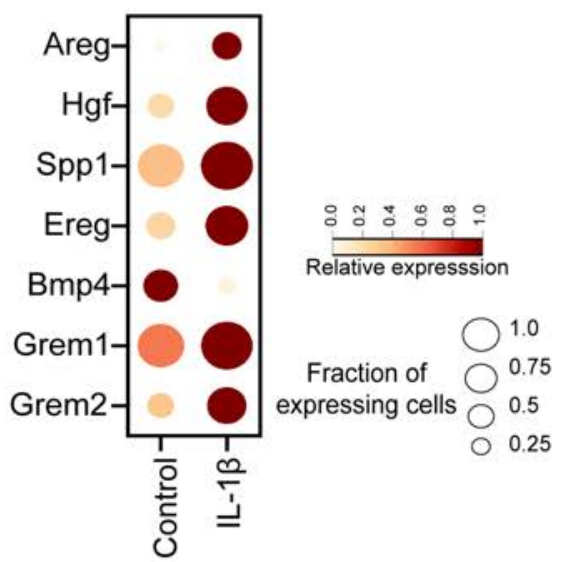

G

Proliferation
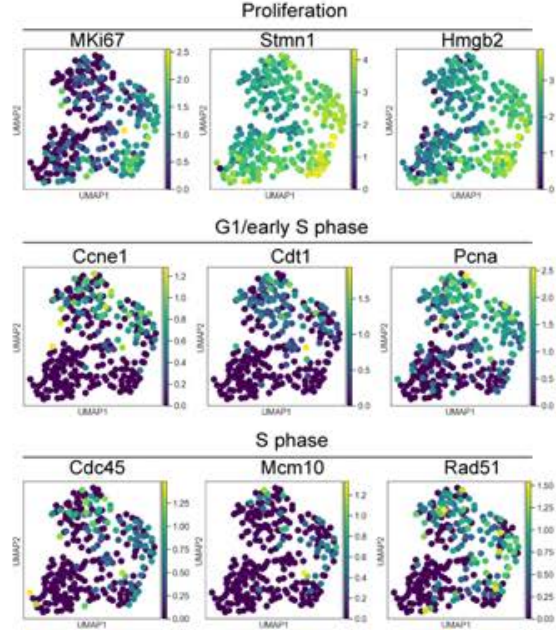

G2/M phase
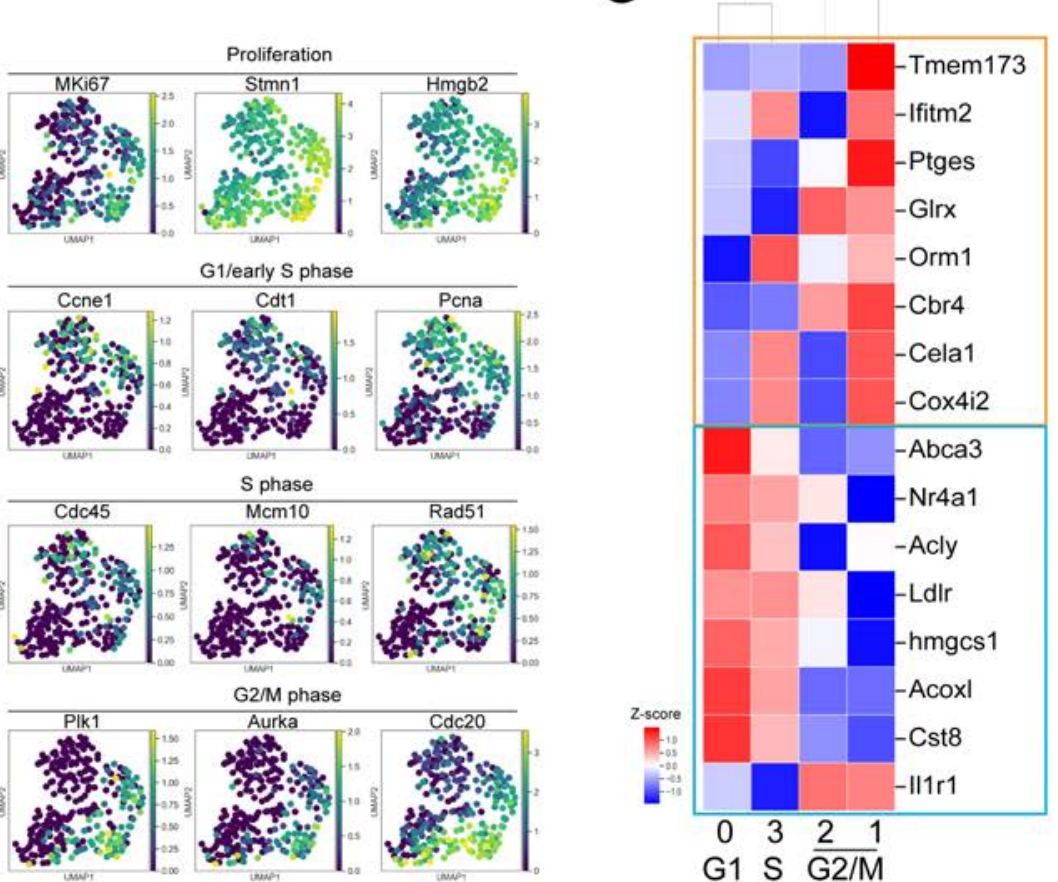

Figure S6, related to Fig. 4, B-E. IL-1ß signaling primes AT2 cells during cell cycle 
1 (A) Representative IF images showing $\mathrm{Ki}^{+} 7^{+}$lineage-labeled AT2 cells in the lung of mice 2 treated with PBS or bleomycin at day 7 post injury: Tomato (for SPC lineage, red), Ki67 3 (green), SPC (white), and DAPI (blue). Arrowheads, Ki67 ${ }^{+}$AT2 cells. Insets show high-power 4 view. Scale bars, $50 \mu \mathrm{m}$. No discernible differences in number of Ki67 ${ }^{+}$AT2 cells were 5 observed in the lung of indicated genotyped mice.

6 (B) Representative IF images showing proliferating cells in AT2 organoids derived from the 7 lungs of indicated genotyped mice. Organoids were pulsed with BrdU for $4 \mathrm{hrs}$ at day 4 in 8 cultures. Notably, IL-1 $\beta$ treatment enhances proliferation in organoids regardless of $I l 1 r 1$ 9 expression in AT2 cells.

10 (C) UMAP visualization of cell clusters from scRNA-seq analysis of epithelial cells and 11 stromal cells from control or IL-1 $\beta$-treated organoids. Cells were isolated at day 21 in organoid 12 culture. Colors indicate distinct cell types (left) and samples (right).

13 (D) UMAP visualization of the log-transformed $\left(\log _{10}(\mathrm{TPM}+1)\right)$, normalized expression of cell 14 type marker genes (e.g. Cdh1 for epithelial cells and Pdgfra for stromal cells/fibroblast) and growth factors in each distinctive cluster.

16 (E) Gene expression of growth factors that may enhance proliferation of AT2 cells in control 17 or IL-1 $\beta$-treated stromal cells.

18 (F) Clusters of Cycling AT2 population (cAT2) shown in Fig. 1B visualized by UMAP, 19 assigned by specific colors. Based on the expression of cell cycle genes, four clusters were classified into two cell cycle phases; G1 (cluster 0), S phase (cluster 3) and G2/M phase (cluster 2 and 1). UMAP visualization of the log-transformed $\left(\log _{10}(\mathrm{TPM}+1)\right)$, normalized expression of marker genes for cell proliferation and cell cycle (G1/early S phase; S phase; G2/M phase). (G) Heap map showing the Illrl expression and acquisition of Primed AT2 cell (pAT2) 24 signatures during cell cycle transition. Acquisition of transcriptional signatures of pAT2 cells 25 by downregulating of naïve AT2 cell markers including Abca3 (blue box) and inducing expression of genes related with inflammatory response including Ptges (orange box) during cell cycle transition from $\mathrm{S}$ to $\mathrm{G} 2 / \mathrm{M}$ phase. 
A

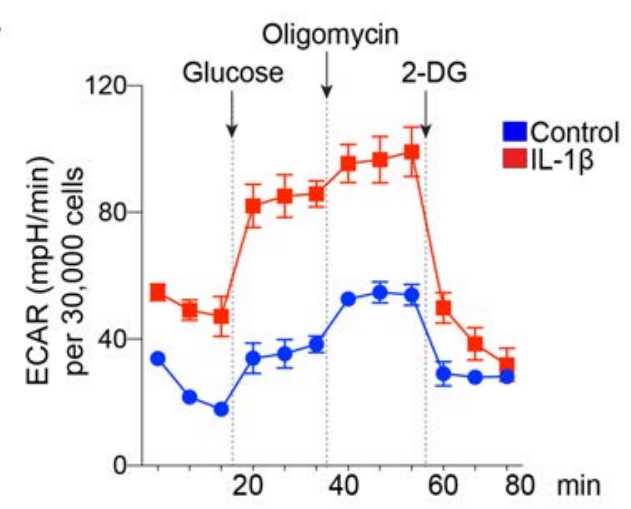

D

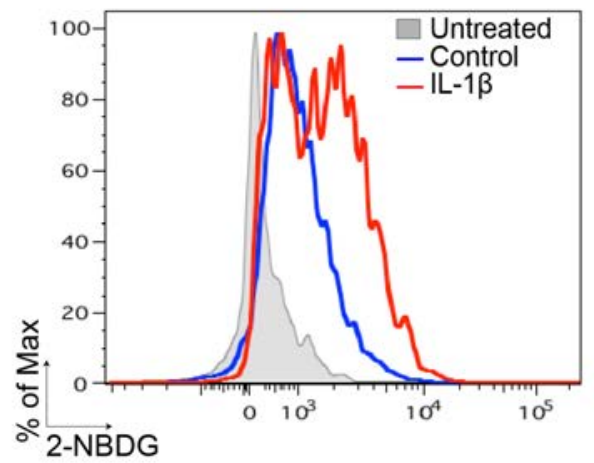

B

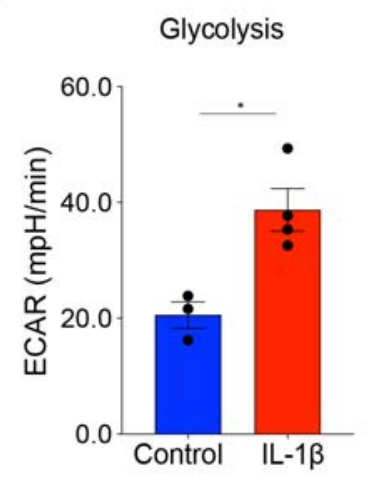

E

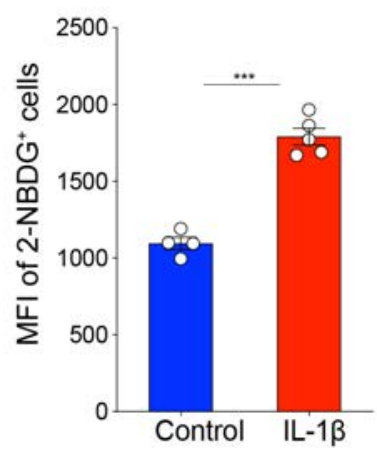

C

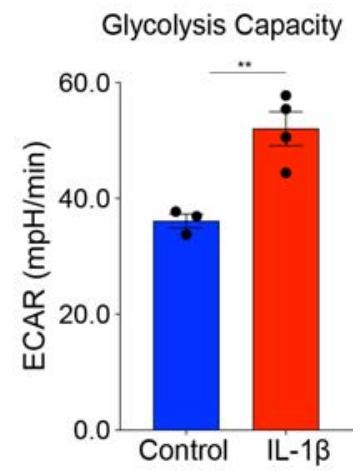

2 Figure S7, related to Fig. $4 F$. IL-1 $\beta$ enhances the glycolysis metabolism.

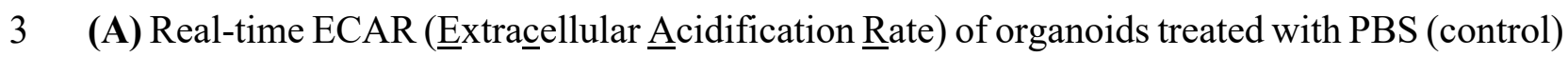
4 and IL-1 $\beta$ was measured by XF-96 analyzer. Vertical lines with arrow indicate addition of 5 glucose (glycolysis substrate, $10 \mathrm{mM}$ ), oligomycin (ATP synthase inhibitor, 1uM), and 26 Deoxy Glucose (2-DG, glycolysis inhibitor, $50 \mathrm{mM}$ ). X axis indicates measurement times.

7 ECAR was normalized to 30,000 cells. data are presented as mean \pm SE ( $n=3$ for control; $n=4$ 8 for IL-1 $\beta$ ).

9 (B, C) Representative graphs output from XF96 anlyzer showing the glycolysis (B) and 10 glycolytic capacity (C). ${ }^{*} \mathrm{p}<0.05$, and ${ }^{* *} \mathrm{p}<0.01$.

11 (D) Effects of IL-1 $\beta$ on glucose uptake. 2-NBDG incorporation from organoids treated with 12 PBS control (blue line) or IL-1 $\beta$ (red line) was determined by flow cytometry. Non-treated 13 cells were used as a negative control for 2-NBDG treatment (grey-filled peak).

14 (E) Representative histograms showing MFI (mean fluorescence of intensity) of 2-NBDG. 15 Each individual dot represents one individual experiment and data are presented as mean \pm $16 \operatorname{SEM}(\mathrm{n}=4$ for control; $\mathrm{n}=5$ for IL-1 $\beta)$. $* * * \mathrm{p}<0.001$. 
A

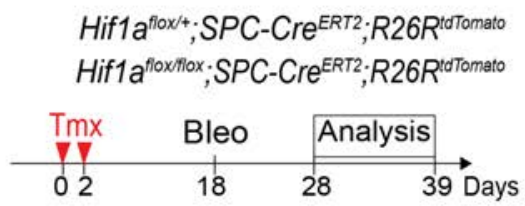

B

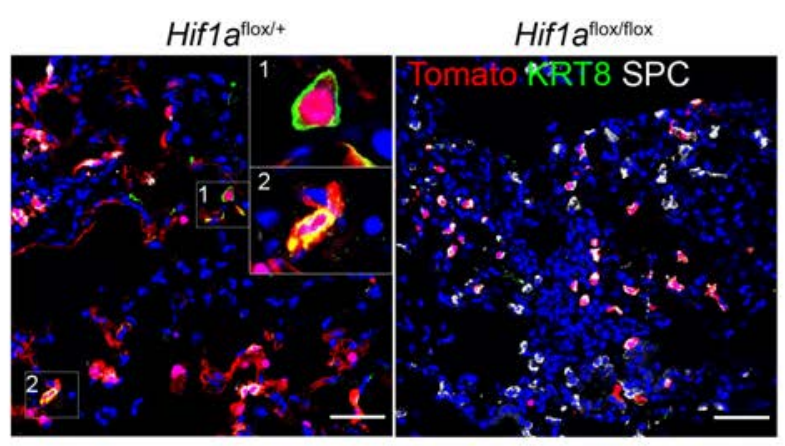

C

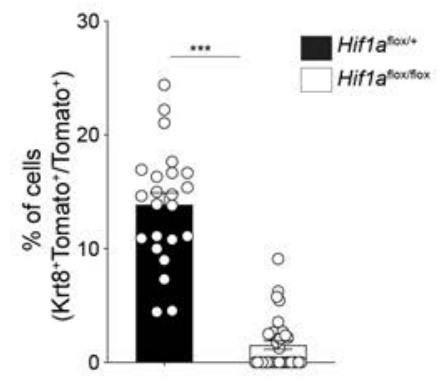

D
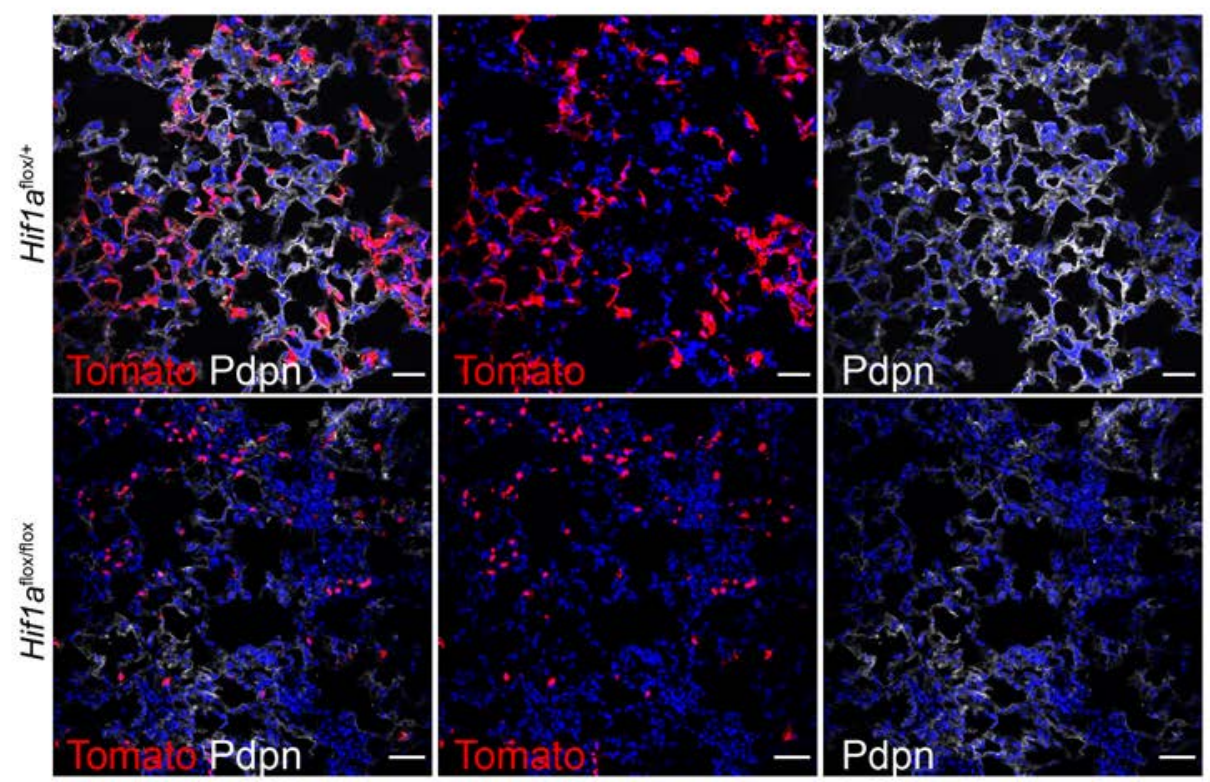

E

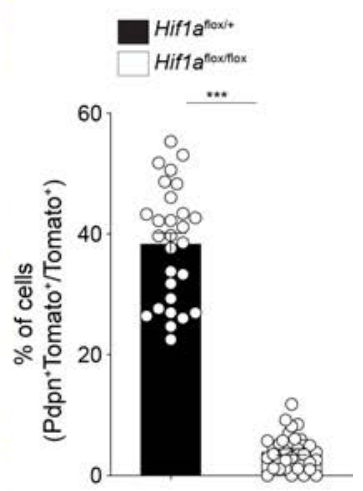

2 Figure S8, related to Fig. $4 \mathrm{H}$. Deletion of Hif1a on AT2 cells impairs DATPs generation 3 and AT1 cell regeneration.

4 (A) Experimental design for lineage tracing. Date for analysis is as indicated.

5 (B) Representative IF images showing $S P C$ lineage-labeled DATPs at day 14 post injury in the 6 lung of indicated genotyped mice: Tomato (for SPC lineage, red), Krt8 (green), SPC (white), 7 and DAPI (blue). Insets (left) show high-power view (right top). Scale bars, $50 \mu \mathrm{m}$.

8 (C) Quantification of SPC lineage-labeled DATPs in (B). Each individual dot represents one 9 section and data are presented as mean \pm SEM with three independent experiments. Notably, 10 there is a significant decrease in number of lineage-labeled DATPs in the absence of Hifla in 11 AT2 cells. 
1 (D) Representative IF images showing AT1 cell differentiation from SPC lineage-labeled cells 2 at day 28 post injury in the lung of indicated genotyped mice: Tomato (for SPC lineage, red), 3 Pdpn (white), and DAPI (blue). Scale bars, $50 \mu \mathrm{m}$.

4 (E) Quantification of lineage-labeled Pdpn ${ }^{+}$AT1 cells in (D). Each individual dot represents 5 one section and data are presented as mean $\pm \operatorname{SEM}\left(\mathrm{n}=3\right.$ for Hifl $\mathrm{a}^{\text {flox/++}} ; \mathrm{n}=4$ for Hifl $\mathrm{a}^{\text {flox } / \text { flox }}$ ). 6 Notably, there is a significant decrease in the number of lineage-labeled AT1 cells in the 7 absence of Hifla in AT2 cells. 
A
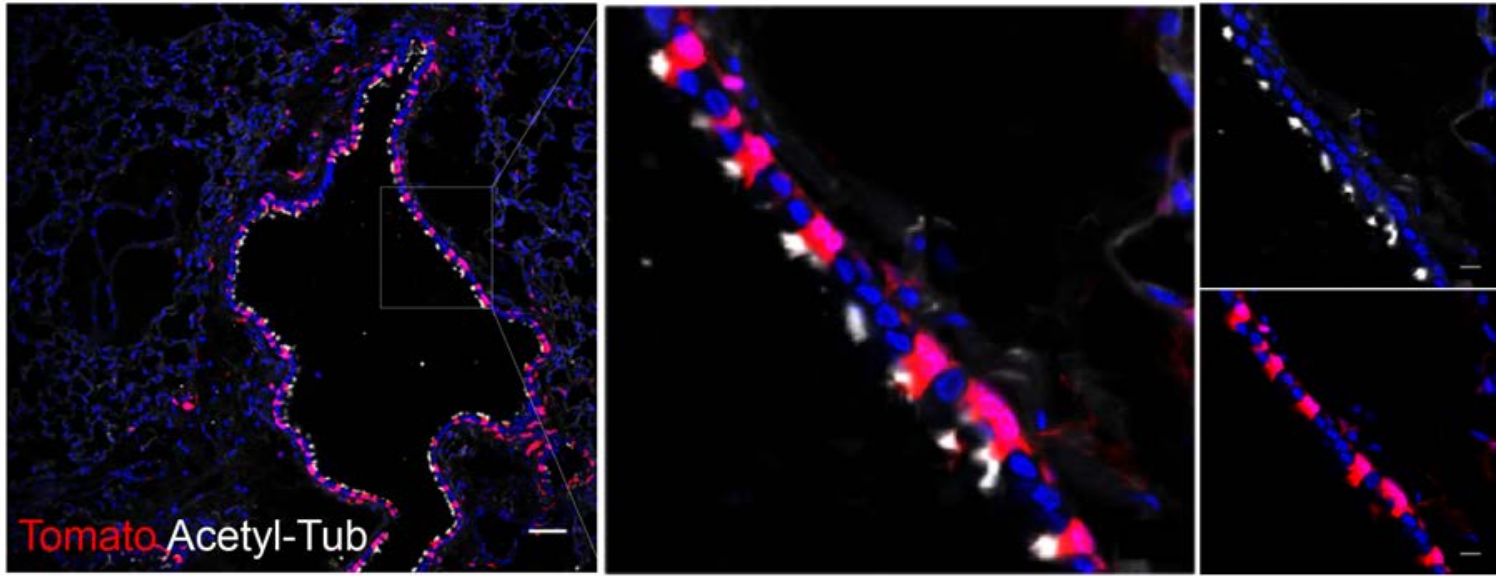

B

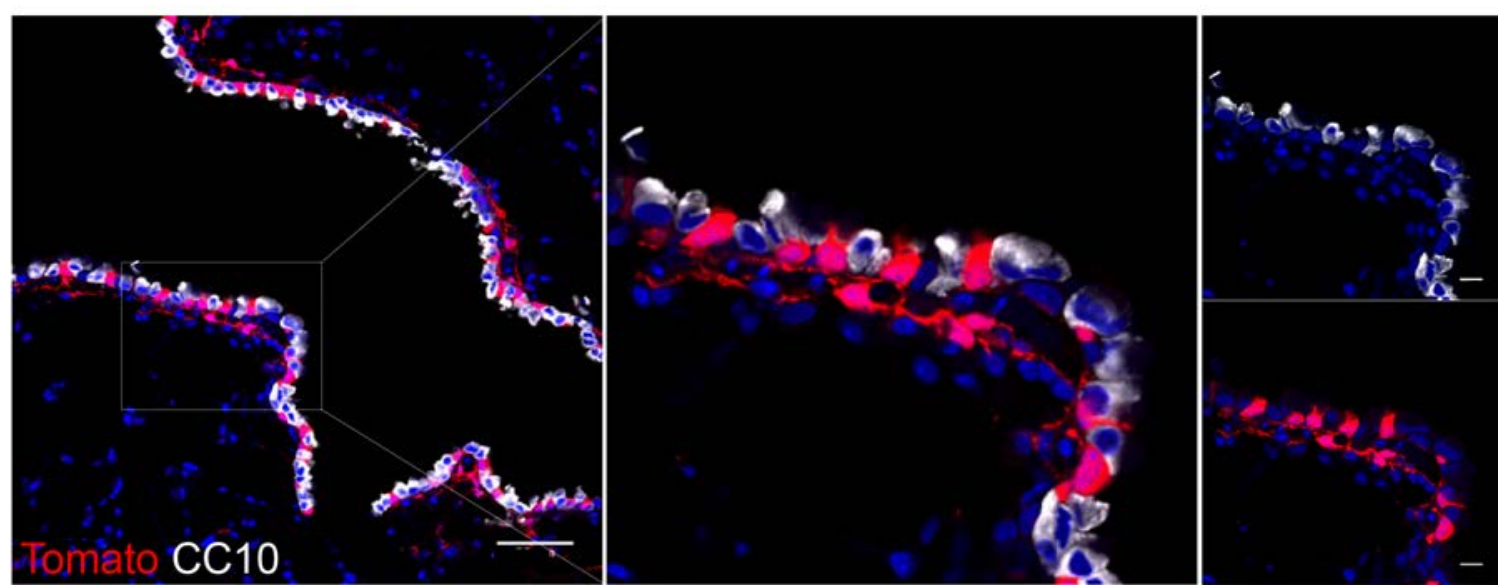

2 Figure S9, related to Fig. 5. Il1r1 lineage-labeled cells are found in airway ciliated cells in 3 uninjured lungs.

4 (A, B) Representative IF images showing Illr 1 lineage-labeled cells only in ciliated cells (A) 5 not in club cells (B) in uninjured lungs at day 14 post two doses of tamoxifen injection: Tomato

6 (for $I l 1 r 1$ lineage, red), Acetyl-Tub (white), CC10 (white), and DAPI (blue). Scale bars: $50 \mu \mathrm{m}$. 
A

B

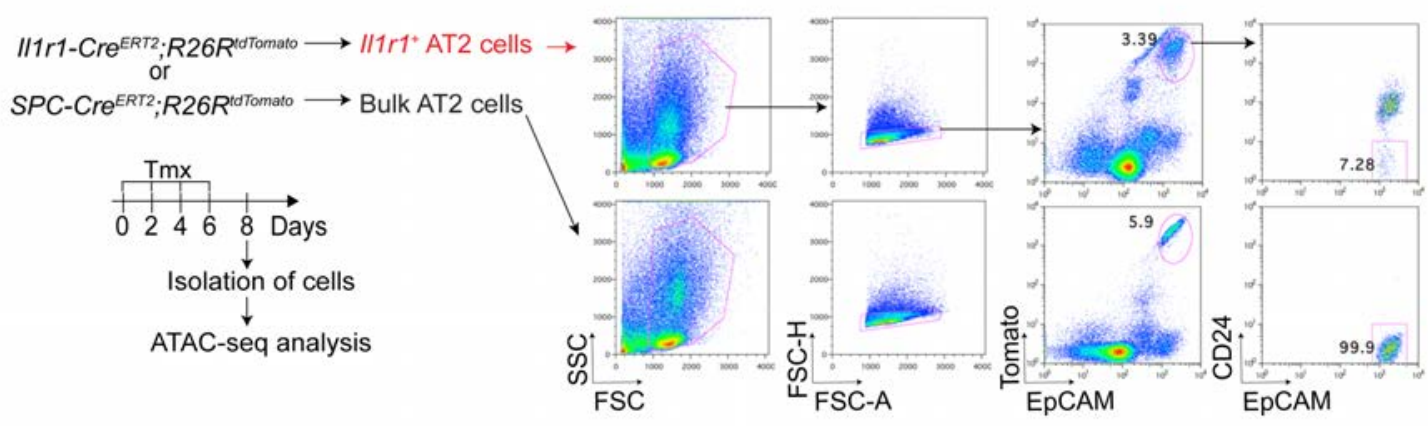

C

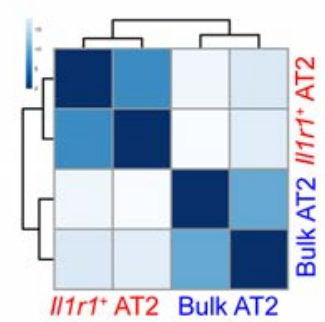

D

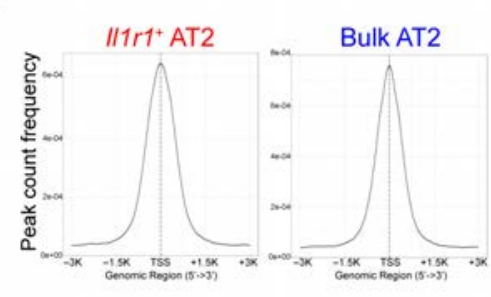

E

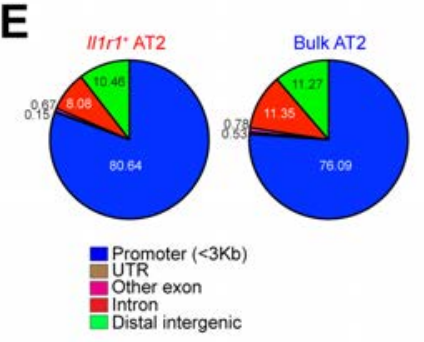

$\mathbf{F}$

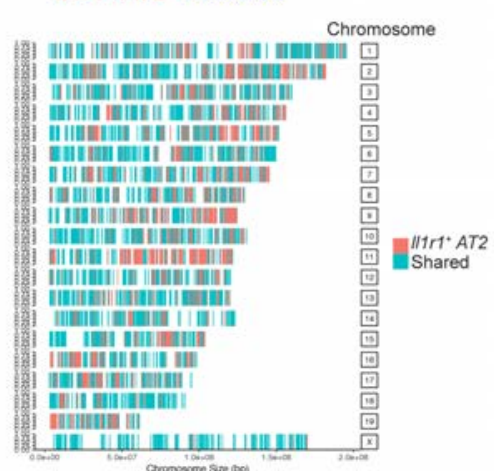

G

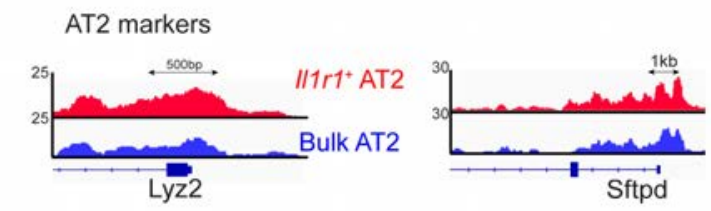

Figure S10, related to Fig. 6. ATAC-seq analysis reveals distinct differences in open chromatin structure in $I l 1 r 1^{+}$AT2 cells versus bulk AT2 cells.

4 (A, B) Experiment design (A) and sorting strategy by flow cytometry (B) for isolating $5 \quad I l 1 r 1^{+} \mathrm{AT} 2$ or bulk AT2 cells from Illr1-Cre $e^{E R T 2} ; R 26 R^{\text {tdTomato }}$ or $S P C-C r e^{E R T 2} ; R 26 R^{\text {tdTomato }}$ 6 mice, respectively.

7 (C) Heat map of poisson distances between samples on the original count matrix.

8 (D) Density plots depicting enrichment of ATAC-seq signals at TSSs $\pm 3 \mathrm{~kb}$.

9 (E) Distribution of ATAC-seq peaks within defined genomic regions of predicted mRNAs.

10 UTR, untranslated regions.

11 (F) Genome-wide profiling of ATAC-seq peaks in $I l 1 r 1^{+}$AT2 and bulk AT2 cells.

12 (G) Snapshots of peaks enriched in shared genes Lyz2 and Sftpd. Arrows denote direction of 13 transcription. 
A
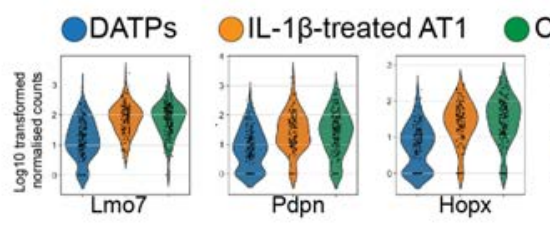

Control AT1

B
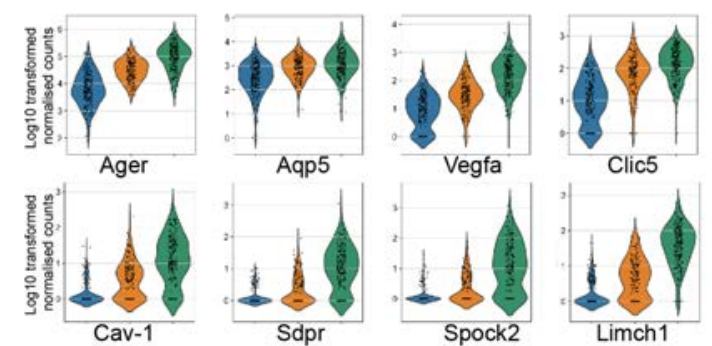

C
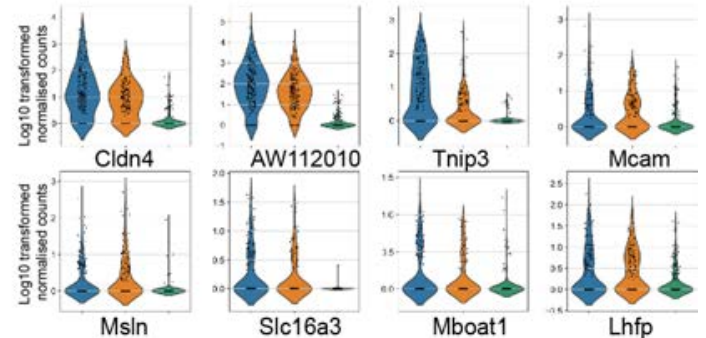

D $\quad$ G control

L-1 $1 \beta$ withdrawal

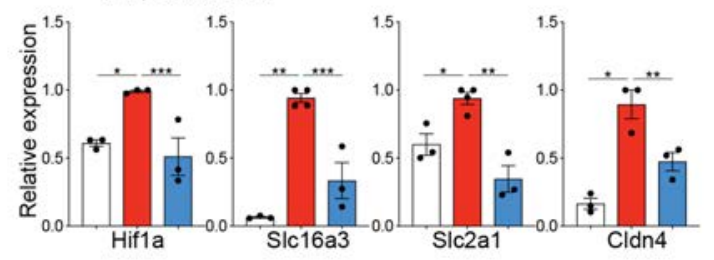

2 Figure S11, related to Fig. 7, A-E. Sustained IL-1ß prohibits mature AT1 differentiation 3 by blocking the progression of DATPs into AT1 lineage.

4 (A-C) Violin plots showing the log-transformed $\left(\log _{10}(\mathrm{TPM}+1)\right)$, normalized expression levels of early AT1 (A), late AT1 (B), and DATP (C) marker genes in DATPs, control or IL-1 $\beta$ 6 treated AT1 cells revealed by scRNA-seq analysis of organoids.

7 (D) qPCR analysis of Cldn4 and Hifla-depenent genes that are involved in the glycolysis 8 pathway after withdrawal of IL-1 $\beta$ in AT2 organoids. Each individual dot represents one 9 experiment and date are presented as mean \pm SEM. ${ }^{*} \mathrm{p}<0.5,{ }^{*} \mathrm{p}<0.01,{ }^{* * *} \mathrm{p}<0.001$. 

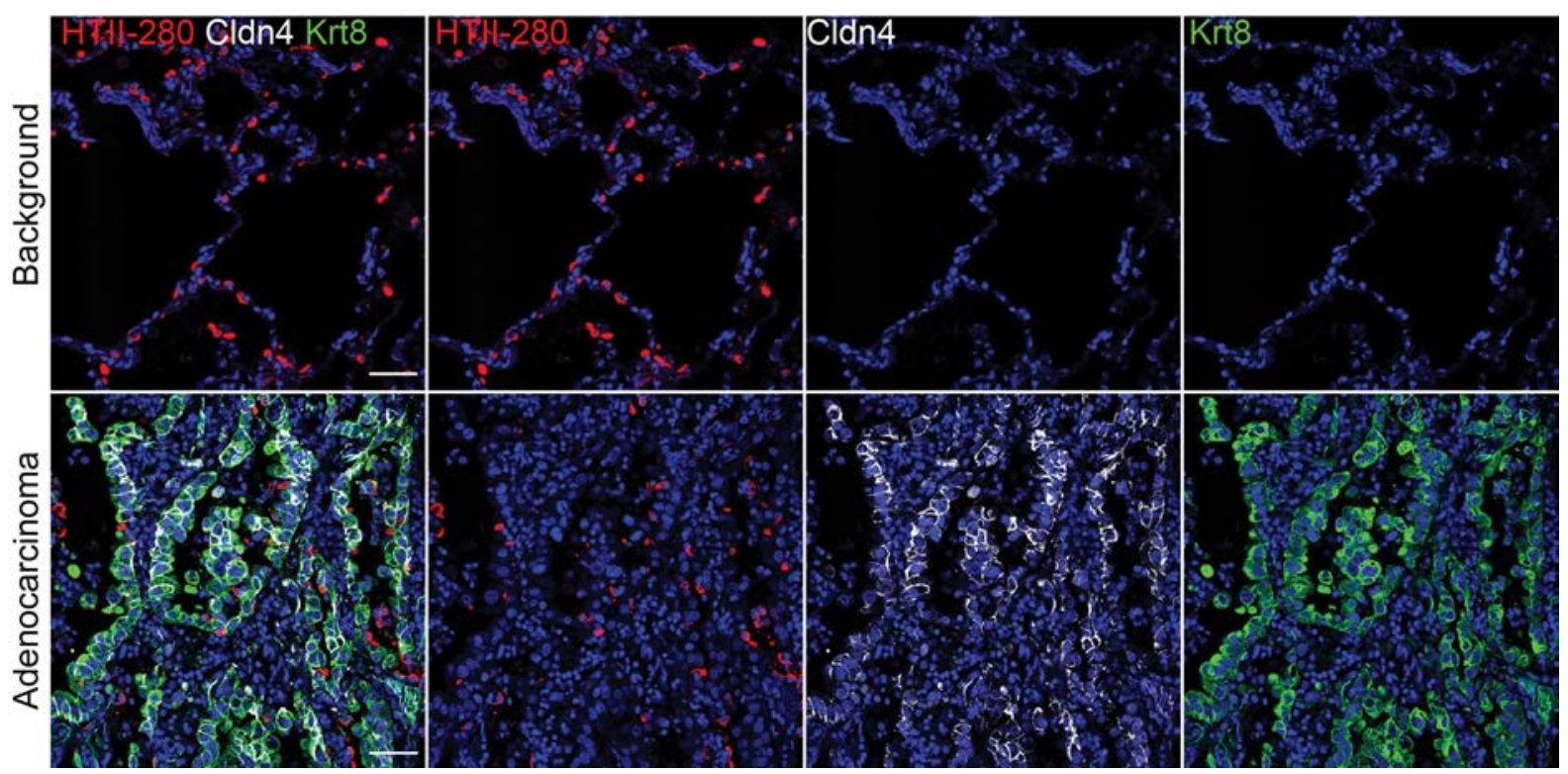

Figure S12, related to Fig. 7, F-H. DATPs-like population is aberrantly accumulated in the lung from adenocarcinoma patients.

4 Representative IF images of $\mathrm{KRT}^{+} \mathrm{CLDN}^{+}$cells in the lung from adenocarcinoma patients 5 (n=3). HTII-280 (red), CLDN4 (white), KRT8 (green) and DAPI (blue). Background region 6 (top) in the lung tissue of the same patient was used for control. Scale bar, $50 \mu \mathrm{m}$. 